\title{
Analytical Methodologies for Agrometallomics: A Critical Review
}

Xue Li, ${ }^{\text {a }}$ Tengpeng Liu, ${ }^{\mathrm{a}}+$ Chunyan Chang, ${ }^{\mathrm{a}}+$ Yajie Lei ${ }^{\mathrm{a}}$, Xuefei Mao ${ }^{\mathrm{a}, *}$

${ }^{a}$ Institute of Quality Standard and Testing Technology for Agro-products, Chinese Academy of Agricultural Sciences, and Key Laboratory of Agro-food Safety and Quality, Ministry of Agriculture and Rural Affairs, Beijing 100081, China

†These authors contributed equally.

E-mail: mxf08@163.com,maoxuefei@caas.cn (X. Mao)

\section{ABBREVIATION}

AAS (Atomic Absorption Spectroscopy)

APGD (Flowing Afterglow Atmospheric Pressure Glow Discharge)

CE (Capillary Electrophoresis)

Cryo-TOF-MS (Electrospray Ionization-TOF-MS)

CV (Cold Vapor Generation)

DBD (Dielectrc Barrier Discharge)

DBDI (Dielectric Barrier Discharge Ion)

d-CPE (Dual-cloud Point Extraction)

DMA (Direct Mercury Analyser)

EXAFS (Extended X-ray Absorption Fine Structure)

FPXRF (Field portable X-ray fluorescence)

GC/QqQ-MS (Gas Chromatography-triple Quadrupole Mass Spectrometry)

GD (Glow Discharge)

HG (Hydride Generation)

HILIC (Hydrophilic Interaction Liquid Chromatography)

HS-SPME (Headspace Solid-phase Microextraction)

IC (Ion Chromatography)

ICP-oa-TOF-MS (Inductively Coupled Plasma Orthogonal Acceleration Time-of-flight Mass Spectrometry )

IEC (Ion Exchange Column)

INAA (Instrumental Neutron Activation Analysis) 
LA-ICP-MS (Laser Ablation - Inductively Coupled Plasma-Mass Spectrometry)

LIBS (Laser-induced Breakdown Spectroscopy)

LIMS (Laser Ionization Mass Spectrometry)

MALDI-FT-ICR-MS (Matrix-assisted Laser Desorption Ionization Fourier Transform Ion Cyclotron Resonance Mass Spectrometry)

MC (Multi-collector)

MIPDI (Microwave-induced Plasma Desorption/ionization Source)

MP (Microwave Plasma)

MWP-PTR-MS (Microwave Plasma- Proton Transfer Reaction-MS

Nano SIMS (Nanometer Scale Secondary Ion Mass Spectrometry)

oa (Orthogonal Acceleration)

P-CT (Purge-cryogenic Trapping)

PD (Point Discharge)

PEVG (Plasma Electrochemical Vapor Generation)

PGD (Pulsed Glow Discharge)

QQQ (Triple Quadrupole)

QT (Quartz Tube)

QTAT (Quartz Tube Atom Trap)

SC (Single-Cell)

SCGD (Solution Cathode Glow Discharge)

SF (Sector Field)

SP (Single Particle)

SPE (Solid Phase Extraction)

SPME (Solid-phase Microextraction)

SRXRF (Synchrotron Radiation X-ray fluorescence)

TIMS (Thermal Ionization Mass Spectrometry)

TOF (Time-of-Flight)

TQ (Triple-Quadrupole)

UVG (Ultraviolet Vapor Generation)

VSG (Volatile Species Generation)

XANES (X-ray Absorption Near Edge Structure)

XPS (X-ray Photoelectron Spectroscopy) 
XRD (X-ray Fluorescence Spectrometry)

XRF (X-ray Fluorescence)

\section{Table titles}

Table S-1 Summarization and comparison of analytical methodologies for agrometallomics from literatures 
Table S-1 Summarization and comparison of analytical methodologies for agrometallomics from literatures

\begin{tabular}{|c|c|c|c|c|c|c|c|c|}
\hline No. & Instrumental & Matrix & Sample preparation & Element or isotope & LOD or LOQ & Calibration & Application and Technical characteristics & Ref. \\
\hline 1 & LA-ICP-MS & Human eyes & $\begin{array}{l}\text { Tissue sections are } \\
\text { fixed on glass slides }\end{array}$ & 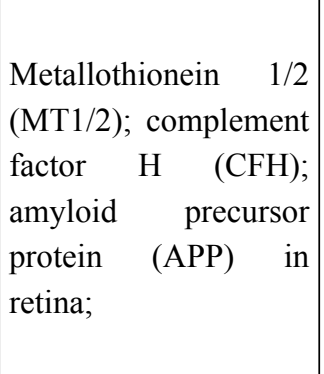 & / & / & $\begin{array}{l}\text { Use LA-ICP-MS to simultaneously locate three } \\
\text { proteins related to neurodegenerative diseases (such } \\
\text { as AMD) in the same eye tissue. } \\
\text { The multiplex methodology allows the amplification } \\
\text { of the protein detection. Moreover, knowing the } \\
\text { number of tag atoms and available antibodies per } \\
\text { labelled immunoprobe, semi-quantification can be } \\
\text { achieved. }\end{array}$ & 10 \\
\hline 2 & MC-ICP-MS & $\begin{array}{lr}\text { Blend } & \text { ore } \\
\text { BCR } & 027 ; \\
\text { rye } & \text { grass } \\
\text { standard } \\
\text { BCR } 281 ; \\
\text { basalt;soil }\end{array}$ & $\begin{array}{l}\text { Microwave digestion; } \\
\text { Anion Exchange } \\
\text { Chromatography. }\end{array}$ & $\begin{array}{l}\text { Zinc stable isotope } \\
\text { ratios }\end{array}$ & $\begin{array}{l}\text { blend ore BCR } 027: \\
0.25 \pm 0.06 \% \text { (2SD); } \\
\text { ryegrass BCR 281: } \\
0.40 \pm 0.09 ; \quad \text { Imperial } \\
\mathrm{Zn:} \quad 0.10 \pm 0.08 \% \text { : } 2 \\
\mathrm{SD} \quad \text { London } \mathrm{Zn}: \\
0.08 \pm 0.04\end{array}$ & \begin{tabular}{|l|} 
Double-spike \\
sample analysis \\
protocol; \\
Standard sample \\
bracketing \\
protocol
\end{tabular} & $\begin{array}{l}\text { Characterize the } \mathrm{Zn} \text { isotope pool available to plants in } \\
\text { a natural setting. } \\
\text { Developed a DS protocol for the accurate and precise } \\
\text { determination of } \mathrm{Zn} \text { isotope ratios. }\end{array}$ & 12 \\
\hline 3 & ICP-MS & $\begin{array}{l}\text { Arctic ice } \\
\text { core samples }\end{array}$ & $\begin{array}{l}\text { Acid washing and } \\
\text { water washing }\end{array}$ & $\begin{array}{l}\text { As, } \mathrm{Cd}, \mathrm{Co}, \mathrm{Cu}, \mathrm{Ni} \\
\mathrm{Pb}, \mathrm{Zn}, \mathrm{U}\end{array}$ & $\begin{array}{l}\text { As: } 1.1 \mathrm{pg} / \mathrm{g} \\
\mathrm{Cd}: 0.9 \mathrm{pg} / \mathrm{g} \\
\mathrm{Co}: 0.1 \mathrm{pg} / \mathrm{g} \\
\mathrm{Cu}: 0.4 \mathrm{pg} / \mathrm{g} \\
\mathrm{Ni}: 0.6 \mathrm{pg} / \mathrm{g} \\
\mathrm{Pb}: 0.1 \mathrm{pg} / \mathrm{g} \\
\mathrm{Zn}: 3.0 \mathrm{pg} / \mathrm{g} \\
\mathrm{U}: 0.1 \mathrm{pg} / \mathrm{g}\end{array}$ & $\begin{array}{l}\text { External } \\
\text { standard } \\
\text { method, } \\
0.1 \quad(\mathrm{U})-673.3 \\
(\mathrm{Zn}) \mathrm{pg} / \mathrm{g}\end{array}$ & $\begin{array}{l}\text { Measurement and Evaluation of Trace Heavy Metals } \\
\text { in Arctic Ice Cores. } \\
\text { An all-plastic device was developed and used } \\
\text { together with ceramic knives to remove the } \\
\text { contaminated surface of ice cores. }\end{array}$ & 14 \\
\hline
\end{tabular}




\begin{tabular}{|c|c|c|c|c|c|c|c|c|}
\hline No. & Instrumental & Matrix & Sample preparation & Element or isotope & LOD or LOQ & Calibration & Application and Technical characteristics & Ref. \\
\hline 4 & ICP-MS/OES & Tea & Microwave digestion & $\begin{array}{l}\text { More than } \\
\text { elements such as } \mathrm{Al}, \\
\mathrm{B}, \mathrm{Cu}, \mathrm{Fe}, \mathrm{Mn}, \mathrm{Na}, \\
{ }^{137} \mathrm{Ba},{ }^{138} \mathrm{Ba}, \quad{ }^{79} \mathrm{Br}, \\
{ }^{81} \mathrm{Br},{ }^{52} \mathrm{Cr},{ }^{53} \mathrm{Cr},{ }^{58} \mathrm{Ni}, \\
{ }^{60} \mathrm{Ni},{ }^{85} \mathrm{Rb},{ }^{86} \mathrm{Sr},{ }^{88} \mathrm{Sr}, \\
{ }^{46} \mathrm{Ti},{ }^{47} \mathrm{Ti},{ }^{48} \mathrm{Ti},{ }^{64} \mathrm{Zn}, \\
{ }^{66} \mathrm{Zn}\end{array}$ & / & $\begin{array}{l}\text { External } \\
\text { standard } \\
\text { method, } \\
\mathrm{R}^{2}>0.999\end{array}$ & $\begin{array}{l}\text { Used for tea traceability. } \\
\text { Simultaneous determination of various mineral } \\
\text { elements and stable isotopes by ICP-MS and } \\
\text { ICP-OES. }\end{array}$ & 15 \\
\hline 5 & ICP-MS/MS & $\begin{array}{l}\text { Fruit } \\
\text { wines }\end{array}$ & $\begin{array}{l}\text { Acidified with nitric } \\
\text { acid. }\end{array}$ & $\begin{array}{l}\mathrm{Al}, \mathrm{V}, \mathrm{Cr}, \mathrm{Mn}, \mathrm{Fe}, \mathrm{Co} \\
\mathrm{Ni}, \mathrm{Cu}, \mathrm{Zn}, \mathrm{As}, \mathrm{Se} \\
\mathrm{Cd}, \mathrm{Hg}, \mathrm{Pb}\end{array}$ & $0.41-58.1 \mathrm{ng} / \mathrm{L}$ & $\begin{array}{l}\text { External } \\
\text { standard } \\
\text { method, } \\
\text { liner range: } 0.1- \\
500 \mu \mathrm{g} / \mathrm{L}\end{array}$ & $\begin{array}{l}\text { Establishing comprehensive standards is necessary } \\
\text { for aiming at the quality control and food safety of } \\
\text { fruit wines. } \\
\text { Spectral interferences in the complex matrix } \\
\text { composition of different fruit wine samples, in the } \\
\text { MS/MS mode, } \\
\text { were eliminated using mixed reaction gases of } \mathrm{O}_{2} / \mathrm{H}_{2} \\
\text { and } \mathrm{NH}_{3} / \mathrm{He} / \mathrm{H}_{2} \text { through the mass shift and on-mass } \\
\text { methods. }\end{array}$ & 16 \\
\hline 6 & $\begin{array}{l}\text { CE/ICP-MS/M } \\
\mathrm{S}\end{array}$ & $\begin{array}{l}\text { Liposomal } \\
\text { doxorubicin } \\
\text { formulations }\end{array}$ & $\begin{array}{l}\text { Dilute with } \quad 5 \% \\
\text { glucose }\end{array}$ & $\begin{array}{l}\text { Intra-liposomal and } \\
\text { external sulfate }\end{array}$ & Sulfate: $0.8 \mu \mathrm{g} / \mathrm{mL}$ & $\begin{array}{l}\text { Internal standard } \\
\text { method } \\
(25.0 \mu \mathrm{g} / \mathrm{mL} \text { of } \\
\text { arsenate in } 5 \% \\
\text { dextrose) }\end{array}$ & $\begin{array}{l}\text { Simultaneously determine the content of liposulfate } \\
\text { in adriamycin liposome preparations in vivo and in } \\
\text { vitro. } \\
\text { CE method is more reliable than the filtration method } \\
\text { for separation of external sulfate and intra-liposomal } \\
\text { sulfate in nanoparticle drug carriers such as } \\
\text { liposomes. }\end{array}$ & 17 \\
\hline
\end{tabular}




\begin{tabular}{|c|c|c|c|c|c|c|c|c|}
\hline No. & Instrumental & Matrix & Sample preparation & Element or isotope & LOD or LOQ & Calibration & Application and Technical characteristics & Ref. \\
\hline 7 & ICP-QQQ-MS & $\begin{array}{l}\text { A mercury } \\
\text { resistant } \\
\text { bacterial } \\
\text { strain } \\
\text { in }\end{array}$ & $\begin{array}{l}\text { Cultivation and } \\
\text { isolation under low } \\
\text { phosphate conditions }\end{array}$ & $\mathrm{Hg}$ & / & / & $\begin{array}{l}\text { Potential of } \mathrm{SA} 2 \text { in the bioremediation of } \\
\text { mercury-contaminated waste. } \\
\text { Rapid removal of } \mathrm{Hg} \text { from experimental medium and } \\
\text { the } \\
\text { presence of mercuric reductase enzyme show the } \\
\text { potential of SA2 in the bioremediation of } \mathrm{Hg} \\
\text { contaminated wastes. }\end{array}$ & 18 \\
\hline 8 & ICP-QQQ-MS & 1 & Digestion & As and $\mathrm{Se}$ & $\begin{array}{l}\text { As: } 0.001 \mu \mathrm{g} / \mathrm{L} \\
\text { Se: } 0.002 \mu \mathrm{g} / \mathrm{L}\end{array}$ & / & $\begin{array}{l}\text { Accurate determination of rare earth elements in } \\
\text { food. } \\
\text { ICP-QQ adopts the mass transfer mode, which } \\
\text { reduces the double charge effect, and accurately } \\
\text { determines As and Se without correction equations. }\end{array}$ & 19 \\
\hline 9 & ICP-TOF -MS & $\begin{array}{l}\text { Natural } \\
\text { water } \\
\text { samples }\end{array}$ & $\begin{array}{l}\text { Acidification } \\
\text { refrigeration }\end{array}$ & $\begin{array}{l}\text { Lead and lead isotope } \\
\text { ratios }\end{array}$ & $6 \mathrm{ng} / \mathrm{L}$ & $\begin{array}{l}\text { Internal standard } \\
\text { method }\end{array}$ & $\begin{array}{l}\text { Aimed at the development of a suitable on-line } \\
\text { preconcentration method for the determination of } \\
\text { precise isotopic ratios in complex matrices. } \\
\text { ICP-TOF-MS provides a very useful technique for } \\
\text { simultaneous determination of traces lead and lead } \\
\text { isotope ratios in natural water samples. }\end{array}$ & 20 \\
\hline 10 & ICP-TOF-MS & Seawater & I & $\begin{array}{l}\text { Transition and rare } \\
\text { earth elements }\end{array}$ & $20-50 \mathrm{pg} / \mathrm{L}$ & / & $\begin{array}{l}\text { Determination of trace elements and rare earth } \\
\text { elements in seawater. } \\
\text { On-line separation and preconcentration was } \\
\text { achieved using a timed flow-injection FI system } \\
\text { incorporating a column. }\end{array}$ & 21 \\
\hline 11 & $\begin{array}{l}\text { ICP-oa } \\
\text {-TOF-MS }\end{array}$ & Tomato & Microwave digestion & $\begin{array}{l}\mathrm{Li}, \mathrm{Be}, \mathrm{Al}, \mathrm{V}, \mathrm{Cr}, \mathrm{Mn} \\
\mathrm{Co}, \mathrm{Cu}, \mathrm{Zn}, \mathrm{Ga}, \mathrm{As}, \\
\mathrm{Rb}, \mathrm{Sr}, \mathrm{Ag}, \mathrm{Cd}, \mathrm{In}, \mathrm{Cs} \\
\mathrm{Ba}, \mathrm{Tl}, \mathrm{Pb}, \mathrm{Bi}, \mathrm{U}\end{array}$ & & $\begin{array}{l}\text { External } \\
\text { standard method }\end{array}$ & $\begin{array}{l}\text { Food traceability. } \\
\text { Features of ICP-oa-TOF-MS simultaneous } \\
\text { measurement. }\end{array}$ & 22 \\
\hline
\end{tabular}




\begin{tabular}{|c|c|c|c|c|c|c|c|c|}
\hline No. & Instrumental & Matrix & Sample preparation & Element or isotope & LOD or LOQ & Calibration & Application and Technical characteristics & Ref. \\
\hline 12 & ICP-SF MS & $\begin{array}{l}\text { Surface and } \\
\text { subsurface } \\
\text { waters }\end{array}$ & Filter & $\begin{array}{l}\text { Rare earth elements } \\
\text { (REE) }\end{array}$ & $0.05-0.2 \mathrm{ng} / \mathrm{L}$ & $\begin{array}{l}\text { External } \\
\text { standard method } \\
\text { line range: } 0.5-5 \\
\mu \mathrm{g} / \mathrm{L}\end{array}$ & $\begin{array}{l}\text { Use of REEs as diagnostic tools for rock-water } \\
\text { interactions and for monitoring surface and } \\
\text { subsurface waters. } \\
\text { Use two atomizers to compare the ability to } \\
\text { determine rare earth metals. }\end{array}$ & 24 \\
\hline 13 & $\begin{array}{l}\text { ICP-MS/MC-I } \\
\text { CP-MS }\end{array}$ & Soil & $\begin{array}{l}\text { Crushing and } \\
\text { digestion with acid }\end{array}$ & $\begin{array}{l}\mathrm{Pb}, \mathrm{Cd}, \\
\mathrm{Pb} \text { isotope }\end{array}$ & / & / & $\begin{array}{l}\text { Elucidate the occurrence and accumulation of } \mathrm{Pb} \text { and } \\
\mathrm{Cd} \text { in the mining region. } \\
\mathrm{MC} \text {-ICP-MS can accurately determine lead isotopes. }\end{array}$ & 25 \\
\hline 14 & $\begin{array}{l}\text { TIMS } \\
\text { ICP-MS }\end{array}$ & $\begin{array}{l}\text { Branches, } \\
\text { leaves and } \\
\text { olives of } \\
\text { olives } \\
\text { trees.;Soil; } \\
\text { Irrigation } \\
\text { and } \\
\text { rainwaters;fe } \\
\text { rtilizers }\end{array}$ & $\begin{array}{l}\text { Nitric acid for } \mathrm{Sr} \\
\text { separation } \\
\text { purification on the } \\
\text { Eichrom Sr-resin }\end{array}$ & Sr isotope & 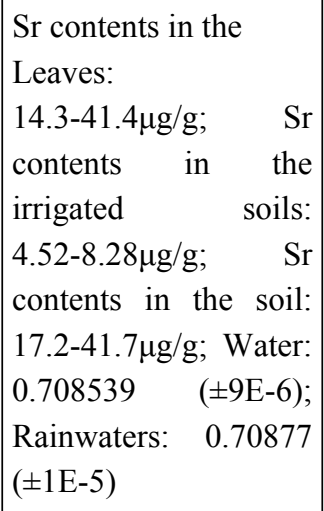 & / & $\begin{array}{l}\text { The sources of strontium absorption by trees in } \\
\text { different cultivation environments were discussed. } \\
\text { Collection and determination of strontium isotopes in } \\
\text { different environments. }\end{array}$ & 26 \\
\hline 15 & TIMS & $\begin{array}{l}\text { Dolomite } \\
\text { basalt } \\
\text { peridotite }\end{array}$ & $\begin{array}{l}\mathrm{HF}+\mathrm{HNO}_{3} \text { digestion, } \\
\text { drying and dissolve } \\
\text { with } \mathrm{HCl} \text {. Separate the } \\
\text { matrix with } \mathrm{LN} \text { resin } \\
\text { column and Ln Spec } \\
\text { resin column }\end{array}$ & $\mathrm{Cr}$ isotope ratios & $\begin{array}{l}\text { Internal precisions: }(2 \\
\text { SE) of } 0.017 \pm 0.037 \\
\text { Reproducibility: } \\
0.113454 \pm 0.000004\end{array}$ & Cr double spike & $\begin{array}{l}\text { To enhance } \mathrm{Cr} \text { ionization efficiency and develop a } \\
\text { highly sensitive and precise analytical protocol to } \\
\text { determine } \mathrm{Cr} \text { isotopes using TIMS. } \\
\text { Propose a } \mathrm{Nb}_{2} \mathrm{O}_{5} \text { emitter and improve the traditional } \\
\text { two-step anion-exchange resin column procedure. }\end{array}$ & 27 \\
\hline
\end{tabular}




\begin{tabular}{|c|c|c|c|c|c|c|c|c|}
\hline No. & Instrumental & Matrix & Sample preparation & Element or isotope & LOD or LOQ & Calibration & Application and Technical characteristics & Ref. \\
\hline 16 & LIMS & Soil & / & $\begin{array}{l}\mathrm{Fe}, \mathrm{Mg}, \mathrm{As}, \mathrm{Na}, \mathrm{K} \\
\mathrm{Ca}, \mathrm{Ga}, \mathrm{Ge}, \mathrm{Ba}, \mathrm{Be}, \\
\mathrm{Bi}, \mathrm{Cd}, \mathrm{Ce}\end{array}$ & / & $\begin{array}{l}\text { The molar } \\
\text { concentration of } \\
\text { the element is } \\
\text { approximately } \\
\text { equal to the } \\
\text { signal intensity } \\
\text { divided by the } \\
\text { total ion current. }\end{array}$ & $\begin{array}{l}\text { Analyze geochemical standard reference soil samples } \\
\text { to demonstrate the rapid analytical capability of this } \\
\text { technique. } \\
\text { Owing to the introduction of buffer gas in the ion } \\
\text { source, the LIMS system proves to be a suitable } \\
\text { technology for rapid detection of multiple elements in } \\
\text { soil with little or no sample preparation. }\end{array}$ & 32 \\
\hline 17 & $\begin{array}{l}\text { MC-ICP-MS } \\
\text { TIMS } \\
\text { ICP-AES }\end{array}$ & $\begin{array}{l}\text { Solid } \\
\text { carbonate } \\
\text { samples }\end{array}$ & $\begin{array}{l}\text { Soak in } \mathrm{H}_{2} \mathrm{O}_{2} \text {, dissolve } \\
\text { in } \mathrm{HCl} \text {, and purify by } \\
\text { Amberlite IRA } 743 \\
\text { resin column and } \\
\text { mixed resin column }\end{array}$ & Boron isotopes & $\begin{array}{l}\text { The average }\left(\mathrm{n}^{1 / 410)}\right. \\
\text { internal analytical } \\
\text { precision and the } \\
\text { external precision of } \\
\text { the r measured } \\
11 \mathrm{~B} / 10 \mathrm{~B} \text { ratios of } \\
\mathrm{NIST} \\
951 \text { are } 70.05 \% \text { and } \\
0.09 \% \text {, respectively. }\end{array}$ & $\begin{array}{l}\text { Sample-standard } \\
\text { bracketing } \\
\text { procedure }(\mathrm{SSB}) \\
\text { PTIMS- } \mathrm{Cs}_{2} \mathrm{BO}_{2} \\
\text { +-static double } \\
\text { collection } \\
\text { method }\end{array}$ & $\begin{array}{l}\text { To achieve high precision and high accuracy } \\
\text { measurements of boron isotopic compositions in } \\
\text { natural geological samples, improving in the } \\
\text { separation/purification process of boron from } \\
\text { complex matrices. } \\
\text { Establishing of static double-collection } \\
\text { PTIMS-Cs }{ }_{2} \mathrm{BO}_{2} \text { pmethod without special } \\
\text { requirements on instrumental hardware. }\end{array}$ & 33 \\
\hline 18 & $\begin{array}{l}\text { TIMS } \\
\text { MC-ICP-MS }\end{array}$ & $\begin{array}{l}\mathrm{Ni} \text { standard } \\
\text { solution }\end{array}$ & / & Ni Isotope & $\begin{array}{l}\text { Internal precision (2 } \\
\mathrm{RSE}) \text { of } \pm 0.03 \text { to } 0.05\end{array}$ & $\begin{array}{l}\text { Isotope dilution } \\
\text { method }\end{array}$ & $\begin{array}{l}\text { Improved the Ni ionization efficiency and precise } \\
\text { measurement. } \\
\text { Proposed a zirconium hydrogen phosphate emitter, } \\
\text { combined with phosphate acid. }\end{array}$ & 34 \\
\hline 19 & $\begin{array}{l}\text { Q-ICP-MS } \\
\text { ICP-MS } \\
\text { AAS }\end{array}$ & Wine & $\begin{array}{l}\text { Microwave digestion } \\
\text { and Dowex } 50 \mathrm{~W}-\mathrm{X} 8 \\
\text { ion exchange resin to } \\
\text { separate } \mathrm{Sr} \text { and } \mathrm{Rb}\end{array}$ & $\begin{array}{l}{ }^{87} \mathrm{Sr} /{ }^{86} \mathrm{Sr} \text { Isotope Ratio } \\
\text { and Mineral elements }\end{array}$ & $\begin{array}{l}\text { ICP-MS: } \quad 0.1-0.6 \\
\mu \mathrm{g} / \mathrm{L} ; \\
\text { AAS: }\end{array}$ & $\begin{array}{l}\text { External } \\
\text { standard method } \\
\text { linear range: } \\
2.5-50 \mu \mathrm{g} / \mathrm{L} \\
\mathrm{R}^{2}: \\
0.9991-0.9999 .\end{array}$ & $\begin{array}{l}\text { Geographical traceability of Wines. } \\
\text { The combination of mineral elements and isotopes } \\
\text { strengthens the feasibility of traceability. }\end{array}$ & 35 \\
\hline
\end{tabular}




\begin{tabular}{|c|c|c|c|c|c|c|c|c|}
\hline No. & Instrumental & Matrix & Sample preparation & Element or isotope & LOD or LOQ & Calibration & Application and Technical characteristics & Ref. \\
\hline 20 & $\begin{array}{l}\text { TIMS } \\
\text { LA-MC-ICP- } \\
\text { MS }\end{array}$ & $\begin{array}{l}\text { Columbite-ta } \\
\text { ntalite } \\
\text { minerals }\end{array}$ & $\begin{array}{l}\mathrm{HF} \text { immersion, ion } \\
\text { exchange } \\
\text { chromatography } \\
\text { column separation of } \\
\mathrm{Pb} \text { and } \mathrm{U}\end{array}$ & U-Pb & $\begin{array}{l}\text { LA-ICP-MS precise } \\
<0.5 \%\end{array}$ & 1 & $\begin{array}{l}\text { To determine reliable crystallisation ages for } \\
\text { rare-element pegmatites. } \\
\text { LA-MC-ICP-MS technique as a method of directly } \\
\text { analysing primary zones in columbite-tantalite, } \\
\text { avoiding inclusions and alteration. }\end{array}$ & 37 \\
\hline 21 & $\begin{array}{l}\text { Compact } \\
\text { quadrupole } \\
\text { mass } \\
\text { spectrometer }\end{array}$ & Water & / & Fe isotope ratio & / & $\begin{array}{l}\text { Isotope dilution } \\
\text { mass } \\
\text { spectrometry }\end{array}$ & $\begin{array}{l}\text { Determined Fe traces in different water. } \\
\text { Using boric acid in addition to silica gel, was } \\
\text { developed to determine Fe isotope ratios with thermal } \\
\text { ionization mass spectrometry. }\end{array}$ & 38 \\
\hline 22 & TIMS & $\begin{array}{l}\text { Fecal } \\
\text { samples; } \\
\text { blood; urine }\end{array}$ & $\begin{array}{l}\text { Dissolve with } \mathrm{HCl} \text { and } \\
\text { purify by Ion } \\
\text { exchange } \\
\text { chromatography }\end{array}$ & $\begin{array}{l}\mathrm{Zn}, \mathrm{P} \text {, and } \mathrm{Fe} \text { stable } \\
\text { isotope }\end{array}$ & 1 & / & $\begin{array}{l}\text { Enriched stable isotopes were used in nutrition } \\
\text { studies. } \\
\text { After obtaining baseline values for zinc, copper, and } \\
\text { Fe absorption from diets adequate in all nutrients, the } \\
\text { effects of age, pregnancy, and several dietary } \\
\text { variables were studied. }\end{array}$ & 39 \\
\hline 23 & $\begin{array}{l}\text { GD } \\
\text {-QMS/ICP-OE } \\
\text { S/XRF }\end{array}$ & Hf metal & $\begin{array}{l}\text { Hf metal was cleaned } \\
\text { with iso-propanol, } \\
\text { dried; Hf } \text { metal } \\
\text { dissolved } \\
\text { water }\end{array}$ & Hf & / & $\begin{array}{l}\text { Non-matrix } \\
\text { matched } \\
\text { standard }\end{array}$ & $\begin{array}{l}\text { Determinated impurities Hf metal. } \\
\text { Utilizes a non-matrix matched standard and an } \\
\text { internal reference element for the quantification of } \\
\text { more than } 70 \text { elements. }\end{array}$ & 40 \\
\hline
\end{tabular}




\begin{tabular}{|c|c|c|c|c|c|c|c|c|}
\hline No. & Instrumental & Matrix & Sample preparation & Element or isotope & LOD or LOQ & Calibration & Application and Technical characteristics & Ref. \\
\hline 24 & $\begin{array}{l}\text { ICP-MS/GD-Q } \\
\text { MS }\end{array}$ & $\begin{array}{l}\text { High purity } \\
\text { cadmium }\end{array}$ & $\begin{array}{l}\text { Dowex-50Wx8 } \\
\text { ion-exchange resin } \\
\text { purification; } \mathrm{HNO}_{3} \text { is } \\
\text { digested, then } \\
\text { dissolved in } \mathrm{HCl}\end{array}$ & $\begin{array}{ll} & \\
\text { Trace } & \text { element } \\
\text { impurities } & \\
& \\
& \end{array}$ & $\begin{array}{l}{ }^{49} \mathrm{Ti}: 0.47 \mathrm{ng} / \mathrm{g} \\
{ }^{51} \mathrm{~V}: 0.30 \mathrm{ng} / \mathrm{g} \\
{ }^{52} \mathrm{Cr}: 1.1 \mathrm{ng} / \mathrm{g} \\
{ }^{55} \mathrm{Mn}: 0.4 \mathrm{ng} / \mathrm{g} \\
{ }^{59} \mathrm{Co}: 0.05 \mathrm{ng} / \mathrm{g} \\
{ }^{62} \mathrm{Ni}: 0.47 \mathrm{ng} / \mathrm{g} \\
{ }^{63} \mathrm{Cu}: 1.1 \mathrm{ng} / \mathrm{g} \\
{ }^{64} \mathrm{Zn}: 6 \mathrm{ng} / \mathrm{g} \\
{ }^{86} \mathrm{Sr}: 0.3 \mathrm{ng} / \mathrm{g}\end{array}$ & 1 & $\begin{array}{l}\text { Developed a separation procedure } \\
\text { suitable for the determination of trace and ultra-trace } \\
\text { level impurities using ICP-QMS. } \\
\text { More elements could be reported using GD-QMS. }\end{array}$ & 41 \\
\hline 25 & PGD -TOFMS & $\begin{array}{l}\mathrm{Cu} / \mathrm{NiCu} \\
\text { nanometric } \\
\text { multilayers }\end{array}$ & $\begin{array}{lr}\text { Samples } & \text { were } \\
\text { prepared } & \text { by using } \\
\mathrm{Si} / / \mathrm{Cr}(5 & \mathrm{nm}) / / \mathrm{Cu}(20 \\
\mathrm{nm}) & \text { substrates } \\
\text { (cathode) } & \end{array}$ & $\begin{array}{l}{ }^{28} \mathrm{Si},{ }^{52} \mathrm{Cr},{ }^{56} \mathrm{Fe},{ }^{59} \mathrm{Co}, \\
{ }^{62} \mathrm{Ni}\end{array}$ & 1 & $\begin{array}{l}\text { Multi-matrix } \\
\text { calibration } \\
\text { approach }\end{array}$ & $\begin{array}{l}\text { Focused towards the depth profile analysis of } \\
\mathrm{Cu} / \mathrm{NiCu} \text { nanolayers and multilayers electrodeposited } \\
\text { on } \mathrm{Si} \text { wafers. } \\
\text { Using the afterglow region for all the sample } \\
\text { components except for the major element }(\mathrm{Cu}) \text { that } \\
\text { was analyzed in the plateau. }\end{array}$ & 42 \\
\hline 26 & GD-MS & $\begin{array}{l}\text { Soil; } \\
\text { sediment and } \\
\text { vegetation }\end{array}$ & $\begin{array}{l}\text { The sample is } \\
\text { compacted with the } \\
\text { silver powder. }\end{array}$ & Trace radioisotopes & $\begin{array}{l}\text { Detection limits in the } \\
\mathrm{ng} / \mathrm{g} \text { range }\end{array}$ & $\begin{array}{l}\text { Optimizing the } \\
\text { mass resolution }\end{array}$ & $\begin{array}{l}\text { Determination of some radioisotopes of cesium, } \\
\text { strontium, plutonium, uranium and thorium in soils, } \\
\text { sediments and vegetations. } \\
\text { Reasonable sample preparation. }\end{array}$ & 44 \\
\hline 27 & $\begin{array}{l}\text { PGD-TOF-MS } \\
\text { /ICP-OES }\end{array}$ & $\begin{array}{l}\text { Geological } \\
\text { sample of } \\
\text { rare earth } \\
\text { elements } \\
\text { enriched ore } \\
65-1 B-A T K- \\
97\end{array}$ & Grinding and pressing & $\begin{array}{l}\text { Major and Trace } \\
\text { Elements }\end{array}$ & $2-4 \times 10^{-6}$ mass $\%$ & $\begin{array}{l}\text { Using relative } \\
\text { sensitivity } \\
\text { factors }\end{array}$ & $\begin{array}{l}\text { Direct Quantification of Major and Trace Elements in } \\
\text { Geological Samples; geological analysis. } \\
\text { The method requires a minimal sample pretreatment } \\
\text { and is applicable for the determination of wide range } \\
\text { of elements of the periodic table in a single analytical } \\
\text { procedure without sample dissolution. }\end{array}$ & 45 \\
\hline
\end{tabular}




\begin{tabular}{|c|c|c|c|c|c|c|c|c|}
\hline No. & Instrumental & Matrix & Sample preparation & Element or isotope & LOD or LOQ & Calibration & Application and Technical characteristics & Ref. \\
\hline 28 & GD-MS & $\begin{array}{l}\text { Certified } \\
\text { reference } \\
\text { materials }\end{array}$ & $\begin{array}{l}\mathrm{HNO}_{3} \text { and water } \\
\text { washing, argon drying }\end{array}$ & $\begin{array}{l}\text { B, C, Al, Si, P, S, V, } \\
\mathrm{Ti}\end{array}$ & 1 & $\begin{array}{l}\text { Universal } \\
\text { (u-RSFs) }\end{array}$ & $\begin{array}{l}\text { Using universal RSFs (u-RSFs) to establish a direct } \\
\text { quantification method by GDMS. } \\
\text { Based on the optimum parameters, a set of u-RSFs } \\
\text { were obtained by averaging the RSFs in certified } \\
\text { reference materials (CRMs) covering most common } \\
\text { matrixes. }\end{array}$ & 46 \\
\hline 29 & GD-MS & $\begin{array}{l}\text { Hromium } \\
(\mathrm{III}) \quad \text { oxide } \\
\left(\mathrm{Cr}_{2} \mathrm{O}_{3}\right) \text { and } \\
\text { chromium } \\
(\mathrm{VI}) \text { oxide } \\
\left(\mathrm{CrO}_{3}\right)\end{array}$ & $\begin{array}{l}\text { Grinding and pressing } \\
\text { of graphite powder or } \\
\text { silver powder }\end{array}$ & Cr speciation & $\begin{array}{l}\text { Chromium (III) oxide } \\
\text { and chromium (VI) } \\
\text { oxide were found to } \\
\text { be } 2.89 \% \text { and } 1.97 \%\end{array}$ & Normalize & $\begin{array}{l}\text { Direct speciation of chromium in solid state samples. } \\
\text { The impact of glow discharge operating conditions on } \\
\text { the appearance of these characteristic cluster ions is } \\
\text { discussed. }\end{array}$ & 47 \\
\hline 30 & $\begin{array}{l}\text { Pulsed } \\
\text { millisecond } \\
\text { radio } \\
\text { frequency-GD- } \\
\text { TOF-MS }\end{array}$ & $\begin{array}{l}\text { Solid state } \\
\text { samples }\end{array}$ & $\begin{array}{l}\text { Sample mixed with } \\
\text { silver powder }\end{array}$ & 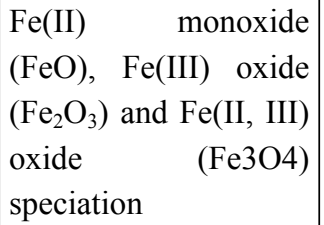 & / & 1 & $\begin{array}{l}\text { Direct FexOy speciation in solid state materials. } \\
\text { Adjustment of parameters such as sampling distance, } \\
\text { temporal regime, discharge gas pressure, pulse } \\
\text { frequency, and duty cycle is essential to enable such } \\
\text { speciation. }\end{array}$ & 48 \\
\hline 31 & APGD -MS & $\begin{array}{l}\text { Apple, } \\
\text { cranberry, } \\
\text { grape and } \\
\text { orange juices }\end{array}$ & $\begin{array}{l}\text { Spray the fruit juice } \\
\text { containing pesticides } \\
\text { on the filter paper strip }\end{array}$ & Pesticides & $\begin{array}{l}\text { Metolcarb: } 1 \mu \mathrm{g} / \mathrm{L} \text {; } \\
\text { Arbofuran and } \\
\text { dinoseb: } 2 \mu \mathrm{g} / \mathrm{L}\end{array}$ & $\begin{array}{l}\text { Internal standard } \\
\text { method }\end{array}$ & $\begin{array}{l}\text { A fast and sensitive analysis of pesticides. } \\
\text { No sample pretreatment was necessary to analyze } \\
\text { these pesticides by direct desorption/ionization using } \\
\text { APGD-MS. }\end{array}$ & 49 \\
\hline
\end{tabular}




\begin{tabular}{|c|c|c|c|c|c|c|c|c|}
\hline No. & Instrumental & Matrix & Sample preparation & Element or isotope & LOD or LOQ & Calibration & Application and Technical characteristics & Ref. \\
\hline 32 & Nano SIMS & $\begin{array}{l}\text { Flooded rice } \\
\text { soil }\end{array}$ & $\begin{array}{l}\text { freeze-dried and } \\
\text { ground. }\end{array}$ & Active diazotrophs & $\begin{array}{l}11.33 \pm 1.90 \mathrm{~kg} \mathrm{~N} / \mathrm{ha} \\
\text { in the rice-planted soil } \\
\text { and } 3.55 \pm 1.18 \mathrm{~kg} \\
\mathrm{~N} / \mathrm{ha} \quad \text { in } \\
\text { nonplanted soil }\end{array}$ & / & $\begin{array}{l}\text { Investigate the effects of rice-planting on the BNF } \\
\text { and its associated diazotrophic communities and } \\
\text { discover the active diazotrophs in a rice-planted soil. } \\
\text { The biological nitrogen fixation in planted and } \\
\text { nonplanted paddy soils was quantified using a } \\
\text { chamber-based }{ }^{15} \mathrm{~N}_{2} \text {-labeling technique, and the active } \\
\text { diazotrophs of soil were assessed by }{ }^{15} \mathrm{~N}_{2} \text {-DNA-stable } \\
\text { isotope probing (SIP). }\end{array}$ & 51 \\
\hline 33 & $\begin{array}{l}\text { Nano SIMS } \\
\text { ICP-MS }\end{array}$ & Radish & $\begin{array}{l}\text { Freeze in liquid } \\
\text { nitrogen, fix the cells } \\
\text { with acrolein, } \\
\text { mbed the sections with } \\
\text { Araldite } 502 \text { resin }\end{array}$ & $\mathrm{Zn}, \mathrm{Ca}$ & $\begin{array}{l}{ }^{70} \mathrm{Zn} \quad 180 \pm 24 \text { and } \\
\mathrm{Cd} 352 \pm 11\end{array}$ & 1 & $\begin{array}{l}\text { Examine the in situ } \mathrm{Zn} \text { and } \mathrm{Cd} \text { distribution in the root } \\
\text { apices of metal-sensitive radish (Raphanus sativus) } \\
\text { plants after short-term ( } 24 \mathrm{~h}) \text { exposure to low } \\
\text { concentration }(2.2 \mu \mathrm{M}) \text { of each } \mathrm{Cd} \text { and } \mathrm{Zn} \text {. } \\
\text { Using Nano-SIMS, we mapped the accumulation of } \\
70 \mathrm{Zn} \text { and } 114 \mathrm{Cd} \text { in various root apical tissues in situ } \\
\text { for the first time. }\end{array}$ & 52 \\
\hline 34 & Nano SIMS & Pea seeds & Protein blot analysis & Fe- Ferritin & / & / & $\begin{array}{l}\text { Fe bioavailability in pea. } \\
\text { Using Nano-SIMS analysis, we provide } \\
\text { unprecedented detail on the subcellular distribution of } \\
\text { Fe and ferritin. }\end{array}$ & 53 \\
\hline 35 & $\begin{array}{l}\text { Cryo } \\
\text {-TOF-MS }\end{array}$ & $\begin{array}{l}\text { sepal tissues } \\
\text { of } \\
\text { Hydrangea } \\
\text { macrophylla }\end{array}$ & $\begin{array}{l}\text { Low temperature } \\
\text { freezing treatment }\end{array}$ & $\begin{array}{l}\text { Hydrangea } \\
\text { blue-complex }\end{array}$ & / & / & $\begin{array}{l}\text { Studied the mechanisms of blue flower coloration and } \\
\text { focused on the color variation of hydrangea. } \\
\text { Imaging mass spectrometry is a powerful tool in } \\
\text { mapping of inorganic ions and organic molecules in } \\
\text { tissues. }\end{array}$ & 54 \\
\hline
\end{tabular}




\begin{tabular}{|c|c|c|c|c|c|c|c|c|}
\hline No. & Instrumental & Matrix & Sample preparation & Element or isotope & LOD or LOQ & Calibration & Application and Technical characteristics & Ref. \\
\hline 36 & ToF-SIMS & $\begin{array}{l}\text { Breast } \\
\text { tissues in } \\
\text { broiler } \\
\text { chicken }\end{array}$ & $\begin{array}{l}\text { Liquid Nitrogen } \\
\text { Freeze Cutting }\end{array}$ & Fatty acid & / & / & $\begin{array}{l}\text { Observe fatty acid profiles of breast tissues in broiler } \\
\text { chicken subjected to varied vegetable oil diet. } \\
\text { ToF-SIMS method allows to obtain useful } \\
\text { information in the comparative analysis of animal } \\
\text { tissue and facilitates the acquisition of new and } \\
\text { previously inaccessible information helpful in } \\
\text { understanding the biology and chemistry of } \\
\text { lipid-related processes. }\end{array}$ & 55 \\
\hline 37 & $\begin{array}{l}\text { ICP-MS } \\
\text { ICP-OES } \\
\text { DMA }\end{array}$ & $\begin{array}{l}\text { Echinoderma } \\
\text { ta and } \\
\text { Chordata } \\
\text { species }\end{array}$ & $\begin{array}{l}\text { The samples were } \\
\text { digested by a } \\
\text { microwave system }\end{array}$ & $\mathrm{Pb}, \mathrm{Cd}$ & $\begin{array}{l}\mathrm{Pb}: 0.002 \mathrm{mg} / \mathrm{kg} \\
\mathrm{Cd}: 0.001 \mathrm{mg} / \mathrm{kg} \\
\text { As: } 0.002 \mathrm{mg} / \mathrm{kg} \\
\mathrm{Hg}: 0.002 \mathrm{mg} / \mathrm{kg} \\
\mathrm{Al}: 0.004 \mathrm{mg} / \mathrm{kg}\end{array}$ & $\begin{array}{l}\text { External } \\
\text { standard method }\end{array}$ & $\begin{array}{l}\text { Analysing concentrations of heavy metals including } \\
\text { arsenic, lead, cadmium, aluminium and mercury in } \\
\text { commonly consumed seafood species. } \\
\text { ICP-MS and ICP-OES can quickly monitor } \\
\text { high-throughput pollutant elements. }\end{array}$ & 60 \\
\hline 38 & $\begin{array}{l}\text { LIBS } \\
\text { ICP-OES }\end{array}$ & $\begin{array}{l}\text { Five species } \\
\text { of the } \\
\text { medicinal } \\
\text { plants }\end{array}$ & $\begin{array}{l}\text { Wash, dry, grind and } \\
\text { press and Microwave } \\
\text { digestion }\end{array}$ & $\begin{array}{l}\text { Carbon, } \quad \text { Fe, } \\
\text { magnesium, silicon, } \\
\text { calcium, oxygen, } \\
\text { hydrogen, nitrogen } \\
\text { and sodium }\end{array}$ & / & $\begin{array}{l}\text { Intensity ratio } \\
\text { method }\end{array}$ & $\begin{array}{l}\text { Rapid analysis of the major and trace elements in five } \\
\text { medicinal plant samples. } \\
\text { The intensity ratio method was adopted for the } \\
\text { relative profiling of the elements qualitatively present } \\
\text { in the five medicinal plant samples. The chemometric } \\
\text { multivariate method PLS-DA was also used on the } \\
\text { LIBS data of plant samples for a better understanding } \\
\text { of their characteristic variations. }\end{array}$ & 61 \\
\hline
\end{tabular}




\begin{tabular}{|c|c|c|c|c|c|c|c|c|}
\hline No. & Instrumental & Matrix & Sample preparation & Element or isotope & LOD or LOQ & Calibration & Application and Technical characteristics & Ref. \\
\hline 39 & MP-AES & $\begin{array}{l}\text { Soil, } \\
\text { sediment, } \\
\text { water } \\
\text { reference } \\
\text { materials, } \\
\text { particulate } \\
\text { matter, and } \\
\text { real- } \\
\text { life samples }\end{array}$ & $\begin{array}{l}\text { Water: acidification } \\
\text { Soil: } \mathrm{HF}:+\mathrm{HNO} 3:+\mathrm{H} \\
\mathrm{C} 1 \mathrm{O}_{4}:+\mathrm{HCl} \text { digestion } \\
\text { RSPM:HNO } \mathrm{HN}_{3} \text { digest }\end{array}$ & As, $\mathrm{Cr}, \mathrm{Ni}, \mathrm{Zn}, \mathrm{Pb}, \mathrm{Cu}$ & $0.05-5 \mathrm{ng} / \mathrm{g}$ & Matrix matching & $\begin{array}{l}\text { Environmental monitoring of contaminated sites. } \\
\text { By exploring the performance of MP-AES under } \\
\text { different conditions, determine the optimal conditions } \\
\text { to measure pollutants. }\end{array}$ & 64 \\
\hline 40 & $\begin{array}{l}\text { MP } \\
\text { (Microwave } \\
\text { Plasma)-AES }\end{array}$ & $\begin{array}{l}\text { Seed } \\
\text { cake } \\
\text { husk }\end{array}$ & $\begin{array}{l}\text { Seeds were dehulled, } \\
\text { milled and } \\
\text { processed }\end{array}$ & $\mathrm{Zn}, \mathrm{As}, \mathrm{Cu}, \mathrm{Fe}, \mathrm{Pb}$ & / & / & $\begin{array}{l}\text { The usefulness of seed cake and husk as industrial } \\
\text { wastes generated from Jatrophacurcas in } \\
\text { biotechnology. } \\
\text { Nutritive components, macro and micro-elements } \\
\text { were investigated following standard protocols. }\end{array}$ & 65 \\
\hline 41 & $\begin{array}{l}\text { MIP } \\
\text { (Microwave-In } \\
\text { duced } \\
\text { Plasma)-OES }\end{array}$ & Fish & $\begin{array}{l}\text { Freeze well and then } \\
\text { digest with nitric acid }\end{array}$ & $\begin{array}{l}\text { Mercury, Cadmium, } \\
\text { Lead, Arsenic, } \\
\text { Copper, Fe, and Zinc }\end{array}$ & $\begin{array}{l}\mathrm{Hg}: 0.01 \quad \mathrm{mg} / \mathrm{kg} \\
\mathrm{Pb}: 0.07 \mathrm{mg} / \mathrm{kg} \\
\mathrm{Cd}: 0.01 \mathrm{mg} / \mathrm{kg} \\
\mathrm{As}: 0.02 \mathrm{mg} / \mathrm{kg} \text { Fe:0.14 } \\
\mathrm{mg} / \mathrm{kg} \\
\mathrm{Cu}: 0.12 \mathrm{mg} / \mathrm{kg} \\
\mathrm{Zn}: 0.05 \mathrm{mg} / \mathrm{kg}\end{array}$ & $\begin{array}{l}\text { External } \\
\text { standard method } \\
\mathrm{R}^{2}>0.995 \\
\end{array}$ & $\begin{array}{l}\text { Determination of heavy metal elements in fish. } \\
\text { The method described can be considered adequate for } \\
\text { the simultaneous determination and quantification of } \\
\text { the chosen heavy metals in fish matrices. }\end{array}$ & 66 \\
\hline
\end{tabular}




\begin{tabular}{|c|c|c|c|c|c|c|c|c|}
\hline No. & Instrumental & Matrix & Sample preparation & Element or isotope & LOD or LOQ & Calibration & Application and Technical characteristics & Ref. \\
\hline 42 & $\begin{array}{l}\text { MP-OES/ICP- } \\
\text { MS }\end{array}$ & Toenails & Digest with nitric acid & $\begin{array}{l} \\
\\
\mathrm{Al}, \mathrm{Ba}, \mathrm{Ca}, \mathrm{Cr}, \mathrm{Cs}, \\
\mathrm{Cu}, \mathrm{Fe}, \mathrm{Mg}, \mathrm{Mn}, \mathrm{Ni} \\
\mathrm{P}, \mathrm{Pb}, \mathrm{Rb}, \mathrm{S}, \mathrm{Sb}, \mathrm{Se} \\
\mathrm{Sn}, \mathrm{Sr}, \mathrm{V} \text { and } \mathrm{Zn}\end{array}$ & $\begin{array}{lrr}\text { As:10 } & \mathrm{ng} / \mathrm{g}, & \mathrm{Ba}: 4 \\
\mathrm{ng} / \mathrm{g}, & \mathrm{Ca}: 0.08 & \mathrm{ng} / \mathrm{g}, \\
\mathrm{Cr}: 10 & \mathrm{ng} / \mathrm{g}, & \mathrm{Cs}: 0.2 \\
\mathrm{ng} / \mathrm{g}, & \mathrm{Cu}: 0.001 & \mathrm{ng} / \mathrm{g}, \\
\mathrm{Fe}: 0.04 & \mathrm{ng} / \mathrm{g}, & \mathrm{Mg}: 30 \\
\mathrm{ng} / \mathrm{g}, & \mathrm{Mn}: 3 & \mathrm{ng} / \mathrm{g}, \\
\mathrm{Ni}: 0.007 & \mathrm{ng} / \mathrm{g}, \\
\mathrm{P}: 0.009 & \mathrm{ng} / \mathrm{g}, & \mathrm{Pb}: 0.04 \\
\mathrm{ng} / \mathrm{g}, & \mathrm{Rb}: 5 & \mathrm{ng} / \mathrm{g}, \\
\mathrm{S}: 0.004 & & \mathrm{ng} / \mathrm{g}, \\
\mathrm{Sb}: 0.003 & \mathrm{ng} / \mathrm{g}, & \mathrm{Se}: 3, \\
\mathrm{ng} / \mathrm{g} & \mathrm{Sn}: 0.001 & \mathrm{ng} / \mathrm{g}, \\
\mathrm{Sr}: 0.5 & \mathrm{ng} / \mathrm{g}, & \mathrm{V}: 0.03 \\
\mathrm{ng} / \mathrm{g}, \mathrm{Zn}: 100 \mathrm{ng} / \mathrm{g}\end{array}$ & $\begin{array}{l}\text { External } \\
\text { standard method }\end{array}$ & $\begin{array}{l}\text { Classification of type- } 2 \text { diabetes. } \\
\text { Combining elemental analysis of toenails and } \\
\text { machine learning techniques as a non-invasive } \\
\text { diagnostic tool for the robust classification of type- } 2 \\
\text { diabetes. }\end{array}$ & 67 \\
\hline 43 & $\begin{array}{l}\text { Matrix-Assiste } \\
\text { d Microwave } \\
\text { Induced } \\
\text { Plasma } \\
\text { Surface } \\
\text { Sampling } \\
\text { Atomic } \\
\text { Emission } \\
\text { Spectrometry }\end{array}$ & $\begin{array}{l}\text { Water, soil, } \\
\text { marine } \\
\text { bottom } \\
\text { sediment, } \\
\text { gold ore }\end{array}$ & $\begin{array}{l}\text { For solid powder } \\
\text { samples } r \text { was } \\
\text { sandwiched between } \\
\text { two sheets of the } \\
\text { whole filter paper. }\end{array}$ & $\begin{array}{l}\mathrm{Ag} 、 \mathrm{Au} 、 \mathrm{Ba} 、 \mathrm{Cd} \\
\mathrm{Cr} 、 \mathrm{Cu} 、 \mathrm{Eu} 、 \mathrm{La} 、 \\
\mathrm{Mn} 、 \mathrm{Ni} 、 \mathrm{~Pb} 、 \mathrm{Sr} 、 \mathrm{y}\end{array}$ & $1.0-88 \mathrm{ng} / \mathrm{mL}$ & / & $\begin{array}{l}\text { Determination of Metallic Elements in Environmental } \\
\text { Samples. } \\
\text { The proposed method provided several advantages, } \\
\text { including fast analysis speed, little sample } \\
\text { consumption, and simple instrument design and } \\
\text { system operation. }\end{array}$ & 69 \\
\hline
\end{tabular}




\begin{tabular}{|c|c|c|c|c|c|c|c|c|}
\hline No. & Instrumental & Matrix & Sample preparation & Element or isotope & LOD or LOQ & Calibration & Application and Technical characteristics & Ref. \\
\hline 44 & $\begin{array}{l}\mathrm{HG} \\
\text {-AFS }\end{array}$ & $\begin{array}{l}\text { Surface } \\
\text { Water }\end{array}$ & Filter paper filtration & As & $1.0 \mathrm{ng} / \mathrm{L}$ & $\begin{array}{l}\text { External } \\
\text { standard method } \\
\text { linear } \\
\text { range } \quad: 0.05 \\
\mu \mathrm{g} / \mathrm{L}-5 \mu \mathrm{g} / \mathrm{L} \\
\mathrm{R}^{2}>0.995\end{array}$ & $\begin{array}{l}\text { Ultra-trace Arsenic Determination in Surface Water. } \\
\text { A novel DBD reactor was designed for arsenic } \\
\text { trap/release coupled to HG-AFS. }\end{array}$ & 70 \\
\hline 45 & $\begin{array}{l}\text { In } \\
\text { Situ-DBDT-A } \\
\text { FS }\end{array}$ & $\begin{array}{l}\text { Tap water, } \\
\text { river water, } \\
\text { and lake } \\
\text { water }\end{array}$ & $\begin{array}{l}\text { The samples were } \\
\text { cleaned using filter } \\
\text { paper prior to usage, } \\
\text { respectively. }\end{array}$ & As & $2.8 \mathrm{pg}$ & $\begin{array}{l}\text { External } \\
\text { standard method } \\
\text { linear } \\
\text { range } \quad: 0.1-8 \\
\mu \mathrm{g} / \mathrm{L} \\
\mathrm{R}^{2}>0.998\end{array}$ & $\begin{array}{l}\text { Rapid determination of arsenic on site. } \\
\text { The in situ DBD trap is applicable to both AAS and } \\
\text { OES as well as a wide array of atomic spectrometers } \\
\text { capable of on-site and fast analysis. }\end{array}$ & 71 \\
\hline 46 & UVG -DBD & $\begin{array}{l}\text { Soil } \\
\text { Surface } \\
\text { Water }\end{array}$ & $\begin{array}{l}\text { Soil digestion, } \\
\text { membrane filtration of } \\
\text { water samples }\end{array}$ & $\mathrm{Se}$ & $4 \mathrm{pg}$ & $\begin{array}{l}\text { External } \\
\text { standard method } \\
\text { linear } \\
\text { range }: 0.05-50 \\
\mu \mathrm{g} / \mathrm{L} \\
\mathrm{R}^{2}>0.995\end{array}$ & $\begin{array}{l}\text { Detection of Se in water and soil samples. } \\
\text { UVG was combined with DBD for the gasphase } \\
\text { preconcentration of volatile selenium species to } \\
\text { enhance the analytical sensitivity and eliminate } \\
\text { matrix interference. }\end{array}$ & 72 \\
\hline 47 & $\begin{array}{l}\text { HG-PD (point } \\
\text { discharge)-OE } \\
\mathrm{S}\end{array}$ & Soil & $\begin{array}{l}\mathrm{HF}+\mathrm{HNO}_{3}+\mathrm{HCl} \\
\text { digestion; } \\
\mathrm{HClO}_{4}+\mathrm{HCl}+\text { ascorbic } \\
\text { acid for subsequent } \\
\text { analysis }\end{array}$ & $\mathrm{As}, \mathrm{Bi}, \mathrm{Sb}, \mathrm{Sn}$ & $\begin{array}{l}\text { As: } 7 \mu \mathrm{g} / \mathrm{L} \\
\text { Bi: } 1 \mu \mathrm{g} / \mathrm{L} \\
\text { Sb: } 5 \mu \mathrm{g} / \mathrm{L} \\
\text { Sn: } 2 \mu \mathrm{g} / \mathrm{L}\end{array}$ & $\begin{array}{l}\text { External } \\
\text { standard method } \\
\text { RSD }<5 \%\end{array}$ & $\begin{array}{l}\text { Simultaneously determine } \mathrm{As}, \mathrm{Bi}, \mathrm{Sb} \text { and } \mathrm{Sn} \text { in soil } \\
\text { samples. } \\
\text { The hydrogen produced by the } \mathrm{HG} \text { process is used to } \\
\text { effectively minimize the background spectrum } \\
\text { emission of the micro-plasma, the analyte is } \\
\text { converted into volatile species, and separated from } \\
\text { the sample solvent and matrix by the HG process to } \\
\text { eliminate the interference of the sample matrix. }\end{array}$ & 75 \\
\hline
\end{tabular}




\begin{tabular}{|c|c|c|c|c|c|c|c|c|}
\hline No. & Instrumental & Matrix & Sample preparation & Element or isotope & LOD or LOQ & Calibration & Application and Technical characteristics & Ref. \\
\hline 48 & PEVG -AFS & $\begin{array}{l}\text { Simulated } \\
\text { natural water } \\
\text { sample } \\
\text { GSB } \\
07-1184-200 \\
0 ; \quad \text { soil } \\
\text { standard; } \\
\text { rice standard }\end{array}$ & $\begin{array}{l}\text { The water sample is } \\
\text { diluted to a } \mathrm{pH} \text { of } 3.2 \text {; } \\
\text { Digestion of solid } \\
\text { samples } \\
\mathrm{HCl}+\mathrm{HNO}_{3}\end{array}$ & $\mathrm{Zn}, \mathrm{Cd}$ & $\begin{array}{l}\text { Zn: } 0.3 \mu \mathrm{g} / \mathrm{L} \\
\text { Cd: } 0.003 \mu \mathrm{g} / \mathrm{L}\end{array}$ & $\begin{array}{l}\text { External } \\
\text { standard method } \\
\text { linear } \\
\text { range }: 0.05-0.5 \\
\mu \mathrm{g} / \mathrm{L} \\
\mathrm{RSD}=2.4 \%\end{array}$ & $\begin{array}{l}\text { Solution anode glow discharge for the determination } \\
\text { of } \mathrm{Cd} \text { and } \mathrm{Zn} \text { by atomic fluorescence spectrometry. } \\
\text { The overall efficiency of the PEVG system was much } \\
\text { higher than the conventional electrochemical hydride } \\
\text { generation (EcHG) and } \mathrm{HCl}-\mathrm{KBH} 4 \text { system. }\end{array}$ & 76 \\
\hline 49 & $\begin{array}{l}\text { HG-SCGD } \\
\text {-AES }\end{array}$ & Rice & $\begin{array}{l}\text { Microwave digestion } \\
\text { with } \mathrm{HNO}_{3} \text { followed } \\
\text { by membrane analysis }\end{array}$ & $\begin{array}{l}\text { Inorganic arsenic } \\
\text { valence }\end{array}$ & $0.3 \mu \mathrm{g} / \mathrm{L}$ & $\begin{array}{l}\text { External } \\
\text { standard method } \\
\text { linear } \\
\text { range } \quad: 2-100 \\
\mu \mathrm{g} / \mathrm{L} \\
\mathrm{RSD}=2.5 \%\end{array}$ & $\begin{array}{l}\text { Separate } \mathrm{As}(\mathrm{III}) \text { and } \mathrm{As}(\mathrm{V}) \text {. } \\
\text { Arsenic was converted into volatile hydrides by the } \\
\text { reaction with } \mathrm{NaBH} 4 \text { and } \mathrm{HCl} \text {, after which they were } \\
\text { delivered and subsequently injected into the } \\
\text { near-anode region of the SCGD. }\end{array}$ & 77 \\
\hline 50 & $\begin{array}{l}\text { MWP } \\
\text {-PTR-MS }\end{array}$ & Water & / & $\begin{array}{l}\text { Volatile organic } \\
\text { compounds }\end{array}$ & $\begin{array}{l}\text { Acetone: } 2.7 \\
\times 10-12 \mathrm{~mol} / \mathrm{L} \\
\text { Toluene: } 12 \\
\times 10-12 \mathrm{~mol} / \mathrm{L} \\
\text { Acetonitrile: } 1.9 \\
\times 10-12 \mathrm{~mol} / \mathrm{L} \\
\text { Acetaldehyde: } 2.3 \times 10 \\
-12 \mathrm{~mol} / \mathrm{L}\end{array}$ & $\begin{array}{l}\text { External } \\
\text { standard method } \\
\text { linear } \\
\text { range }: 4.5 \times 10^{-11} \\
-4.5 \times 10^{-9} \mathrm{~mol} / \mathrm{L}\end{array}$ & $\begin{array}{l}\text { Volatile Organic Compound Monitoring. } \\
\text { MWP has high potential in improving the } \\
\text { performance and reliability of current PTR-MS. }\end{array}$ & 79 \\
\hline
\end{tabular}




\begin{tabular}{|c|c|c|c|c|c|c|c|c|}
\hline No. & Instrumental & Matrix & Sample preparation & Element or isotope & LOD or LOQ & Calibration & Application and Technical characteristics & Ref. \\
\hline 51 & MIPDI & $\begin{array}{l}\text { Drug } \\
\text { tablets, } \\
\text { capsules, and } \\
\text { ointments }\end{array}$ & $\begin{array}{l}\text { No preprocessing } \\
\text { required }\end{array}$ & $\begin{array}{l}\text { Volatile } \quad \text { Organic } \\
\text { Compound } \\
\text { Monitoring }\end{array}$ & $60 \mathrm{pg}$ & / & $\begin{array}{l}\text { Experiments have been demonstrated that this } \\
\text { method can be used to produce positive and negative } \\
\text { ion mass spectra with a wide range of organic } \\
\text { compounds. } \\
\text { The simple construction, easy operation, stability, } \\
\text { reproducibility, the possibility of producing plasmas } \\
\text { with alternative gases, and its high efficiency for } \\
\text { desorbing/ionizing analytes directly from sample } \\
\text { surfaces in an ambient atmosphere. }\end{array}$ & 80 \\
\hline 52 & DLAAS & $\begin{array}{l}\text { Chlorine and } \\
\text { fluorine. }\end{array}$ & / & $\mathrm{CCl}_{2} \mathrm{~F}_{2}$ & $\begin{array}{l}\text { Detection limits of } \\
400 \mathrm{ppt} \text { and } 2 \mathrm{ppb} \text { for } \\
\mathrm{CCl}_{2} \mathrm{~F}_{2} \text { in } \mathrm{He} \text { were } \\
\text { found using the } \mathrm{Cl} \\
837 \mathrm{~nm} \text { and the } \mathrm{F} 685 \\
\mathrm{~nm} \text { line, respectively. }\end{array}$ & / & $\begin{array}{l}\text { Evaluate the results of diode laser absorption } \\
\text { spectrometry obtained with the dielectric barrier } \\
\text { discharge and DBD measurement. } \\
\text { Complete dissociation and efficient excitation of } \\
\text { metastable atoms. }\end{array}$ & 84 \\
\hline 53 & $\begin{array}{l}\text { HG-DBD-AA } \\
\text { S }\end{array}$ & $\begin{array}{l}\text { SRM } \\
2670 \text { Urine } \\
\text { SRM } 1571 \\
\text { orchard } \\
\text { leaves }\end{array}$ & $\begin{array}{l}\text { Add water directly to } \\
\text { the freeze-dried urine }\end{array}$ & Arsenic Speciation & $\begin{array}{l}\operatorname{As}(\mathrm{III}): 1.0 \mu \mathrm{g} / \mathrm{L} \\
\operatorname{As}(\mathrm{V}): 11.8 \mu \mathrm{g} / \mathrm{L} \\
\text { MMA }: 2.0 \mu \mathrm{g} / \mathrm{L} \\
\text { DMA }: 18.0 \mu \mathrm{g} / \mathrm{L}\end{array}$ & $\begin{array}{l}\text { External } \\
\text { standard method } \\
\text { arsenic } \\
\text { range: }\end{array}$ & $\begin{array}{l}\text { Arsenic Speciation Analysis. } \\
\text { A novel hydride atomizer based on atmospheric } \\
\text { pressure DBD plasma. }\end{array}$ & 85 \\
\hline
\end{tabular}




\begin{tabular}{|c|c|c|c|c|c|c|c|c|}
\hline No. & Instrumental & Matrix & Sample preparation & Element or isotope & LOD or LOQ & Calibration & Application and Technical characteristics & Ref. \\
\hline 54 & $\begin{array}{l}\text { Atmospheric } \\
\text { pressure } \\
\text { dielectric } \\
\text { barrier } \\
\text { discharge } \\
\text { plasma }\end{array}$ & $\begin{array}{l}\text { Stock } \\
\text { solutions of } \\
1000 \quad \mathrm{mg} \\
1-1 \text { of } \mathrm{Se}, \mathrm{Sn} \\
\text { and } \mathrm{Sb}\end{array}$ & I & $\mathrm{Se}, \mathrm{Sb}$ and $\mathrm{Sn}$ & $\begin{array}{l}\mathrm{Se}: 13.0 \mu \mathrm{g} / \mathrm{L} \\
\mathrm{Sb}: 0.6 \mu \mathrm{g} / \mathrm{L} \\
\mathrm{Sn}: 10.6 \mu \mathrm{g} / \mathrm{L}\end{array}$ & $\begin{array}{l}\text { External } \\
\text { standard method } \\
\text { Sb linear range: } \\
25-500 \mu \mathrm{g} / \mathrm{L} \\
\text { Se linear range: } \\
25-100 \mu \mathrm{g} / \mathrm{L} \\
\text { Sn linear range: } \\
25-100 \mu \mathrm{g} / \mathrm{L} \\
\mathrm{R}^{2}>0.9999\end{array}$ & $\begin{array}{l}\text { Determination of Se, Sb, and } \mathrm{Sn} \text { with Ar as plasma } \\
\text { gas to investigate its applicability to other } \\
\text { hydride-forming elements. } \\
\text { A new atomizer sensitive to hydride. }\end{array}$ & 86 \\
\hline 55 & DBD-AFS & $\begin{array}{l}\text { Lake water, } \\
\text { River water }\end{array}$ & / & $\operatorname{As}(\mathrm{III})$ & As(III): $0.04 \mu \mathrm{g} / \mathrm{L}$ & $\begin{array}{l}\text { External } \\
\text { standard method } \\
\text { linear } \\
\text { range } \quad: 0.5-50 \\
\mu \mathrm{g} / \mathrm{L}\end{array}$ & $\begin{array}{l}\text { On-site arsenic analysis. } \\
\text { The most attractive characteristic of the present DBD } \\
\text { atomizer is the low operation temperature. }\end{array}$ & 87 \\
\hline 56 & $\begin{array}{l}\text { DBDI } \\
-\mathrm{MS}\end{array}$ & / & / & Explosive chemicals & Pg-ng & 1 & $\begin{array}{l}\text { Used for the fast detection of explosives in the field } \\
\text { of antiterrorism and conservation. } \\
\text { Demonstrated to be highly sensitive for the detection } \\
\text { of explosives which is comparable with that of } \\
\text { DART and DESI. }\end{array}$ & 88 \\
\hline 57 & DBDI-MS & $\begin{array}{l}\text { Monosodium } \\
\text { glutamate }\end{array}$ & $\begin{array}{l}\text { Filtered and placed on } \\
\text { a glass slide. }\end{array}$ & Amino acids & L-alanine: 3.5 pmol & / & $\begin{array}{l}\text { For rapid monitoring in the field. } \\
\text { A new ion source based on dielectric barrier } \\
\text { discharge was developed as an alternative ionization } \\
\text { source for ambient mass spectrometry. }\end{array}$ & 89 \\
\hline
\end{tabular}




\begin{tabular}{|c|c|c|c|c|c|c|c|c|}
\hline No. & Instrumental & Matrix & Sample preparation & Element or isotope & LOD or LOQ & Calibration & Application and Technical characteristics & Ref. \\
\hline 58 & UVG-DBD & $\begin{array}{l}\text { Soil,surface } \\
\text { water }\end{array}$ & $\begin{array}{l}\text { Soil digestion, } \\
\text { membrane filtration of } \\
\text { water samples }\end{array}$ & $\mathrm{Se}$ & $4 \mathrm{pg}$ & $\begin{array}{l}\text { External } \\
\text { standard method } \\
\text { linear } \\
\text { range }: 0.05-50 \\
\mu \mathrm{g} / \mathrm{L} \\
\mathrm{R}^{2}>0.995\end{array}$ & $\begin{array}{l}\text { Detection of Se in water and soil samples. } \\
\text { For the first time, UVG was combined with DBD for } \\
\text { the gasphase preconcentration of volatile selenium } \\
\text { species to enhance the analytical sensitivity and } \\
\text { eliminate matrix interference. }\end{array}$ & 91 \\
\hline 59 & $\begin{array}{l}\text { ETV-DBD-AF } \\
\mathrm{S}\end{array}$ & Aquatic food & soild sampling & $\mathrm{Hg}$ & $0.5 \mu \mathrm{g} / \mathrm{kg}$ & $\begin{array}{l}\text { External } \\
\text { standard method } \\
\text { linear } \\
\text { range }: 2-12 \mathrm{mg} / \mathrm{k} \\
\mathrm{g} \\
\mathrm{R}^{2}>0.996\end{array}$ & $\begin{array}{l}\text { On-line microplasma decomposition of gaseous phase } \\
\text { interference for solid sampling mercury analysis in } \\
\text { aquatic food samples. } \\
\text { DBD was first utilized to eliminate volatile matrix } \\
\text { interference for } \mathrm{Hg} \text { analysis in aquatic food samples. } \\
\text { On-line DBD reactor succeeds in replacing catalytic } \\
\text { pyrolysis furnace for decomposing VOCs. }\end{array}$ & 92 \\
\hline 60 & $\begin{array}{l}\text { Electromagneti } \\
\text { c } \\
\text { heating-microp } \\
\text { lasma AES }\end{array}$ & Soil & Soild sampling & $\mathrm{Hg}, \mathrm{Cd}, \mathrm{Pb}$ & $\begin{array}{l}\mathrm{Hg}: 8.0 \mu \mathrm{g} / \mathrm{kg} \\
\mathrm{Cd}: 17.8 \mu \mathrm{g} / \mathrm{kg} \\
\mathrm{Pb}: 3.5 \mathrm{mg} / \mathrm{kg}\end{array}$ & $\begin{array}{l}\text { External } \\
\text { standard method } \\
\text { Hg linear range: } \\
0.015-0.590 \\
\mathrm{mg} / \mathrm{kg} \\
\mathrm{Cd} \text { linear range: } \\
0.060-0.450 \\
\mathrm{mg} / \mathrm{kg} \\
\mathrm{Pb} \quad 14.0-314.0 \\
\mathrm{mg} / \mathrm{kg}\end{array}$ & $\begin{array}{l}\text { Developed portable, miniaturized atomic } \\
\text { spectrometers for solid sample analysis. } \\
\text { Electromagnetic heating was firstly explored as } \\
\text { sample introduction approach in portable DBD-AES } \\
\text { to directly analyze soil. }\end{array}$ & 93 \\
\hline
\end{tabular}




\begin{tabular}{|c|c|c|c|c|c|c|c|c|}
\hline No. & Instrumental & Matrix & Sample preparation & Element or isotope & LOD or LOQ & Calibration & Application and Technical characteristics & Ref. \\
\hline 61 & INAA & Cigarettes & $\begin{array}{l}\text { Grinding, sieving and } \\
\text { drying }\end{array}$ & Toxic heavy metals & 1 & $\begin{array}{l}\text { NAA } \\
\text { k0-standardizati } \\
\text { on method }\end{array}$ & $\begin{array}{l}\text { Analysis of toxic heavy metals in cigarettes. } \\
\text { The samples were irradiated at the core of the Second } \\
\text { Research Egyptian Reactor ET-RR-2, and the } \\
\text { Induced activities were counted by <gamma-ray } \\
\text { spectrometry using an efficiency-calibrated High } \\
\text { Purity Germanium (HPGe) detector. }\end{array}$ & 97 \\
\hline 62 & INAA & Beef & Freeze-drying, & $\begin{array}{l}\mathrm{Br}, \mathrm{Ca}, \mathrm{Cs}, \mathrm{La}, \mathrm{Sc}, \mathrm{Se}, \\
\mathrm{Sr}, \mathrm{Th}, \mathrm{Zn}\end{array}$ & I & / & $\begin{array}{l}\text { Discriminate between beef cattle diets. } \\
\text { The feeding method implemented in the finishing } \\
\text { stage of beef cattle was investigated as a case study, } \\
\text { applying NAA and data mining techniques for } \\
\text { assessing the differences between two types of diets } \\
\text { commonly used. }\end{array}$ & 99 \\
\hline 63 & INAA & $\begin{array}{l}\text { Biological } \\
\text { materials }\end{array}$ & Irradiation samples & $\mathrm{Al}$ & / & $\begin{array}{l}\text { Internal standard } \\
\text { method }\end{array}$ & $\begin{array}{l}\text { Determination of aluminum in various biological } \\
\text { materials. } \\
\text { In order to determine the interference factors from } \mathrm{Si} \\
\text { and } \mathrm{P}, \mathrm{SiO}_{2} \text { and }\left(\mathrm{NH}_{4}\right)_{2} \mathrm{HPO}_{4} \text { were used. }\end{array}$ & 101 \\
\hline 64 & IBA, INAA & $\begin{array}{l}\text { Drug } \\
\text { products }\end{array}$ & Crushed into granules & $\begin{array}{l}\text { Sildenafil; } \mathrm{Na}, \mathrm{Mg}, \mathrm{Si} \\
\mathrm{P}, \mathrm{S}, \mathrm{Ca}, \mathrm{Ti}, \mathrm{Fe}, \mathrm{Ni} \\
\mathrm{Zn}\end{array}$ & / & / & $\begin{array}{l}\text { Identify drugs. } \\
\text { It is proposed for the first time a combined approach } \\
\text { based on IBA (both PIXE and MeV-SIMS) and } \\
\text { INAA, allowing characterisation of both authentic } \\
\text { and illegal pharmaceuticals containing sildenafil. }\end{array}$ & 102 \\
\hline
\end{tabular}




\begin{tabular}{|c|c|c|c|c|c|c|c|c|}
\hline No. & Instrumental & Matrix & Sample preparation & Element or isotope & LOD or LOQ & Calibration & Application and Technical characteristics & Ref. \\
\hline 65 & INAA & $\begin{array}{l}\text { Stream } \\
\text { sediments }\end{array}$ & $\begin{array}{l}\text { Filtering drying } \\
\text { grinding }\end{array}$ & As, $\mathrm{Ba}, \mathrm{Mn}, \mathrm{Sb}, \mathrm{V}, \mathrm{Zn}$ & $\begin{array}{l}\text { As: } 0.94 \mathrm{mg} / \mathrm{kg} \\
\mathrm{Ba}: 43.0 \mathrm{mg} / \mathrm{kg} \\
\mathrm{Mn}: 7.35 \mathrm{mg} / \mathrm{kg} \\
\mathrm{Sb}: 0.14 \mathrm{mg} / \mathrm{kg} \\
\mathrm{V}: 34.9 \mathrm{mg} / \mathrm{kg} \\
\mathrm{Zn}: 5.43 \mathrm{mg} / \mathrm{kg}\end{array}$ & $\begin{array}{l}\text { Uncertainty } \\
\text { sources can be } \\
\text { defined in terms } \\
\text { of a gamma-ray } \\
\text { counting, } \\
\text { weighing and } \\
\text { the uncertainty } \\
\text { of a reference } \\
\text { material. }\end{array}$ & $\begin{array}{l}\text { Determination of pollutant elements in river } \\
\text { sediments. } \\
\text { INAA was applied for the determination of the } \\
\text { elemental contents in the sediment samples by using } \\
\text { the NAA irradiation holes of the HANARO research } \\
\text { reactor and HPGe gamma-ray spectrometers. }\end{array}$ & 103 \\
\hline 66 & INAA & $\begin{array}{l}\text { Algerian } \\
\text { Artemisia } \\
\text { Plant }\end{array}$ & Grind & $\begin{array}{l}\mathrm{As}, \mathrm{Ba}, \mathrm{Br}, \mathrm{Ca}, \mathrm{Ce}, \\
\mathrm{Co}, \mathrm{Cr}, \mathrm{Cs}, \mathrm{Eu}, \mathrm{Fe}, \\
\mathrm{Hf}, \mathrm{K}, \mathrm{La}, \mathrm{Na}, \mathrm{Rb}, \mathrm{Sb} \\
\mathrm{Sc}, \mathrm{Sm}, \mathrm{Sr}, \mathrm{Yb} \text {, and } \\
\mathrm{Zn}\end{array}$ & / & $\begin{array}{l}\text { Internal standard } \\
\text { method }\end{array}$ & $\begin{array}{l}\text { Used to offer scientific basis for an optimum usage of } \\
\text { the studied plants and so enriches the database of } \\
\text { medicinal herbs. } \\
\text { A sensitive nuclear analytical approach }\end{array}$ & 104 \\
\hline 67 & $\begin{array}{l}\text { AES } \\
\text { XRF } \\
\text { ICP-MS } \\
\text { AFS }\end{array}$ & Soil & Digestion & As $、 \mathrm{~Pb} 、 \mathrm{Cu} 、 \mathrm{Zn}$ & $\begin{array}{l}\text { AES: Cd : } 0.01 \\
\mathrm{mg} / \mathrm{kg} ; \\
\text { PXRF: } \mathrm{As}, \quad \mathrm{Pb}, \mathrm{Cu} \\
\mathrm{Zn:} 7 \mathrm{mg} / \mathrm{kg}, 8 \mathrm{mg} / \mathrm{kg} \\
15 \mathrm{mg} / \mathrm{kg}, 12 \mathrm{mg} / \mathrm{kg}\end{array}$ & $\begin{array}{l}\text { External } \\
\text { standard method } \\
\text { RSD }<20 \%\end{array}$ & $\begin{array}{l}\text { Rapid risk assessment of heavy metals in agricultural } \\
\text { soils. } \\
\text { Rapid heavy metal analysis using PXRF and AES for } \\
\text { accurately assessing ecological risk of agricultural } \\
\text { soils in greenhouses. }\end{array}$ & 106 \\
\hline 68 & ICP-MS PXRF & Rice & Digestion & $\begin{array}{l}\text { As, } \mathrm{Mn}, \mathrm{Fe}, \mathrm{Ni}, \mathrm{Cu} \text {, } \\
\mathrm{Zn}\end{array}$ & 1 & $\begin{array}{l}\text { External } \\
\text { standard method }\end{array}$ & $\begin{array}{l}\text { Use of portable XRF for the assessment of trace } \\
\text { elements in rice and rice products. } \\
\text { Portable XRF has the advantage of being a fully } \\
\text { mobile technique which is rapid, cost effective, and } \\
\text { requires little sample preparation. Since different } \\
\text { elements of interest emit characteristic x-rays with } \\
\text { different photon energies. }\end{array}$ & 107 \\
\hline
\end{tabular}




\begin{tabular}{|c|c|c|c|c|c|c|c|c|}
\hline No. & Instrumental & Matrix & Sample preparation & Element or isotope & LOD or LOQ & Calibration & Application and Technical characteristics & Ref. \\
\hline 69 & ED-XRF & Soybean & Digestion & $\begin{array}{l}\mathrm{Mg}, \mathrm{K}, \mathrm{Ca}, \mathrm{Mn}, \mathrm{Fe} \\
\mathrm{Ni}, \mathrm{Cu}, \mathrm{Zn} \text {, and } \mathrm{Rb}\end{array}$ & 1 & $\begin{array}{l}\text { The certified } \\
\text { samples were } \\
\text { employed as } \\
\text { matching matrix } \\
\text { for } \quad \text { XRF } \\
\text { calibration; } \\
\text { External } \\
\text { standard method }\end{array}$ & $\begin{array}{l}\text { Soybean Traceability. } \\
\text { A novel technical combination of a quick testing } \\
\text { method with ED-XRF and MLP data analysis. }\end{array}$ & 108 \\
\hline 70 & $\begin{array}{l}\text { TXRF } \\
\text { ICP-MS }\end{array}$ & $\begin{array}{l}\text { Whole blood } \\
\text { reference } \\
\text { materials }\end{array}$ & Digestion & $\mathrm{Pb}$ & $\begin{array}{l}0.28 \mu \mathrm{g} / \\
\mathrm{dL}\end{array}$ & $\begin{array}{l}\text { External } \\
\text { standard method }\end{array}$ & $\begin{array}{l}\text { Developed, validated, and applied a method to } \\
\text { analyze Pb in DBS samples using TXRF for use in } \\
\text { human biomonitoring studies. } \\
\text { Developed a method and demonstrated that TXRF } \\
\text { analysis of processed DBS filter paper samples yields } \\
\text { results that are accurate and precise; By purposefully } \\
\text { applying the method to study two populations that } \\
\text { typify divergent conditions. }\end{array}$ & 109 \\
\hline 71 & IC -HG-AFS & $\begin{array}{l}\text { Underground } \\
\text { water, urine }\end{array}$ & Urine: acid extraction & As speciation & $\begin{array}{l}\text { As (III): } 0.02 \mathrm{ng} \\
\text { As (V): } 0.166 \mathrm{ng} \\
\text { MMA: } 0.043 \mathrm{ng} \\
\text { DMA: } 0.045 \mathrm{ng}\end{array}$ & $\begin{array}{l}\text { External } \\
\text { standard method }\end{array}$ & $\begin{array}{l}\text { Separation of arsenic species. } \\
\text { A new gas-liquid separator system in IC-HG-AFS. }\end{array}$ & 112 \\
\hline 72 & $\begin{array}{l}\text { HPLC-CV)-A } \\
\text { FS }\end{array}$ & $\begin{array}{l}\text { Fish muscle } \\
\text { tissue, water }\end{array}$ & Acid leaching & Hg speciation & $\begin{array}{lcc}\mathrm{Hg}^{2+}: & 0.7 & \mu \mathrm{g} / \mathrm{L} \\
\mathrm{MeHg}: & 1.1 & \mu \mathrm{g} / \mathrm{L} \\
\text { EtHg: } & 0.8 & \mu \mathrm{g} / \mathrm{L} \\
\text { PhHg: } & 0.9 \mu \mathrm{g} / \mathrm{L} & \end{array}$ & $\begin{array}{l}\text { External } \\
\text { standard method } \\
\text { correlation } \\
\text { coefficients: } \\
0.9974-0.9982\end{array}$ & $\begin{array}{l}\text { High sensitivities analysis of both } \mathrm{CV} \text { inactive and } \\
\text { active mercury species. } \\
\text { Post-column oxidation method using } \mathrm{Fe}_{3} \mathrm{O}_{4} \text { magnetic } \\
\text { nanoparticles. }\end{array}$ & 114 \\
\hline
\end{tabular}




\begin{tabular}{|c|c|c|c|c|c|c|c|c|}
\hline No. & Instrumental & Matrix & Sample preparation & Element or isotope & LOD or LOQ & Calibration & Application and Technical characteristics & Ref. \\
\hline 73 & IC-ICP-MS & Soil & $\mathrm{KOH}$ extraction & $\begin{array}{l}\text { AMPA, phosphate, } \\
\text { glyphosate }\end{array}$ & $\begin{array}{l}\text { AMPA: } 1.0 \mu \mathrm{g} / \mathrm{L}, \\
\text { phosphate: } 1.0 \mu \mathrm{g} / \mathrm{L}, \\
\text { glyphosate: } 1.5 \mu \mathrm{g} / \mathrm{L}\end{array}$ & $\begin{array}{l}\text { External } \\
\text { standard method } \\
\text { linear range: } \\
5.0-1000 \mu \mathrm{g} / \mathrm{L}, \\
\text { correlation } \\
\text { coefficient } \\
\mathrm{s}>0.999\end{array}$ & $\begin{array}{l}\text { Detection of complexes in the soil extract without } \\
\text { pre-treatment. } \\
\text { Separate phosphate from glyphosate and AMPA by } \\
\text { anion-exchange chromatography. }\end{array}$ & 115 \\
\hline 74 & $\begin{array}{l}\text { HPLC-ID-ICP } \\
\text {-MS }\end{array}$ & Soil & Citric acid extraction & Inorganic $\mathrm{Sb}$ & $\begin{array}{l}\mathrm{Sb}(\mathrm{V}): 20 \mathrm{ng} / \mathrm{L} \\
\mathrm{Sb} \text { (III): } 65 \mathrm{ng} / \mathrm{L}\end{array}$ & $\begin{array}{l}\mathrm{Sb} \text { species } \quad \\
\text { isotope dilution, } \\
\text { linear range: } \\
0.2-50 \mu \mathrm{g} / \mathrm{L}\end{array}$ & $\begin{array}{l}\text { The first application of HPLC species unspecific } \\
\text { spike isotope dilution ICP-MS to separate and } \\
\text { quantify inorganic Sb species in real soil samples. } \\
\text { Online isotope dilution concentration determination } \\
\text { after a chromatographic separation. }\end{array}$ & 116 \\
\hline 75 & $\begin{array}{l}\text { HILIC } \\
\text {-ICP-MS }\end{array}$ & $\begin{array}{l}\text { Human } \\
\text { plasma }\end{array}$ & $\begin{array}{lr}\text { Protein } & \text { precipitation } \\
\text { by } & \text { acetonitrile } \\
\text { addition } & \end{array}$ & Total Pt/Pt species & $\begin{array}{l}\text { Cisplatin: } 9.8 \mu \mathrm{g} / \mathrm{L}, \\
\text { Oxaliplatin: } 40 \mu \mathrm{g} / \mathrm{L}, \\
\text { Carboplatin: } 28.4 \\
\mu \mathrm{g} / \mathrm{L}\end{array}$ & $\begin{array}{l}\text { External } \\
\text { calibration }\end{array}$ & $\begin{array}{l}\text { The determination of the free intact CPC in human } \\
\text { plasma. } \\
\text { The potential of a novel HILIC-ICP-MS approach in } \\
\text { combination with simplified sample preparation } \\
\text { procedures. }\end{array}$ & 117 \\
\hline 76 & LC-ICP-OES & $\begin{array}{l}\text { absorbing } \\
\text { liquid } \\
\text { samples }\end{array}$ & Denitrification system & $\begin{array}{l}\text { Fe(II)-EDTA, } \\
\text { Fe(II)-EDTA }\end{array}$ & $\begin{array}{l}\mathrm{Fe}(\mathrm{III})-\mathrm{EDTA}: \\
1.2 * 10^{-5} \mathrm{~mol} / \mathrm{L} \\
\mathrm{Fe}(\mathrm{II})-\mathrm{EDTA}: \\
1.6^{*} 10^{-5} \mathrm{~mol} / \mathrm{L}\end{array}$ & $\begin{array}{l}\text { External } \\
\text { standard method } \\
\text { typical } \\
\text { concentration: } \\
0.025-0.1 \mathrm{~mol} / \mathrm{L} \\
\mathrm{R}>0.9991\end{array}$ & $\begin{array}{l}\text { Speciationof Fe (II)-EDTA and Fe(III)-EDTA. } \\
\text { The hyphenated technique of LC-ICP-OES based on } \\
\text { ultrasound-assisted replacement reaction. }\end{array}$ & 118 \\
\hline 77 & IC-ICP-MS & $\begin{array}{l}\text { Rain, snow, } \\
\text { aerosols }\end{array}$ & Filtered & Iodine speciation & Iodate: $0.2 \mathrm{nmol} / \mathrm{L}$, & $\begin{array}{l}\text { Calibration } \\
\text { curve }\end{array}$ & $\begin{array}{l}\text { Aqueous phase } \\
\text { iodine chemistry. } \\
\text { / }\end{array}$ & 119 \\
\hline
\end{tabular}




\begin{tabular}{|c|c|c|c|c|c|c|c|c|}
\hline No. & Instrumental & Matrix & Sample preparation & Element or isotope & LOD or LOQ & Calibration & Application and Technical characteristics & Ref. \\
\hline 78 & $\begin{array}{l}\text { HPLC-(UV)-H } \\
\text { G-AFS }\end{array}$ & $\begin{array}{l}\text { Biological } \\
\text { reference } \\
\text { materials }\end{array}$ & $\begin{array}{l}\text { Water-methanol } \\
\text { mixture extraction }\end{array}$ & Arsenic species & $\begin{array}{l}\text { Anion } \quad \text { exchange } \\
\text { columns: } 0.2 \mathrm{ng}, \\
\text { cation } \quad \text { exchange } \\
\text { columns: } 0.4 \mathrm{ng}\end{array}$ & $\begin{array}{lr}\text { External } & \\
\text { standard } & \\
\text { method, } & \text { linear } \\
\text { range: } & 0-20 \\
\mu \mathrm{g} / \mathrm{g}, \mathrm{R}^{2}= & 0.998\end{array}$ & $\begin{array}{l}\text { Identification and quantification of arsenic } \\
\text { compounds. } \\
\text { Anion exchange chromatography and cation } \\
\text { exchange chromatography. }\end{array}$ & 120 \\
\hline 79 & $\begin{array}{l}\text { HPLC-HG-AA } \\
\text { S }\end{array}$ & $\begin{array}{l}\text { Edible } \\
\text { Boletus } \\
\text { badius }\end{array}$ & $\begin{array}{l}\text { Phosphoric acid and } \\
\text { Triton-X-100 } \\
\text { extraction }\end{array}$ & Arsenic species & $1.00 \mathrm{mg} / \mathrm{kg}$ & $\begin{array}{l}\text { External } \\
\text { standard method }\end{array}$ & $\begin{array}{l}\text { The arsenic species in edible Boletus badius with } \\
\text { ambient substrate contamination. } \\
\text { Total arsenic concentration was determined by } \\
\text { GFAAS, As(III) and } \mathrm{As}(\mathrm{V}) \text { were determined by } \\
\text { HPLC-HG-AAS. }\end{array}$ & 121 \\
\hline 80 & $\begin{array}{l}\text { LC-HG-in situ } \\
\text { DBDT-AFS }\end{array}$ & Rice & $\begin{array}{l}1 \% \quad(\mathrm{v} / \mathrm{v}) \quad \mathrm{HNO}_{3} \text { and } \\
1 \% \quad(\mathrm{v} / \mathrm{v}) \quad \mathrm{H}_{2} \mathrm{O}_{2} \\
\text { extraction }\end{array}$ & As & $0.05 \mu \mathrm{g} / \mathrm{L}$ & $\begin{array}{l}\text { External } \\
\text { standard } \\
\text { method, } \\
\text { range: } \quad 0.5-50 \\
\mu \mathrm{g} / \mathrm{L}, \mathrm{R}>0.997\end{array}$ & $\begin{array}{l}\text { Elemental speciation analysis, LC atomic } \\
\text { spectrometric instrumentation. } \\
\text { LC combined with DBDT for the gas phase } \\
\text { preconcentration of iAs species to enhance the } \\
\text { analytical sensitivity. }\end{array}$ & 122 \\
\hline 81 & $\begin{array}{l}\text { AEC-HPLC-I } \\
\text { CP-MS }\end{array}$ & $\begin{array}{l}\text { Edible } \\
\text { seaweed }\end{array}$ & $\begin{array}{lr}\text { In vitro digestion } \\
\text { procedure } r \text { and } \\
\text { Microwave assisted } \\
\text { alkaline digestion }\end{array}$ & $\begin{array}{l}\text { Iodine/bromine } \\
\text { species }\end{array}$ & $\begin{array}{lcr}\text { Iodine: } & 24.6 & \mathrm{ng} / \mathrm{g} ; \\
\text { bromine: } & 19.9 & \mathrm{ng} / \mathrm{g} ; \\
\text { Iodide: } & 26.9 & \mathrm{ng} / \mathrm{g} ; \\
\text { Iodade: } & 4.8 & \mathrm{ng} / \mathrm{g} ; \\
\text { MIT: } & 1.11 \mathrm{ng} / \mathrm{g} ; & \mathrm{DIT}: \\
1.35 & \mathrm{ng} / \mathrm{g} ; & \text { bromide: } \\
124 & \mathrm{ng} / \mathrm{g} ; & \text { bromate: } \\
174 \mathrm{ng} / \mathrm{g}\end{array}$ & $\begin{array}{l}\text { External } \\
\text { standard } \\
\text { method, }\end{array}$ & $\begin{array}{l}\text { Assess the bioavailable fractions, positive correlation } \\
\text { between } \\
\text { bioavailability and protein contents was found. } \\
\text { AEC hyphenated with ICP-MS. }\end{array}$ & 124 \\
\hline
\end{tabular}




\begin{tabular}{|c|c|c|c|c|c|c|c|c|}
\hline No. & Instrumental & Matrix & Sample preparation & Element or isotope & LOD or LOQ & Calibration & Application and Technical characteristics & Ref. \\
\hline 82 & $\begin{array}{l}\text { HPLC-ICP-M } \\
\text { S }\end{array}$ & Lotus seed & $\mathrm{HNO}_{3}$ extraction & $\begin{array}{l}\text { As-species; } \\
\text { Hg-species; } \\
\text { Pb-species }\end{array}$ & $\begin{array}{l}\text { As-species: } \\
0.036-0.20 \quad \mu \mathrm{g} / \mathrm{L} ; \\
\text { Hg-species: } \\
0.023-0.041 \quad \mu \mathrm{g} / \mathrm{L} ; \\
\text { Pb-species: } \\
0.0076-0.14 \mu \mathrm{g} / \mathrm{L}\end{array}$ & $\begin{array}{l}\text { External } \\
\text { standard } \\
\text { method, } \\
\text { linear range: As: } \\
1-500 \quad \mu \mathrm{g} / \mathrm{L} \text {, } \\
\mathrm{R}^{2}>0.9965 ; \\
\mathrm{Hg}: \\
0.2-100 \mu \mathrm{g} / \mathrm{L}, \\
\mathrm{R}^{2}>0.9929 ; \\
\mathrm{Pb} \quad 0.5-100 \\
\mu \mathrm{g} / \mathrm{L}, \mathrm{R}^{2}>0.9942\end{array}$ & $\begin{array}{l}\text { A promising tool for studying the toxic, metabolic } \\
\text { and bioavailable behaviors of arsenic, mercury and } \\
\text { lead. } \\
\text { Simultaneous speciation of arsenic, mercury and lead } \\
\text { was analyzed by HPLC-ICP-MS; four As- and Hg-, } \\
\text { and three } \mathrm{Pb} \text { species were simultaneously eluted } \\
\text { within } 8 \text { min. }\end{array}$ & 125 \\
\hline 83 & $\begin{array}{l}\text { SPME } \\
\text {-GC-ICP-MS }\end{array}$ & $\begin{array}{l}\text { Plants, } \\
\text { Brassica } \\
\text { juncea } \\
\text { seedlings }\end{array}$ & $\begin{array}{l}\text { SPME, thermally } \\
\text { desorb }\end{array}$ & $\begin{array}{l}\text { Volatile } \\
\text { alkyl-selenides and } \\
\text { their sulfur analogues }\end{array}$ & $\begin{array}{l}\text { Se-species: 1-10 ppt; } \\
\text { volatile S species: } \\
30-300 \mathrm{ppt}\end{array}$ & $\begin{array}{l}\text { External } \\
\text { standard } \\
\text { method, } \\
\text { linearity up to } \\
0.5 \text { ppm; }\end{array}$ & $\begin{array}{l}\text { Investigate Se metabolism in Brassica juncea } \\
\text { seedlings, identify unknown species in the standards. } \\
\text { coupled technique of } \mathrm{HS}-\mathrm{SPME} / \mathrm{GC} / \mathrm{ICP}-\mathrm{MS} \text { has } \\
\text { proven suitable for the speciation of volatile selenium } \\
\text { species in plants. }\end{array}$ & 128 \\
\hline 84 & $\begin{array}{l}\text { SPME-MC- } \\
\text { MIP-AES }\end{array}$ & $\begin{array}{l}\text { Lupine; } \\
\text { Yeast; Indian } \\
\text { mustard; } \\
\text { Garlic }\end{array}$ & SPME & $\begin{array}{l}\text { Organo-selenium } \\
\text { species }\end{array}$ & $\begin{array}{l}\text { DMSe: } 0.57 \mathrm{ng} / \mathrm{mL}, \\
\text { DEtSe: } 0.47 \mathrm{ng} / \mathrm{mL} \text {, } \\
\text { DMDSe: } 0.19 \mathrm{ng} / \mathrm{mL}\end{array}$ & $\begin{array}{l}\text { External } \\
\text { standard } \\
\text { method; } \\
\text { linearity up to } \\
100 \mathrm{ng} / \mathrm{mL} ; \\
\text { DMSe: } \\
\mathrm{R}^{2}>0.991, \\
\text { DEtSe: } \\
\mathrm{R}^{2}>0.975, \\
\text { DMDSe: } \\
\mathrm{R}^{2}>0.967\end{array}$ & $\begin{array}{l}\text { Element specific detection of volatile species; } \\
\text { inorganic selenium transformation research during } \\
\text { metabolism. } \\
\text { SPME-MC-MIP-AES for organo-selenium detection } \\
\text { in selenium accumulating biological matter. }\end{array}$ & 129 \\
\hline
\end{tabular}




\begin{tabular}{|c|c|c|c|c|c|c|c|c|}
\hline No. & Instrumental & Matrix & Sample preparation & Element or isotope & LOD or LOQ & Calibration & Application and Technical characteristics & Ref. \\
\hline 85 & $\begin{array}{l}\text { HS-SPME } \\
\text {-GC-MS /MS }\end{array}$ & $\begin{array}{l}\text { Surface } \\
\text { water; } \\
\text { wastewater }\end{array}$ & $\begin{array}{l}\text { HS-SPME, } \\
\text { home-made } \\
\text { polydimethylsiloxane } \\
\text { fiber }\end{array}$ & Mercury speciation & $\begin{array}{l}\text { Alkyl mercury: } 0.03 \\
\mathrm{ng} / \mathrm{L} ; \quad \text { inorganic } \\
\text { mercury: } 6 \mathrm{ng} / \mathrm{L}\end{array}$ & $\begin{array}{l}\text { External } \\
\text { standard } \\
\text { method; } \quad \text { Linear } \\
\text { range: } \\
\mathrm{Hg}^{2+}: 25.0-200 \\
\text { ng/L, } \quad \text { alkyl } \\
\text { mercury:0.12-80 } \\
\text { ng/L; } \\
\text { correlation } \\
\text { coefficients }(\mathrm{R})> \\
0.994\end{array}$ & $\begin{array}{l}\text { Speciation of trace and ultra-trace mercury in some } \\
\text { surface water and wastewater samples. } \\
\text { A home-made PDMS fiber was applied for the } \\
\text { extraction of mercury species coupled with } \\
\text { GC-MS/MS. }\end{array}$ & 131 \\
\hline 86 & GC-ICP-MS & Seafoods & $\begin{array}{l}\text { ExtrFaction( } \mathrm{KOH}, \mathrm{HCl} \\
\text {, } \mathrm{KBr} / \mathrm{CuSO} 4)\end{array}$ & Mercury species & $\begin{array}{l}\text { MeHg: } 0.5 \mathrm{pg} ; \text { EtHg: } \\
1.0 \mathrm{pg}\end{array}$ & $\begin{array}{l}\text { External } \\
\text { standard } \\
\text { method; Linear } \\
\text { range: } 1-1000 \mathrm{pg}\end{array}$ & $\begin{array}{l}\text { Mercury speciation in seafoods. } \\
\text { GC-ICP-MS. }\end{array}$ & 132 \\
\hline 87 & $\begin{array}{l}\text { CGC-pyro-AF } \\
\text { S }\end{array}$ & $\begin{array}{l}\text { Fish } \\
\text { reference } \\
\text { materials }\end{array}$ & $\begin{array}{l}\text { Closed-vessel } \\
\text { microwave-assisted } \\
\text { extraction (methanolic } \\
\text { tetramethylammonium } \\
\text { hydroxide) }\end{array}$ & Mercury species & $\begin{array}{l}\text { MMHg: } 2 \text { pg; } \\
\text { inorganic mercury: } \\
\text { lpg }\end{array}$ & $\begin{array}{l}\text { External } \\
\text { standard } \\
\text { method; } \quad \text { Linear } \\
\text { range: } \quad 5-200 \\
\mu \mathrm{g} / \mathrm{L} ; \\
\text { determination } \\
\text { coefficients }\left(\mathrm{R}^{2}\right): \\
\text { MeHgEt: }>0.995 \\
\text { inorganic } \\
\text { mercury: }{ }^{>} 0.996\end{array}$ & $\begin{array}{l}\text { Mercury speciation in fish materials, simultaneous } \\
\text { determination of methylmercury and inorganic } \\
\text { mercury. } \\
\text { Closed-vessel microwave-assisted extraction coupled } \\
\text { with ethylation and analysis by capillary GC with } \\
\text { AFS. }\end{array}$ & 133 \\
\hline
\end{tabular}




\begin{tabular}{|c|c|c|c|c|c|c|c|c|}
\hline No. & Instrumental & Matrix & Sample preparation & Element or isotope & LOD or LOQ & Calibration & Application and Technical characteristics & Ref. \\
\hline 88 & $\begin{array}{l}\text { P-CT-GC- } \\
\text { ICP-MS }\end{array}$ & $\begin{array}{l}\text { Natural } \\
\text { waters }\end{array}$ & $\begin{array}{l}\text { Cryogenic traps ash } \\
\text { desorption }\end{array}$ & $\begin{array}{lr}\mathrm{Me}_{2} \mathrm{Se}, & \mathrm{Me}_{2} \mathrm{Se}_{2}, \\
\mathrm{Me}_{2} \mathrm{Hg}, & \mathrm{Et}_{2} \mathrm{Hg} \\
\mathrm{Me}_{4} \mathrm{Sn}, \mathrm{Et}_{4} \mathrm{Sn}, \mathrm{Me}_{4} \mathrm{~Pb} & \\
\mathrm{Et}_{4} \mathrm{~Pb} & \end{array}$ & 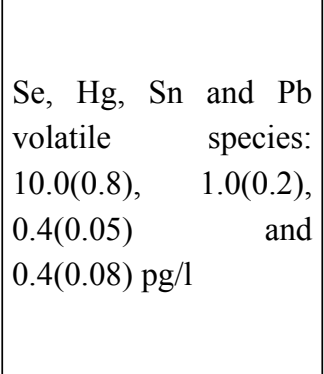 & $\begin{array}{l}\text { External } \\
\text { standard } \\
\text { method; relative } \\
\text { isotopic } \\
\text { abundance } \\
\text { measurement }\end{array}$ & $\begin{array}{l}\text { New assessment on the occurrence and speciation of } \\
\text { dissolved volatile compounds of trace metals and } \\
\text { metalloids in coastal envFements; Overall } \\
\text { distribution of volatile metal and metalloid species in } \\
\text { estuarine waters. } \\
\text { Purge and cryogenic trapping method for the } \\
\text { pre-concentration; - ash desorption, cryofocusing gas } \\
\text { chromatography system hyphenated to an ICP/MS. }\end{array}$ & 135 \\
\hline 89 & CE-VSG -AFS & $\begin{array}{l}\text { Certified } \\
\text { biological } \\
\text { reference } \\
\text { Material } \\
\text { (dogfish } \\
\text { muscle), lake } \\
\text { water and } \\
\text { river water }\end{array}$ & $\begin{array}{l}\text { CE } \quad \text { (capillary } \\
\text { electrophoresis) }\end{array}$ & Mercury species & $6.8-16.5 \mu \mathrm{g} / \mathrm{L}$ & $\begin{array}{l}\text { External } \\
\text { standard } \\
\text { method; } \\
\text { correlation } \\
\text { coefficients(R)> } \\
0.9918\end{array}$ & $\begin{array}{l}\text { Analysis of a certified biological reference material. } \\
\text { CE-VSG-AFS technique for mercury speciation in } \\
\text { biological materials. }\end{array}$ & 137 \\
\hline 90 & $\begin{array}{l}\text { CE-VSG-QIC } \\
\text { P-MS }\end{array}$ & $\begin{array}{l}\text { Certified } \\
\text { biological } \\
\text { reference } \\
\text { material } \\
\text { (ddogfish } \\
\text { Liver) }\end{array}$ & $\mathrm{CE}$ & Mercury species & $\begin{array}{l}\mathrm{Hg}_{2}^{+}: 0.2 \mathrm{pg} \\
\mathrm{CH}_{3} \mathrm{Hg}^{+}: 7 \mathrm{pg}\end{array}$ & $\begin{array}{l}\text { External } \\
\text { standard } \\
\text { method; } \\
\text { correlation } \\
\text { coefficients }(\mathrm{R})= \\
0.9949\end{array}$ & $\begin{array}{l}\text { Analysis of a certified biological reference material. } \\
\text { Capillary electrophoresis coupled to volatile species } \\
\text { generation-inductively coupled plasma mass } \\
\text { spectrometry. }\end{array}$ & 138 \\
\hline 91 & $\begin{array}{l}\text { CE-ICP-OES/ } \\
\text { MS }\end{array}$ & $\begin{array}{l}\text { Certified } \\
\text { biological } \\
\text { reference } \\
\text { material } \\
\text { (ddogfish } \\
\text { Liver) }\end{array}$ & $\mathrm{CE}$ & Elemental species & $\begin{array}{l}\text { ICP-OES }: 0.1-100 \\
\text { ppb } \\
\text { ICP-MS }: \\
\text { ppb }\end{array}$ & $\begin{array}{l}\text { External } \\
\text { standard } \\
\text { method; } \\
\text { linear over } \\
\text { orders } \\
\text { magnitude }\end{array}$ & $\begin{array}{l}\text { CE-ICP spectrometry for elemental speciation. } \\
\text { Combination of capillary electrophoresis and } \\
\text { inductively coupled plasma optical emission or mass } \\
\text { spectrometry holds great promise for rapid elemental } \\
\text { speciation at concentrations as low as part per million } \\
\text { to part per billion levels. }\end{array}$ & 140 \\
\hline
\end{tabular}




\begin{tabular}{|c|c|c|c|c|c|c|c|c|}
\hline No. & Instrumental & Matrix & Sample preparation & Element or isotope & LOD or LOQ & Calibration & Application and Technical characteristics & Ref. \\
\hline 92 & CE-ICP-MS & Rice & $\begin{array}{l}\text { Extraction (protease, } \\
\text { lipase, water); CE }\end{array}$ & Se species & $0.1-0.9 \mathrm{ng} / \mathrm{mL}$ & $\begin{array}{l}\text { External } \\
\text { standard } \\
\text { method; } \\
\text { linear range: } \\
10-400 \mathrm{ng} / \mathrm{mL} ; \\
\text { Correlation } \\
\text { coefficient: } \\
0.990-0.998\end{array}$ & $\begin{array}{l}\text { The nutritional and toxical evaluation of different } \\
\text { selenium compounds in nutritional supplements. } \\
\text { CE-ICP-MS and a enzyme-assisted extraction used } \\
\text { to extractall species of selenium in rice sample. }\end{array}$ & 141 \\
\hline 93 & CE-ICP-MS & $\begin{array}{l}\text { Human } \\
\text { Plasma }\end{array}$ & $\mathrm{CE}$ & $\begin{array}{l}\text { Free Calcium and } \\
\text { Calcium-Containing } \\
\text { Species }\end{array}$ & $\mathrm{Ca}^{2+}: 25 \mu \mathrm{g} / \mathrm{L}$ & $\begin{array}{l}\text { External } \\
\text { standard } \\
\text { method; }\end{array}$ & $\begin{array}{l}\text { A new method for the determination of free calcium } \\
\text { concentration in human plasma. } \\
\text { Determination of free calcium and concentration } \\
\text { estimation of calcium for other calcium-containing } \\
\text { species in human plasma have been developed using } \\
\text { CE-ICP-MS. }\end{array}$ & 142 \\
\hline 94 & CE-HG-AFS & I & $\mathrm{CE}$ & $\begin{array}{l}\text { Speciation } \\
\text { Organotin } \\
\text { Compounds }\end{array}$ & $1-10 \mu \mathrm{mol} / \mathrm{L}$ & $\begin{array}{l}\text { External } \\
\text { standard } \\
\text { method; }\end{array}$ & $\begin{array}{l}\text { Speciation analysis of organotin compounds. } \\
\text { Hydride-generation atomic fluorescence } \\
\text { spectrometric detector was employed to detect } \\
\text { organotin compounds after eluted from the outlet of } \\
\text { capillary. }\end{array}$ & 143 \\
\hline
\end{tabular}




\begin{tabular}{|c|c|c|c|c|c|c|c|c|}
\hline No. & Instrumental & Matrix & Sample preparation & Element or isotope & LOD or LOQ & Calibration & Application and Technical characteristics & Ref. \\
\hline 95 & $\begin{array}{l}\text { PT-LLLME } \\
\text {-LVSS-CE/UV }\end{array}$ & $\begin{array}{l}\text { Biological } \\
\text { and } \\
\text { envFemental } \\
\text { samples }\end{array}$ & $\begin{array}{l}\text { PT-LLLME (phase } \\
\text { transfer based liquid-- } \\
\text { liquid-liquid } \\
\text { microextraction) }\end{array}$ & Mercury species & $1.40-5.21 \mathrm{ng} / \mathrm{mL}$ & $\begin{array}{lr}\text { External } & \\
\text { standard } & \\
\text { method; } & \\
\text { linear } & \text { range: } \\
\mathrm{EtHg}^{+} & 0.5-50 \\
\mathrm{ng} / \mathrm{mL}, & \mathrm{R}^{2}= \\
0.9957 ; & \mathrm{MeHg} \\
0.5-50 & \mathrm{ng} / \mathrm{mL}, \\
\mathrm{R}^{2}= & 0.9976 ; \\
\mathrm{PhHg}^{+} 0.25-25 \\
\mathrm{ng} / \mathrm{Ml}, & \mathrm{R}^{2}= \\
0.9971 ; & \\
\mathrm{Hg} 2^{+} 2.5-100 \\
\mathrm{ng} / \mathrm{mL}, & \mathrm{R}^{2}= \\
0.9993 & \end{array}$ & $\begin{array}{l}\text { The CE-UV-based approach is applicable for } \mathrm{Hg} \\
\text { speciation in real sample analysis. } \\
\text { A phase transfer-based liquid-liquid-liquid } \\
\text { microextraction technique with high sensitivity and } \\
\text { selectivity and fast extraction kinetics; A new } \\
\text { approach for the simultaneous speciation of } \\
\text { inorganic/organic Hg. }\end{array}$ & 144 \\
\hline 96 & $\begin{array}{l}\text { CE-ICP-MS, } \\
\text { CE-ESI-MS/M } \\
\text { S }\end{array}$ & Goji berries & $\begin{array}{l}\text { Grounded, } \\
\text { homogenizated; } \\
\text { Tris-HCl }\end{array}$ & Zinc speciation & 1 & / & $\begin{array}{l}\text { Zinc binding ligands identification using CE-ICP-MS } \\
\text { and CE-ESI-MS/MS; identification of those } \\
\text { compounds in fruits extracts. } \\
\text { Detection and identification of Zn-binding ligands } \\
\text { based on using CE-ICP-MS and CE-ESI-MS/MS. }\end{array}$ & 146 \\
\hline 97 & CE-ICP-MS, & Liver & $\mathrm{CE}$ & $\begin{array}{l}\text { Speciate } \mathrm{Ag}^{+}, \mathrm{AgNPs} \text {, } \\
\text { Ag-metallothionein } \\
\text { species }\end{array}$ & 1 & / & $\begin{array}{l}\text { Investigated applicability of different CE methods } \\
\text { hyphenated to ICP-MS for speciation of AgNPs in } \\
\text { biological systems. } \\
\text { CE hyphenated to the ICP-MS as promising and } \\
\text { elegant technique to study AgNPs in biological } \\
\text { systems. }\end{array}$ & 147 \\
\hline
\end{tabular}




\begin{tabular}{|c|c|c|c|c|c|c|c|c|}
\hline No. & Instrumental & Matrix & Sample preparation & Element or isotope & LOD or LOQ & Calibration & Application and Technical characteristics & Ref. \\
\hline 98 & CE-ICP-MS & Liver & $\mathrm{CE}$ & Mn speciation & $1.1 \mu \mathrm{g} / \mathrm{L}$ & $\begin{array}{l}\text { Standard } \\
\text { addition; } \\
\text { linear range: } \\
10-500 \mu \mathrm{g} / \mathrm{L} ; \\
\text { coefficients } \\
\left(\mathrm{R}^{2}\right)=0.9998\end{array}$ & $\begin{array}{l}\text { Speciate the compounds quickly and with minimal } \\
\text { risk of species alteration. } \\
\text { Develop a speciation method for manganese species } \\
\text { in liver extracts. }\end{array}$ & 148 \\
\hline 99 & CE-ESI-MS & $\begin{array}{l}\text { Bottled, tap, } \\
\text { spring and } \\
\text { well water } \\
\text { samples }\end{array}$ & CE & $\begin{array}{l}\text { Organic and inorganic } \\
\text { arsenic }\end{array}$ & $0.02-0.04 \mu \mathrm{g} / \mathrm{L}$ & $\begin{array}{l}\text { External } \\
\text { standard } \\
\text { method; }\end{array}$ & $\begin{array}{l}\text { The validated method CE-ESI(-)-MS for arsenic } \\
\text { speciation was applied to the analysis of the weakly } \\
\text { mineralized water sample (dry residue }<50 \mathrm{mg} \mathrm{L}-1 \text { ) } \\
\text { of both groundwater and bottled water. } \\
\text { Ammonia and hexafluoro-2-propanol mixtures as } \\
\text { efficient media for CE-ESI(-)-MS; } \\
\text { CE-ESI(-)-MS as a sensitive and suitable alternative } \\
\text { to speciation of inorganic and organic As species; } \\
\text { Coupling of DLLME to CE-ESI(-)-MS for } \\
\text { determination of total inorganic As.. }\end{array}$ & 149 \\
\hline 100 & SR-m-XRF & Rat brain & $\begin{array}{l}\text { Brain specimens were } \\
\text { cut into } 80 \mathrm{~mm}\end{array}$ & $\mathrm{Ca}, \mathrm{Fe}, \mathrm{Cu}, \mathrm{Zn}$ & $\begin{array}{l}\mathrm{Ca}: 1.15 \mu \mathrm{g} / \mathrm{g} \\
\mathrm{Fe}: 0.53 \mu \mathrm{g} / \mathrm{g} \\
\mathrm{Cu}: 0.21 \mu \mathrm{g} / \mathrm{g} \\
\mathrm{Zn}: 0.20 \mu \mathrm{g} / \mathrm{g}\end{array}$ & $\begin{array}{l}\text { The Compton } \\
\text { scattering is } \\
\text { used as an } \\
\text { internal standard }\end{array}$ & $\begin{array}{l}\text { Accurate and precise imaging of the element } \\
\text { variations in the brain section of a transgenic mouse } \\
\text { model of Alzheimer's disease; quantitative imaging } \\
\text { of trace elements in sections of bio-tissues. } \\
\text { Quantitative imaging of element spatial distribution } \\
\text { in the brain section of a mouse model of Alzheimer's } \\
\text { disease using synchrotron radiation X-ray } \\
\text { fluorescence analysis. }\end{array}$ & 150 \\
\hline
\end{tabular}




\begin{tabular}{|c|c|c|c|c|c|c|c|c|}
\hline No. & Instrumental & Matrix & Sample preparation & Element or isotope & LOD or LOQ & Calibration & Application and Technical characteristics & Ref. \\
\hline 101 & FPXRF & Soil & Dry & 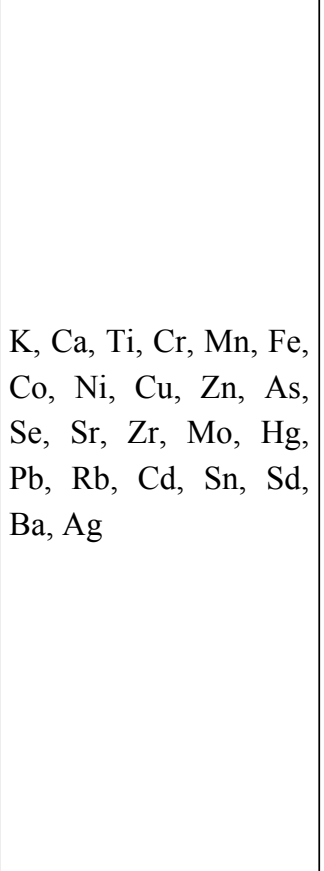 & $\begin{array}{l}\text { Cr: } 295 \mathrm{mg} / \mathrm{kg} \\
\text { Mn: } 1010 \mathrm{mg} / \mathrm{kg} \\
\mathrm{Co}: 1160 \mathrm{mg} / \mathrm{kg} \\
\mathrm{Ni}: 350 \mathrm{mg} / \mathrm{kg} \\
\mathrm{Cu}: 137 \mathrm{mg} / \mathrm{kg} \\
\mathrm{Zn}: 204 \mathrm{mg} / \mathrm{kg} \\
\text { As: } 134 \mathrm{mg} / \mathrm{kg} \\
\mathrm{Se}: 59 \mathrm{mg} / \mathrm{kg} \\
\mathrm{Sr}: 72 \mathrm{mg} / \mathrm{kg} \\
\mathrm{Zr}: 44 \mathrm{mg} / \mathrm{kg} \\
\mathrm{Mo}: 13 \mathrm{mg} / \mathrm{kg} \\
\mathrm{Hg}: 150 \mathrm{mg} / \mathrm{kg} \\
\mathrm{Pb}: 66 \mathrm{mg} / \mathrm{kg} \\
\mathrm{Rb}: 79 \mathrm{mg} / \mathrm{kg} \\
\mathrm{Cd}: 110 \mathrm{mg} / \mathrm{kg} \\
\mathrm{Sn}: 67 \mathrm{mg} / \mathrm{kg} \\
\mathrm{Sd}: 52 \mathrm{mg} / \mathrm{kg} \\
\mathrm{Ba}: 58 \mathrm{mg} / \mathrm{kg} \\
\mathrm{Ag}: 85 \mathrm{mg} / \mathrm{kg} .\end{array}$ & NIST SRM 2709 & $\begin{array}{l}\text { In situ analysis of metals in soils and sediments, thin } \\
\text { films/particulates, and lead in paint. } \\
\text { FPXRF spectrometry has become a common } \\
\text { analytical technique for on-site screening and fast } \\
\text { turnaround analysis of contaminant elements in } \\
\text { environmental samples. }\end{array}$ & 154 \\
\hline 102 & SXRF & Target cells & $\begin{array}{l}\text { Homogenizing } \\
\text { medium }\end{array}$ & $\begin{array}{l}\mathrm{Si}, \mathrm{Mn}, \mathrm{Fe}, \\
\mathrm{Ni}, \mathrm{Zn}\end{array}$ & $\begin{array}{l}\mathrm{Si}: 7.0 \times 10^{-16} \mathrm{~mol} / \mu \mathrm{m}^{2} \\
\mathrm{Mn}, \quad \mathrm{Fe}, \quad \mathrm{Ni}, \quad \mathrm{Zn}: \\
5.0 \times 10^{-20}-3.9 \times 10^{-19} \\
\mathrm{~mol} / \mu \mathrm{m}^{2}\end{array}$ & $\begin{array}{l}\text { NIST thin-film } \\
\text { standards (SRM } \\
1832 \text { and } 1833 \text { ), } \\
\text { Si: } \quad \mathrm{R}^{2}=0.993, \\
\text { Fe: } \mathrm{R}^{2}=0.9998\end{array}$ & $\begin{array}{l}\text { Identify and quantify the elemental composition of a } \\
\text { wide variety of geological, biological, and } \\
\text { manufactured targets; synoptic quantitative analyses } \\
\text { of cellular element contents. } \\
\text { Enables the accurate and precise measurement of } \\
\text { trace metals in individual aquatic protists collected } \\
\text { from natural environments; This technique } \\
\text { distinguishes between different types of cells in an } \\
\text { assemblage and between cells and other particulate } \\
\text { matter. }\end{array}$ & 155 \\
\hline
\end{tabular}




\begin{tabular}{|c|c|c|c|c|c|c|c|c|}
\hline No. & Instrumental & Matrix & Sample preparation & Element or isotope & LOD or LOQ & Calibration & Application and Technical characteristics & Ref. \\
\hline 103 & SRXRF & $\begin{array}{l}\text { Fresh green } \\
\text { leaves }\end{array}$ & Cut into sections & $\begin{array}{l}\mathrm{Pb}, \mathrm{As}, \mathrm{Cd}, \mathrm{K}, \mathrm{Ca}, \\
\mathrm{Mn}, \mathrm{Ni}, \mathrm{Cu}, \mathrm{Zn}\end{array}$ & $\begin{array}{l}\mathrm{Pb}: 1215 \mu \mathrm{g} / \mathrm{g}, \\
\text { As: } 708.9 \mu \mathrm{g} / \mathrm{g}, \\
\mathrm{Cd}: 255.6 \mu \mathrm{g} / \mathrm{g}, \\
\mathrm{K}: 2046 \mu \mathrm{g} / \mathrm{g}, \\
\mathrm{Ca}: 2977 \mu \mathrm{g} / \mathrm{g}, \\
\mathrm{Mn}: 212.9 \mu \mathrm{g} / \mathrm{g}, \\
\mathrm{Ni}: 105.1 \mu \mathrm{g} / \mathrm{g}, \\
\mathrm{Cu}: 34.61 \mu \mathrm{g} / \mathrm{g}, \\
\mathrm{Zn}: 389.5 \mu \mathrm{g} / \mathrm{g} .\end{array}$ & / & $\begin{array}{l}\text { The cellular distributions of } \mathrm{Pb} \text { and } \mathrm{As} \text { in the leaves } \\
\text { of co-hyperaccumulator Viola principis } \mathrm{H} \text {. de Boiss. } \\
\text { In vivo cellular localization of } \mathrm{Pb} \text { and } \mathrm{As} \text { in the } \\
\text { leaves provides insight into the physiological } \\
\text { mechanisms of metal tolerance and } \\
\text { hyperaccumulation in the hyperaccumulators. }\end{array}$ & 157 \\
\hline 104 & m-SRXRF & $\begin{array}{l}\text { Caenorhabdi } \\
\text { tis elegans } \\
\text { (C. elegans) }\end{array}$ & $\begin{array}{l}\text { Homogenizing } \\
\text { medium }\end{array}$ & $\mathrm{La}, \mathrm{Cu}, \mathrm{Cd}, \mathrm{Pb}$ & $\begin{array}{l}\mathrm{Cd}: 14.4-19.4 \mathrm{mg} / \mathrm{L}, \\
\mathrm{Cu}: 2.84-4.07 \mathrm{mg} / \mathrm{L} \\
\mathrm{Pb}: 7.54-9.76 \mathrm{mg} / \mathrm{L}\end{array}$ & / & $\begin{array}{l}\text { Developed as a sensitive technique to illustrate the } \\
\text { response of C. elegans to toxicant. } \\
\text { Life-cycle endpoints were chosen along with } \\
\text { elemental assay to evaluate the aquatic toxicity of } \\
\text { lanthanum (La), a representative of REEs. }\end{array}$ & 158 \\
\hline 105 & SRXRF & seeds & $\begin{array}{l}\text { Elements } \quad \text { excess } \\
\text { treatments }\end{array}$ & $\mathrm{Cu}, \mathrm{Fe}, \mathrm{Zn}, \mathrm{Mn}$ & / & / & $\begin{array}{l}\text { Distribution characters of } \mathrm{Cu} \text { and other metals in root } \\
\text { growth zones were investigated by SRXRF. } \\
\text { SRXRF. }\end{array}$ & 159 \\
\hline 106 & SRXRF & $\begin{array}{l}\text { seeds; Roots } \\
\text { and shoots }\end{array}$ & $\begin{array}{l}\text { Elements } \\
\text { treatments }\end{array}$ & $\begin{array}{l}\mathrm{Cr}, \mathrm{Ca}, \mathrm{Mn}, \mathrm{Fe}, \mathrm{Cu}, \\
\mathrm{Zn}, \mathrm{Pb}\end{array}$ & $\begin{array}{l}\mathrm{Pb}: 200 \mathrm{mg} / \mathrm{L} \\
\mathrm{Cr}: 5 \mathrm{mg} / \mathrm{L}\end{array}$ & / & $\begin{array}{l}\text { Determination of the distribution of elements in } \\
\text { heavy metal stressed plants by SRXRF. } \\
\text { Differential centrifugation and SRXRF microprobe } \\
\text { were used to study the distribution of the elements in } \\
\text { tissue cross sections of pakchoi (Brassica chinensis } \\
\text { L.) under stress of elevated } \mathrm{Pb} \text { and } \mathrm{Cr} \text {. }\end{array}$ & 161 \\
\hline
\end{tabular}




\begin{tabular}{|c|c|c|c|c|c|c|c|c|}
\hline No. & Instrumental & Matrix & Sample preparation & Element or isotope & LOD or LOQ & Calibration & Application and Technical characteristics & Ref. \\
\hline 107 & SRXRF & $\begin{array}{l}\text { Ricer seeds } \\
\text { (Oryza sativa } \\
\text { L.) }\end{array}$ & Elements treatments & $\mathrm{Hg}, \mathrm{Se}$ & $2.5 \mu \mathrm{mol} / \mathrm{L}$ & $\begin{array}{l}\text { Peak areas of } \mathrm{Hg} \\
\text { and Se were } \\
\text { normalized by } \\
\text { the Compton } \\
\text { scattering's peak } \\
\text { count. }\end{array}$ & $\begin{array}{l}\text { Better understand the molecular mechanism of } \mathrm{Hg} \\
\text { tolerance as well as the molecular antagonism } \\
\text { between Hg and Se in rice plants. } \\
\text { We investigated the effect of Se on Hg containing } \\
\text { and Hg-responsive proteins in rice using 1, } \\
\text { 2-dimensional electrophoresis combined with } \\
\text { SR-XRF techniques. }\end{array}$ & 162 \\
\hline 108 & m-SRXRF & $\begin{array}{l}180 \quad \text { leaves } \\
\text { from } \quad 60 \\
\text { Citrus } \\
\text { sinensis (L.) } \\
\text { Osbeck, } \\
\text { variety } \\
\text { Valencia/Sw } \\
\text { ingle }\end{array}$ & PCR amplifification & $\mathrm{K}, \mathrm{Ca}, \mathrm{Fe}, \mathrm{Cu}, \mathrm{Zn}$ & 1 & $\begin{array}{l}\text { A calibration } \\
\text { model was } \\
\text { constructed } \\
\text { using soft } \\
\text { independent } \\
\text { modelling of } \\
\text { class analogy } \\
\text { (SIMCA)21 with } \\
\text { the whole } \\
\text { spectral region } \\
\text { and the matrix } \\
\text { with the mean } \\
\left.\text { data } \mathrm{R}^{2}=0.995\right) \text {. }\end{array}$ & $\begin{array}{l}\text { Investigated the mineral constituents of healthy } \\
\text { leaves and leaves infected with citrus greening (or } \\
\text { Huanglongbing). } \\
\text { Investigate the mineral composition of citrus leaves } \\
\text { infected by citrus greening using spectra obtained by } \\
\text { m-SR-XRF. }\end{array}$ & 163 \\
\hline
\end{tabular}




\begin{tabular}{|c|c|c|c|c|c|c|c|c|}
\hline No. & Instrumental & Matrix & Sample preparation & Element or isotope & LOD or LOQ & Calibration & Application and Technical characteristics & Ref. \\
\hline 109 & SRXRF & $\begin{array}{l}\text { Elsholtzia } \\
\text { splendens }\end{array}$ & 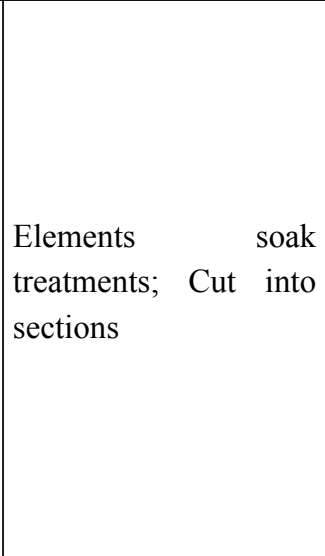 & $\begin{array}{l}\mathrm{P}, \mathrm{S}, \mathrm{Cl}, \mathrm{K}, \mathrm{Ca}, \mathrm{Mn} \\
\mathrm{Fe}, \mathrm{Cu}, \mathrm{Zn}\end{array}$ & $<0.01 \mathrm{pg}$ & I & $\begin{array}{l}\text { Synchrotron radiation X-ray fluorescence } \\
\text { spectroscopy (SRXRF) microprobe was used to study } \\
\text { the } \mathrm{Cu} \text { and other elements distribution in } \mathrm{E} \text {. } \\
\text { splendens. } \\
\text { There was a significant correlation between } \mathrm{Cu} \text { and } \mathrm{P} \text {, } \\
\mathrm{S}, \mathrm{Ca} \text { in distribution, which suggested } \mathrm{P}, \mathrm{S} \text {, and } \mathrm{Ca} \\
\text { played an important role in } \mathrm{Cu} \text { accumulation of } \mathrm{E} \text {. } \\
\text { splendens. Based on the significant correlation } \\
\text { between } \mathrm{Cu} \text { and elements } \mathrm{Mn}, \mathrm{Fe} \text {, and } \mathrm{Zn} \text { in } \\
\text { distribution, it seemed that } \mathrm{Cu}, \mathrm{Mn}, \mathrm{Fe} \text {, and } \mathrm{Zn} \text { could } \\
\text { be transported by the same transporters with a broad } \\
\text { substrate range. }\end{array}$ & 164 \\
\hline 110 & $\begin{array}{l}\text { SRXRF and } \\
\text { LA-ICP-MS }\end{array}$ & C. chinensis & $\begin{array}{l}\text { Elements } \quad \text { expose } \\
\text { treatments }\end{array}$ & $\mathrm{Cr}$ & $\begin{array}{l}\text { LA-ICP-MS: } 0.01 \\
\mu \mathrm{g} / \mathrm{g}, \\
\text { XRF: 0.1-1 } \mu \mathrm{g} / \mathrm{g}\end{array}$ & $\begin{array}{l}\text { SRM NIST } 1547 \\
\text { Peach Leaves } \\
\text { was used for } \\
\text { calibration and } \\
\text { used SRM NIST } \\
1570 \text { to validate } \\
\text { the } \\
\text { quantification } \\
\text { procedure. } \\
\mathrm{R}^{2}=0.9961(\mathrm{Mn}) \\
\text { and } \mathrm{R}^{2}=0.9991 \\
\text { (Ca) }\end{array}$ & $\begin{array}{l}\text { Spatially locate Cr, analyze Cr speciation, detect } \mathrm{Cr} \\
\text { subcellular concentration. } \\
\text { We utilized synchrotron radiation microscopic } \\
\text { SRXRF and LA-ICP-MS to spatially locate } \mathrm{Cr} \text {, } \\
\text { XANES to analyze Cr speciation, and } \\
\text { ICP-MS to detect Cr subcellular concentration. }\end{array}$ & 169 \\
\hline
\end{tabular}




\begin{tabular}{|c|c|c|c|c|c|c|c|c|}
\hline No. & Instrumental & Matrix & Sample preparation & Element or isotope & LOD or LOQ & Calibration & Application and Technical characteristics & Ref. \\
\hline 111 & $\begin{array}{l}\text { SEM-EDS, } \\
\text { XRD, FT-IR }\end{array}$ & $\begin{array}{l}\text { The } \\
\text { magnetic } \\
\text { biochar }\end{array}$ & Pyrolyze & $\mathrm{Cd}$, As & 1 & 1 & $\begin{array}{l}\text { Elucidate the relevant processes and mechanisms of } \\
\text { As (III) and Cd (II) co-adsorption on the magnetic } \\
\text { biochar. } \\
\text { Elucidates mutual effects of Cd (II) and As (III) on } \\
\text { their adsorption. } \\
\text { Both competition and synergistic effects exist } \\
\text { between Cd (II) and As (III). } \\
\text { The synergistic effect is controlled by formation of } \\
\text { type B ternary complex. }\end{array}$ & 170 \\
\hline 112 & $\begin{array}{l}\text { XANES, } \\
\mu \text {-XRF }\end{array}$ & Soils & / & $\mathrm{Cd}$, As & 1 & $\begin{array}{l}\text { Arsenic was } \\
\text { detected over the } \\
\text { whole area with } \\
\text { hotspots highly } \\
\text { correlated to the } \\
\text { Fe hotspots }\left(\mathrm{R}^{2}\right. \\
=0.789) \text {; The } \\
\text { distribution } \\
\text { pattern of Cd } \\
\text { was more } \\
\text { similar to that of } \\
\text { Ca with a } \\
\text { relatively higher } \\
\text { correlation } \\
\left(\mathrm{R}^{2}=0.498\right)\end{array}$ & \begin{tabular}{|l} 
Evaluate the effect of Ca-MBC on speciation, spatial \\
distribution and stabilization mechanisms of As and \\
Cd using synchrotron-based techniques. \\
The stabilization mechanisms were explored through \\
synchrotron-based micro-XRF and XANE.
\end{tabular} & 171 \\
\hline
\end{tabular}




\begin{tabular}{|c|c|c|c|c|c|c|c|c|}
\hline No. & Instrumental & Matrix & Sample preparation & Element or isotope & LOD or LOQ & Calibration & Application and Technical characteristics & Ref. \\
\hline 113 & XPS & Ssoil & 1 & $\mathrm{Cr}$ & I & 1 & $\begin{array}{l}\text { XPS for qualitative analysis of elemental speciation } \\
\text { in the soils before and after the GATP amendment. } \\
\text { Prepared green-tea impregnated attapulgite promoted } \\
\text { the conversion of weak acid extractable } \mathrm{Cr} \text { to the } \\
\text { residual state such as stable } \mathrm{Cr} \text { (III) and } \mathrm{Cr} \text {-Si oxide } \\
\text { in soil. }\end{array}$ & 172 \\
\hline 114 & XPS & Tailing soil & 1 & $\mathrm{C}, \mathrm{O}, \mathrm{S}$ & / & / & $\begin{array}{l}\text { XPS testified the thiol group that was easily oxidized. } \\
/ /\end{array}$ & 173 \\
\hline 115 & XPS & Fertilizer & I & $\mathrm{P}, \mathrm{F}$ and heavy metals & / & I & $\begin{array}{l}\text { Verify the mechanism underlying } \mathrm{P}, \mathrm{F} \text { and heavy } \\
\text { metals in phosphogypsum (PG) leachates adsorbed } \\
\text { onto biochar. } \\
\text { Showing that heavy metal precipitation and } \\
\text { complexation was caused by surface ions and } \\
\text { different functional groups and application of the } \\
\text { combination to loam or sand soil significantly } \\
\text { increased crop yield. }\end{array}$ & 174 \\
\hline 116 & XPS & $\begin{array}{l}\text { Aromatic } \\
\text { Compounds } \\
\text { Polymerizati } \\
\text { on }\end{array}$ & 1 & $\begin{array}{l}\text { Aromatic Compounds } \\
\text { Polymerization; } \\
\text { C1s, O1s }\end{array}$ & 1 & 1 & $\begin{array}{l}\text { XPS spectra indicate the presence of oxygen } \\
\text { containing groups in the chemical composition of } \\
\text { plasma-polymerized films and pointethe oxidation } \\
\text { reactions are pointed. } \\
\text { Identify the potential intermediary reactions during } \\
\text { plasma polymerization process. }\end{array}$ & 175 \\
\hline 117 & XPS & $\begin{array}{l}\text { Polythiophen } \\
\text { e }\end{array}$ & 1 & $\mathrm{O}, \mathrm{C}, \mathrm{S}$ & / & 1 & $\begin{array}{l}\text { Adsorption of ozone was examined on PTh surfaces } \\
\text { by angle resolved XPS. } \\
\text { /Chemical shift or peaks could suggest the structure } \\
\text { changes of samples. }\end{array}$ & 176 \\
\hline
\end{tabular}




\begin{tabular}{|c|c|c|c|c|c|c|c|c|}
\hline No. & Instrumental & Matrix & Sample preparation & Element or isotope & LOD or LOQ & Calibration & Application and Technical characteristics & Ref. \\
\hline 118 & XPS & $\begin{array}{l}\mathrm{PANI} @ \mathrm{TiO}_{2} \\
\text { composites. }\end{array}$ & 1 & $\mathrm{C}$ & 1 & 1 & $\begin{array}{l}\text { XPS was employed to analyze the chemical } \\
\text { components of PANI@ } \mathrm{TiO}_{2} \text { composites. } \\
\text { XPS peaks originate from aromatic compounds. The } \\
\text { XPS results further confirm that PANI was } \\
\text { successfully coated onto the surface of } \mathrm{TiO}_{2} \mathrm{NPs} \text {. }\end{array}$ & 177 \\
\hline 119 & XPS & $\begin{array}{l}\text { CDs (carbon } \\
\text { dot) }\end{array}$ & I & $\mathrm{C}, \mathrm{O}$ & I & 1 & $\begin{array}{l}\text { The elemental compositions of CDs were researched } \\
\text { by XPS. } \\
\text { / }\end{array}$ & 178 \\
\hline 120 & XPS & A-CDs & I & $\mathrm{Cu}$ & I & 1 & $\begin{array}{l}\text { Fluorescence quenching mechanism. } \\
\text { The fluorescence quenching mechanism of the } \\
\mathrm{A}-\mathrm{CDs} \text { by } \mathrm{Cu}^{2+} \text { is investigated; } \\
\text { XPS and XAES are further used to probe the valence } \\
\text { state of } \mathrm{Cu} \text { element. }\end{array}$ & 179 \\
\hline 121 & XPS & $\begin{array}{l}\text { Biological } \\
\text { samples }\end{array}$ & I & $\mathrm{C} 1 \mathrm{~s}$ & I & I & $\begin{array}{l}\text { Imaging XPS, surface chemical mapping and blood } \\
\text { cell visualization. } \\
\text { XPS combined with photoemission electron } \\
\text { microscopy (PEEM) to fulfil the surface chemical } \\
\text { mapping and blood cell visualization. }\end{array}$ & 180 \\
\hline 122 & XRD & $\begin{array}{l}\text { Adsorption } \\
\text { of toxic } \mathrm{Pb} \\
\text { (II) on } \\
\text { agriculture } \\
\text { waste } \\
\text { (Mahogany } \\
\text { fruit shell) }\end{array}$ & / & $\mathrm{Pb}(\mathrm{II})$ & I & / & $\begin{array}{l}\text { Derived adsorbent material properties and plausible } \\
\text { adsorption mechanism. } \\
\text { XRD pattern confirm the amorphous and graphitic } \\
\text { nature of MFSAC adsorbent. }\end{array}$ & 181 \\
\hline
\end{tabular}




\begin{tabular}{|c|c|c|c|c|c|c|c|c|}
\hline No. & Instrumental & Matrix & Sample preparation & Element or isotope & LOD or LOQ & Calibration & Application and Technical characteristics & Ref. \\
\hline 123 & XRD & $\begin{array}{l}\text { Phosphate } \\
\text { Fertilizer }\end{array}$ & / & $\begin{array}{l}\text { Magnesium Silicate } \\
\text { Nanocomposites } \\
\text { Coating }\end{array}$ & 1 & 1 & $\begin{array}{l}\text { The formation of struvite in a calcareous soil was } \\
\text { evaluated in three incubation periods by XRD. } \\
\text { The XRD patterns showed the transformation of } \\
\text { sepiolite to amorphous fibrous silica. }\end{array}$ & 182 \\
\hline 124 & XRD & $\begin{array}{l}\text { Agriculture } \\
\text { waste }\end{array}$ & / & Au-Pt nanoparticles & / & 1 & $\begin{array}{l}\text { XRD analyze synthesized Au-Pt NPs structurally } \\
\text { characterized. } \\
\text { The crystalline nature of the bimetallic nano fluidwas } \\
\text { determined by XRD; XRD data confirmed the } \\
\text { polycrystalline nature of the Au-Pt, NPs. }\end{array}$ & 183 \\
\hline 125 & XRD & Rapeseed & / & Nano zinc & / & / & $\begin{array}{l}\text { Characterization of } \mathrm{Zn} \text { nanoparticles. } \\
\text { XRD authenticates the crystalline nature of } \\
\text { nanoparticles and provides the average size of the } \\
\text { particle. }\end{array}$ & 184 \\
\hline 126 & XRD & $\begin{array}{l}\text { Cotton } \\
\text { fabrics }\end{array}$ & / & $\begin{array}{l}\mathrm{CS} / \mathrm{ZnO} \\
\text { nanocomposite }\end{array}$ & / & / & $\begin{array}{l}\text { Reveal wurtzite crystalline structure of } \mathrm{CS} / \mathrm{ZnO} \\
\text { nanocomposite for cotton fabrics. } \\
\text { The XRD analysis revealed wurtzite crystalline } \\
\text { structure of CS/ZnO nanocomposite. }\end{array}$ & 185 \\
\hline 127 & XRD & $\begin{array}{l}\text { Agricultural } \\
\text { by-products( } \\
\text { hydroxyl-eg } \\
\text { gshell), } \\
\text { aqueous } \\
\text { solutions }\end{array}$ & / & $P$ recovered & 1 & 1 & $\begin{array}{l}\text { On-firm the primary process of } \mathrm{P} \text { recovered by } \\
\text { agricultural by-products named hydroxyl-eggshell } \\
\text { was via precipitation as hydroxyapatite to highly } \\
\text { recover phosphorus from aqueous solutions. } \\
\text { Fourier transform infrared spectroscopy (FTIR), } \\
\text { scanning electron microscopy with energy dispersive } \\
\text { X-ray spectrometry (SEM-EDS), and XRD were used } \\
\text { to characterize the material before and after P } \\
\text { reaction. }\end{array}$ & 186 \\
\hline
\end{tabular}




\begin{tabular}{|c|c|c|c|c|c|c|c|c|}
\hline No. & Instrumental & Matrix & Sample preparation & Element or isotope & LOD or LOQ & Calibration & Application and Technical characteristics & Ref. \\
\hline 128 & XRD & $\begin{array}{l}\text { Starch gel } \\
\text { samples }\end{array}$ & I & Corn starch gels & I & I & $\begin{array}{l}\text { A novel method of preparing starch gels by alcohol } \\
\text { soaking was developed; showed that the crystallinity } \\
\text { of starch gel increased from } 3.8 \% \text { to } 8.9 \% \text { after } \\
\text { alcohol soaking for rapid production of corn starch } \\
\text { gels. } \\
\text { The mechanical properties, crystallization } \\
\text { behaviors, and structural characteristics of starch gels } \\
\text { were investigated by XRD; gels and improves the } \\
\text { starch concentration in the gels, thus promoting the } \\
\text { retrogradation of side chains of the amylopectins and } \\
\text { forming more crystals. }\end{array}$ & 187 \\
\hline 129 & LA-ICP-MS & $\begin{array}{l}\text { Brain, Gels, } \\
\text { plants }\end{array}$ & Cut into sections & $\mathrm{Fe}, \mathrm{Zn}, \mathrm{Cu}, \mathrm{C}, \mathrm{P}, \mathrm{Mg}$ & $\begin{array}{l}\mathrm{Cu}: 0.34 \mathrm{mg} / \mathrm{g} \\
\mathrm{Zn}: 0.14 \mathrm{mg} / \mathrm{g} \\
\mathrm{Pb}: 12.5 \mathrm{ng} / \mathrm{g} \mathrm{g} \\
\mathrm{U}: 6.9 \mathrm{ng} / \mathrm{g}\end{array}$ & $\begin{array}{l}\text { standard } \\
\text { reference } \\
\text { material (NIST } \\
\text { SRM 1515 apple } \\
\text { leaves }\end{array}$ & $\begin{array}{l}\text { Apply as a powerful imaging (mapping) technique to } \\
\text { produce quantitative images of detailed regionally } \\
\text { specific element distributions in thin tissue sections } \\
\text { of human or rodent brain , investigate metal } \\
\text { distributions in plant and animal sections to study. } \\
\text { Using quadrupole-based LA-ICP-MS in comparison } \\
\text { to the more sensitive double-focusing sector field } \\
\text { LA-ICP-MS to perform imaging analysis of metals } \\
\text { and non-metals on soft biological tissues for selected } \\
\text { life science studies. }\end{array}$ & 192 \\
\hline 130 & ICP-MS & $\begin{array}{l}\text { Concentratio } \\
\mathrm{ns}\end{array}$ & Coprecipitation & $\begin{array}{l}\text { Rare earth and other } \\
\text { trace elements }(\mathrm{Y}, \mathrm{Sc} \text {, } \\
\mathrm{Zr}, \mathrm{Ba}, \mathrm{Hf}, \mathrm{Th})\end{array}$ & I & $\begin{array}{lr}\text { Nine } \quad \text { certified } \\
\text { reference } \\
\text { materials } \\
\text { analyzed } \\
\text { validate: }\end{array}$ & $\begin{array}{l}\text { The } \mathrm{Na}_{2} \mathrm{O}_{2}-\mathrm{NaOH} \text { fusion is suitable for the } \\
\text { determination of several trace elements. } \\
\text { The determination of concentrations of rare earth } \\
\text { (REE) and other trace elements ( } \mathrm{Y}, \mathrm{Sc}, \mathrm{Zr}, \mathrm{Ba}, \mathrm{Hf} \text {, } \\
\text { Th) in geological samples. }\end{array}$ & 194 \\
\hline
\end{tabular}




\begin{tabular}{|c|c|c|c|c|c|c|c|c|}
\hline No. & Instrumental & Matrix & Sample preparation & Element or isotope & LOD or LOQ & Calibration & Application and Technical characteristics & Ref. \\
\hline 131 & GC/QqQ-MS & $\begin{array}{l}\text { Anabolic } \\
\text { agents in } \\
\text { human urine }\end{array}$ & Solvent extraction & $\begin{array}{l}\text { Clenbuterol, } \\
\text { 19-norandrosterone, } \\
\text { 19-Noretiocholanolon } \\
\text { e, } \\
\text { 17-Methyl-5-androst- } \\
\text { 1-ene-3, } \quad \text { 17-diol, } \\
\text { 17-Methyl-5-androsta } \\
\text { ne- } \\
\text { 3, } \\
\text { 3-Hydroxystanozolol, } \\
\text { 16-Hydroxyfurazabol }\end{array}$ & $\begin{array}{l}\text { Clenbuterol: } \\
\text { 0.01ng/ml; } \\
\text { 19-norandrosterone: } \\
\text { 0.3ng/ml; } \\
\text { 19-Noretiocholanolon } \\
\text { e: 0.2ng/ml; } \\
\text { 17-Methyl-5-and } \\
\text { rost-1-ene-3, 17-diol: } \\
\text { 0.8ng/ml; } \\
\text { 17-Methyl-5-androsta } \\
\text { ne-3,17-diol:0.2ng/ml; } \\
\text { 3-Hydroxystanozolol: } \\
\text { 0.3ng/ml; } \\
\text { 16-Hydroxyfurazabol: } \\
\text { 1ng/ml }\end{array}$ & $\begin{array}{l}\text { Methyltestostero } \\
\text { ne used as } \\
\text { internal standard } \\
\end{array}$ & $\begin{array}{l}\text { The use of a complementary GC/QqQ qualitative } \\
\text { method for the detection of a selected number of } \\
\text { anabolic agents with special sensitivity requirements } \\
(2 \quad \mathrm{ng} / \mathrm{mL}) \\
\text { including } \\
\text { A rapid, sensitive and robust gas chromatography- } \\
\text { triple quadrupole mass spectrometry method was } \\
\text { developed for the determination of seven anabolic } \\
\text { agents in human urine. }\end{array}$ & 196 \\
\hline 132 & $\begin{array}{l}\text { NF-LA-ICP-M } \\
\text { S }\end{array}$ & $\begin{array}{ll}\text { A } 20 \mathrm{~nm} & \mathrm{Au} \\
\text { film } & \\
\text { deposited } & \\
\text { onto a } & \mathrm{Si} \\
\text { substrate } & \end{array}$ & 1 & $\mathrm{Au}$ & $\begin{array}{l}2.7 \times 10^{-5} \mathrm{cps} \text { per } \\
\text { ablated } \mathrm{Au} \text { atom }\end{array}$ & I & $\begin{array}{l}\text { Applying for measurements of thin Au film deposited } \\
\text { onto a Si substrate. } \\
\text { A near-field laser ablation inductively coupled } \\
\text { plasma mass spectrometric (NF-LA-ICP-MS) } \\
\text { procedure was created for element analysis in the nm } \\
\text { resolution range. }\end{array}$ & 197 \\
\hline 133 & $\begin{array}{l}\text { LA-MC-ICP- } \\
\text { MS }\end{array}$ & $\begin{array}{l}\text { Sagittal } \\
\text { otoliths }\end{array}$ & Cut into sections & $\mathrm{Sr}, \mathrm{Ba}, \mathrm{Mg}, \mathrm{Ca}$ & / & $\begin{array}{l}\text { Internal } \\
\text { standard: }{ }^{83} \mathrm{Kr} r{ }^{84} \mathrm{~S} \\
\mathrm{r},{ }^{85} \mathrm{Rb},{ }^{86} \mathrm{Sr},{ }^{87} \mathrm{Sr}\end{array}$ & $\begin{array}{l}\text { Measurements of } \mathrm{Sr} \text { isotopic compositions together } \\
\text { with elemental abundances }(\mathrm{Ca}, \mathrm{Ba}, \mathrm{Sr}, \mathrm{Mg}) \text {. } \\
\text { Using in situ } \mathrm{LA} \mathrm{MC}-\mathrm{ICP}-\mathrm{MS} \text { measurements of } \mathrm{Sr} \\
\text { isotopic compositions together with elemental } \\
\text { abundances }(\mathrm{Ca}, \mathrm{Sr}, \mathrm{Ba} \text { and } \mathrm{Mg}) \text {, characterize the } \\
\text { various types of habitats encountered throughout the } \\
\text { lifecycle history of individual barramundi. }\end{array}$ & 199 \\
\hline
\end{tabular}




\begin{tabular}{|c|c|c|c|c|c|c|c|c|}
\hline No. & Instrumental & Matrix & Sample preparation & Element or isotope & LOD or LOQ & Calibration & Application and Technical characteristics & Ref. \\
\hline 134 & $\begin{array}{l}\text { LA-MC-ICPM } \\
\text { S }\end{array}$ & $\begin{array}{l}\text { The PSPT-2 } \\
\text { and PSPT-3 } \\
\text { samples are } \\
\text { pyrite and } \\
\text { sphalerite } \\
\text { powders }\end{array}$ & In situ analysis & Sulfur isotope & 1 & $\begin{array}{l}\text { The external } \\
\text { bracketing } \\
\text { standards for in } \\
\text { situ sulfur } \\
\text { isotope analysis } \\
\text { comprise some } \\
\text { natural sulfides }\end{array}$ & $\begin{array}{l}\text { In situ sulfur isotope analysis by LA-MC-ICPMS has } \\
\text { an advantage in tracing sources of sulfur in an ore } \\
\text { deposit that has complex mineral types and multiple } \\
\text { ore-forming processes. } \\
\text { Matrix effects of different sulfides were examined by } \\
\text { matrix-unmatched tests, in which the } \delta 34 \mathrm{~S} \text { values of } \\
\text { different types of sulfides were calibrated against a } \\
\text { laboratory pyrite standard. }\end{array}$ & 200 \\
\hline 135 & $\begin{array}{l}\text { LA-ICP-TOF- } \\
\text { MS }\end{array}$ & Rat kidney & Cut into sections & Platinum & $4.5 \mathrm{mg}$ & $\begin{array}{l}\text { External } \\
\text { calibration }\end{array}$ & $\begin{array}{l}\text { A cisplatin perfused rat kidney sample was analyzed } \\
\text { using a high-throughput and quasi-simultaneous full } \\
\text { spectral imaging approach using LA-ICP-TOF-MS. } \\
\text { The platinum concentration results of a previous } \\
\text { study could be consumed with additional } \\
\text { all-elemental information revealing interesting } \\
\text { elemental distributions for copper, nickel and } \\
\text { tungsten. }\end{array}$ & 201 \\
\hline 136 & $\begin{array}{l}\text { LA-ICP-TOF- } \\
\text { MS }\end{array}$ & $\begin{array}{l}\text { Rat brain } \\
\text { tissues }\end{array}$ & Homogenize & 1 & 1 & 1 & $\begin{array}{l}\text { Developing a calibration strategy procedure in } \\
\text { bioimaging trace elements in rat brain tissue by the } \\
\text { LA ICP-TOF-MS method. } \\
\text { Discussed the steps of a developed calibration } \\
\text { procedure in the determination of trace elements in } \\
\text { rat brain tissues by LA ICP-TOF-MS method. }\end{array}$ & 202 \\
\hline
\end{tabular}




\begin{tabular}{|c|c|c|c|c|c|c|c|c|}
\hline No. & Instrumental & Matrix & Sample preparation & Element or isotope & LOD or LOQ & Calibration & Application and Technical characteristics & Ref. \\
\hline 137 & $\begin{array}{l}\text { LA-ICP-MS, } \\
\text { SR- } \mu \text {-XRF, } \\
\text { XANES } \\
\text { EXAFS }\end{array}$ & Mushrooms & Cut into sections & $\mathrm{Hg}$ & MeHg: $4 \mu \mathrm{g} / \mathrm{kg}$ & $\begin{array}{l}\mathrm{Ge}, \mathrm{Ga}, \mathrm{Y}, \mathrm{Sc}(5 \\
\mathrm{mg} / \mathrm{L}) \text { were used } \\
\text { as internal } \\
\text { standards }\end{array}$ & $\begin{array}{l}\text { Provide novel information on the localization and } \\
\text { chemical speciation of Hg in caps of } B \text {. aereus, } B \text {. } \\
\text { edulis and } S \text {. pescaprae by LA-ICP-MS, } \mu \text {-XRF and } \\
\text { XANES/EXAFS. } \\
\text { EXAFS has opened new possibilities to study the } \\
\text { chemical speciation and ligand environment in } \\
\text { biological materials, without the use of extraction } \\
\text { procedures that can alter the "in-vivo" ligand state; } \\
\text { EXAFS has opened new possibilities to study the } \\
\text { chemical speciation and ligand environment in } \\
\text { biological materials, without the use of extraction } \\
\text { procedures that can alter the "in-vivo" ligand state. }\end{array}$ & 203 \\
\hline 138 & LA-ICP-MS & Soil & $\begin{array}{l}\text { Homogenize, tablet } \\
\text { compressing }\end{array}$ & Rare earth elements & $\begin{array}{l}\text { Ce: } 0.63 \mu \mathrm{g} / \mathrm{g} \text {; } \\
\text { Dy: } 0.34 \mu \mathrm{g} / \mathrm{g} \\
\text { Er: } 0.48 \mu \mathrm{g} / \mathrm{g} \\
\text { EU: } 0.23 \mu \mathrm{g} / \mathrm{g} \\
\text { Gd: } 0.21 \mu \mathrm{g} / \mathrm{g} \\
\text { Ho: } 0.34 \mu \mathrm{g} / \mathrm{g} \\
\text { La: } 0.87 \mu \mathrm{g} / \mathrm{g} \\
\text { Lu: } 0.15 \mu \mathrm{g} / \mathrm{g} \\
\text { Nd: } 0.99 \mu \mathrm{g} / \mathrm{g} \\
\text { Pr: } 0.75 \mu \mathrm{g} / \mathrm{g} \\
\text { Sm: } 0.70 \mu \mathrm{g} / \mathrm{g} \\
\text { Tb: } 0.25 \mu \mathrm{g} / \mathrm{g} \\
\text { Tm: } 0.15 \mu \mathrm{g} / \mathrm{g} \\
\text { Yb: } 0.96 \mu \mathrm{g} / \mathrm{g}\end{array}$ & Internal standard & $\begin{array}{l}\text { Evaluated the concentration and distribution of REEs } \\
\text { in cultivated and non-cultivated soil. } \\
\text { Establish a method for direct solid sample analysis by } \\
\text { LA-ICP-MS. }\end{array}$ & 204 \\
\hline
\end{tabular}




\begin{tabular}{|c|c|c|c|c|c|c|c|c|}
\hline No. & Instrumental & Matrix & Sample preparation & Element or isotope & LOD or LOQ & Calibration & Application and Technical characteristics & Ref. \\
\hline 139 & $\begin{array}{l}\text { MALDI-FT-IC } \\
\text { R-MS }\end{array}$ & $\begin{array}{l}\text { Yeast } \\
\text { mitochondria } \\
1 \text { proteins }\end{array}$ & Microwave digestion & Sulfur & $\begin{array}{l}\text { P: } 0.18 \mathrm{mg} / \mathrm{g}, \mathrm{S}: 1.3 \\
\mathrm{mg} / \mathrm{g}, \mathrm{Cu}: 6.4 \mathrm{mg} / \mathrm{g} \text {, } \\
\mathrm{Zn}: 17.6 \mathrm{mg} / \mathrm{g}, \mathrm{Fe}: 9.5 \\
\mathrm{mg} / \mathrm{g} \backslash\end{array}$ & $\begin{array}{l}\text { Internal standard } \\
\text { element }\end{array}$ & $\begin{array}{l}\text { Protein spots in two-dimensional gels were screened } \\
\text { with respect to P, S, Fe, Cu and Zn content, and } \\
\text { multielement determination was investigated in } \\
\text { separated protein spots by LA-ICP-MS as the } \\
\text { microlocal analytical technique. } \\
\text { A new screening technique using two-dimensional } \\
\text { gels was developed in order to rapidly identify } \\
\text { various elements in well-separated protein spots. }\end{array}$ & 206 \\
\hline 140 & $\begin{array}{l}\text { LA-ICP-MS/ } \\
\text { LC-MS }\end{array}$ & $\begin{array}{l}\text { Roots of } \\
\text { Elsholtzia } \\
\text { splendens }\end{array}$ & Cut into smaller pieces & $\begin{array}{l}\mathrm{Cu}, \mathrm{Zn}, \mathrm{Na}, \mathrm{Mg}, \mathrm{K} \\
\mathrm{Ca}, \mathrm{Mn}, \mathrm{Fe}, \mathrm{P}, \mathrm{S}, \mathrm{Ag}\end{array}$ & I & $\begin{array}{l}\text { Internal } \\
\text { standards }\end{array}$ & $\begin{array}{l}\text { LA-ICP-MS is used to screen metal-containing } \\
\text { proteins on the dried } 2 \mathrm{D} \text { gels. } \\
\text { LA-ICP-MS imaging technique, via the images of } \\
\mathrm{Ag} \text {, was able to distinguish almost all the protein } \\
\text { spots in 2D gels, even those with relative low } \\
\text { abundance. The metal images were correlated very } \\
\text { well with those obtained by Ag staining. }\end{array}$ & 207 \\
\hline 141 & LA-ICP-MS & Wheat seeds & I & ${ }^{70} \mathrm{Zn}$ & I & $\begin{array}{l}\text { The } \mathrm{Zn}:{ }^{13} \mathrm{C} \text { ratio } \\
\left({ }^{13} \mathrm{C} \text { as internal }\right. \\
\text { standard) of the } \\
\text { calibration } \\
\text { standards }\end{array}$ & $\begin{array}{l}\text { Using LA-ICP-MS, the spatial distribution of } \mathrm{Zn} \\
\text { within the grains was studied to elucidate the } \mathrm{Zn} \\
\text { transport pathway within the developing grain. } \\
\text { The spatial distribution of } \mathrm{Zn} \text { within the grains was } \\
\text { studied by LA-ICP-MS. }\end{array}$ & 208 \\
\hline 142 & $\begin{array}{l}\text { HPLC-ID-ICP } \\
\text {-MS }\end{array}$ & $\begin{array}{l}\text { Standard } \\
\text { proteins }\end{array}$ & Filter & $\mathrm{S}, \mathrm{Fe}$ & I & $\begin{array}{l}\text { Sulfur isotopic } \\
\text { reference } \\
\text { material with a } \\
\text { natural } \\
\text { abundance }\end{array}$ & $\begin{array}{l}\text { The quantification of proteins by ICP-MS offers an } \\
\text { alternative method for quantitative proteomics. } \\
\text { Developed a method based on HPLC coupled to } \\
\text { ICP-MS via post-column isotope dilution for the } \\
\text { quantification of transferrin (Tf) and albumin (Alb) in } \\
\text { human serum using enriched } 34 \mathrm{~S} \text { and } 54 \mathrm{Fe} \text { isotopic } \\
\text { solutions. }\end{array}$ & 212 \\
\hline
\end{tabular}




\begin{tabular}{|c|c|c|c|c|c|c|c|c|}
\hline No. & Instrumental & Matrix & Sample preparation & Element or isotope & LOD or LOQ & Calibration & Application and Technical characteristics & Ref. \\
\hline 143 & LA-ICP-MS & $\begin{array}{l}\text { Human } \\
\text { Serum } \\
\text { Transferrin }\end{array}$ & Homogenize & ${ }^{56} \mathrm{Fe},{ }^{13} \mathrm{C}$ & / & $\begin{array}{l}\text { A serum } \\
\text { certified } \\
\text { reference } \\
\text { material } \\
\text { (ERM-DA470k/ } \\
\text { IFCC) }\end{array}$ & $\begin{array}{l}\text { The absolute quantification of a metalloprotein } \\
\text { separated by nondenaturing gel electrophoresis } \\
\text { using LA-ICP-MS in combination with } \\
\text { species-specific IDMS. } \\
\text { Absolute Quantification of Human Serum Transferrin } \\
\text { by Species-Specific Isotope Dilution Laser Ablation } \\
\text { ICP-MS. }\end{array}$ & 213 \\
\hline 144 & LA-ICP-MS & Brain tissues & $\begin{array}{l}\text { Homogenize, cut into } \\
40 \mathrm{~mm} \text { sections }\end{array}$ & $\mathrm{Fe}, \mathrm{Cu}, \mathrm{Zn}$ & / & $\begin{array}{l}\text { Homogeneous } \\
\text { in-house } \\
\text { standard; }{ }^{54} \mathrm{Fe} /{ }^{56} \mathrm{~F} \\
\mathrm{e},{ }^{63} \mathrm{Cu} /{ }^{65} \mathrm{Cu} \text { and } \\
{ }^{64} \mathrm{Zn} /{ }^{67} \mathrm{Znare} \\
0.11313 \text {, } \\
0.11584 \text { and } \\
0.02486\end{array}$ & $\begin{array}{l}\text { A quantitative imaging strategy of intact brain } \\
\text { section. } \\
\text { Spatial resolution capacity and precise means for } \\
\text { quantification; quantitative imaging of trace elements } \\
\text { in biological samples. }\end{array}$ & 214 \\
\hline 145 & LA-ICP-MS & Moss & Cut into sections & ${ }^{242} \mathrm{Pu},{ }^{243} \mathrm{Am}$ & Pu: $3.6 \mathrm{fg} / \mathrm{g}$ & $\begin{array}{l}\text { Calibration } \\
\text { against the } \\
\text { NIST-500 SRM } \\
\text { using TIMS }\end{array}$ & $\begin{array}{l}\text { The direct determination of long-lived radionuclides } \\
\text { at ultra-trace concentration levels in solid } \\
\text { environmental samples. } \\
\text { LA-ICP-MS was combined with isotope dilution for } \\
\text { the ultra-trace level determination of }{ }^{239} \mathrm{Pu},{ }^{240} \mathrm{Pu} \text { and } \\
{ }^{241} \mathrm{Am} \text { on the surface of targets after electroplating. }\end{array}$ & 215 \\
\hline 146 & $\begin{array}{l}\text { SC-IDLA-ICP } \\
-\mathrm{MS}\end{array}$ & $\begin{array}{l}\text { Macrophage } \\
\text { cells }\end{array}$ & Digest & Silver NPs & $0.2 \mathrm{fg} \mathrm{Ag}$ per cell & $\begin{array}{l}\text { NIST } 612 \text { glass } \\
\text { standard RM }\end{array}$ & $\begin{array}{l}\text { LA-ICP-MS is an emerging method for the analysis } \\
\text { of metal nanoparticles (NPs) in single cells. } \\
\text { Multiplexed imaging of proteins and protein } \\
\text { modifications in tumor tissues with a subcellular } \\
\text { resolution }(\sim 1 \mu \mathrm{m}) \text { is achieved using } \\
\text { immunohistochemical techniques coupled to the new } \\
\text { generation of LA-ICP-MS. }\end{array}$ & 216 \\
\hline
\end{tabular}




\begin{tabular}{|c|c|c|c|c|c|c|c|c|}
\hline No. & Instrumental & Matrix & Sample preparation & Element or isotope & LOD or LOQ & Calibration & Application and Technical characteristics & Ref. \\
\hline 147 & $\begin{array}{l}\text { W-coil } \\
\text { ET-AFS/AAS }\end{array}$ & $\begin{array}{l}\text { Rice and } \\
\text { water }\end{array}$ & $\begin{array}{l}\text { Cloud point extraction } \\
\text { (Triton X-114) }\end{array}$ & $\mathrm{Cd}$ & $\begin{array}{l}\text { W-coil ET-AFS: } 0.01 \\
\mu \mathrm{g} / \mathrm{L} \\
\text { W-coil ET-AAS: } 0.03 \\
\mu \mathrm{g} / \mathrm{L}\end{array}$ & \begin{tabular}{|l|} 
External \\
standard \\
method; \\
linear range: \\
W-coil \\
ET-AFS:0.01-0. \\
$5 \quad \mu \mathrm{g} / \mathrm{L} ; \mathrm{W}-$ coil \\
ET-AAS:0.03-2 \\
$\mu \mathrm{g} / \mathrm{L}$ \\
$\mathrm{R}^{2}>0.994 ;$
\end{tabular} & $\begin{array}{l}\text { The accurate determination of trace amounts of } \\
\text { cadmium in rice and water samples by W-coil } \\
\text { ETVAFS and ET-AAS after CPE preconcentration. } \\
\text { Use of CPE with W-coil atomization/vaporization, } \\
\text { high sensitivities and improved LODs were easily } \\
\text { obtained for cadmium. }\end{array}$ & 217 \\
\hline 148 & SPE -ICP-OES & $\begin{array}{l}\text { Water and } \\
\text { food samples }\end{array}$ & SPE & $\begin{array}{l}\mathrm{Cd} \text { (II), } \mathrm{Cu} \quad(\mathrm{II}), \mathrm{Ni} \\
(\mathrm{II}), \mathrm{Pb} \text { (II), }\end{array}$ & $\begin{array}{llr}0.012, & 0.098, & 0.056 \\
\text { and } & 0.14 \mu \mathrm{g} / \mathrm{L} & \text { for } \\
\mathrm{Cd}(\mathrm{II}), \mathrm{Cu}(\mathrm{II}), & \mathrm{Ni}(\mathrm{II}) \\
\text { and } \mathrm{Pb}(\mathrm{II}) & \\
\text { enrichment } & \text { factor: } \\
100 & \end{array}$ & $\begin{array}{|lr|}\text { Calibration } \\
\text { curve; } \\
\text { linear } \\
0.5-4 \mu \mathrm{g} / \mathrm{mL} \text { for } \\
\mathrm{Cd}(\mathrm{II}), \quad 0.5-4 \\
\mu \mathrm{g} / \mathrm{mL} & \text { for } \\
\mathrm{Cu}(\mathrm{II}), & 0.5-4 \\
\mu \mathrm{g} / \mathrm{mL} & \text { for } \\
\mathrm{Ni}(\mathrm{II}) \\
\text { and } & 0.5-4 \\
\mu \mathrm{g} / \mathrm{mL} \text { for } \mathrm{Pb}(\mathrm{II})\end{array}$ & $\begin{array}{l}\text { A simple and efficient AEDHB-SG column solid } \\
\text { phase extraction method was used for the separation, } \\
\text { preconcentration and simultaneous determination of } \\
\mathrm{Cd}(\mathrm{II}), \mathrm{Cu}(\mathrm{II}), \mathrm{Ni}(\mathrm{II}) \text { and } \mathrm{Pb}(\mathrm{II}) \text { ions in water and } \\
\text { food samples using ICP-OES. } \\
\mathrm{Silica} \text { gel was functionalized with } \\
\mathrm{N} \text {-(2-aminoethyl)-2,3-dihydroxybenzaldimine for } \\
\text { solid phase extraction of trace elements. } \\
\text { This study allows separation and preconcentration at } \\
\mu \mathrm{g} / \mathrm{L} \text { level of trace elements; } \\
\mathrm{Simultaneous} \text { determination of } \mathrm{Cd}(\mathrm{II}), \mathrm{Cu}(\mathrm{II}), \mathrm{Ni}(\mathrm{II}) \\
\text { and } \mathrm{Pb}(\mathrm{II}) \text { in water and food samples using ICP-OES. }\end{array}$ & 218 \\
\hline
\end{tabular}




\begin{tabular}{|c|c|c|c|c|c|c|c|c|}
\hline No. & Instrumental & Matrix & Sample preparation & Element or isotope & LOD or LOQ & Calibration & Application and Technical characteristics & Ref. \\
\hline 149 & ETV-ICP-AES & $\begin{array}{l}\text { Seawater, } \\
\text { tap water }\end{array}$ & $\begin{array}{l}\text { On-site } \\
\text { electrodeposition }\end{array}$ & $\mathrm{Pb}$ & $25 \mathrm{pg} / \mathrm{mL}(3 \mathrm{~min})$ & $\begin{array}{l}\text { External } \\
\text { standard } \\
\text { method; } \\
\text { linear range: } \\
100-1000 \mathrm{pg} / \mathrm{ml} \\
\mathrm{R}^{2}>0.9974\end{array}$ & $\begin{array}{l}\text { An electrodeposition method for preconcentration } \\
\text { and separation of labile } \mathrm{Pb} \text { from liquid samples with a } \\
\text { complex matrix is described. } \\
\text { Electrothermal, near torch vaporization sample } \\
\text { introduction for ICP-AES was used. Liquid samples } \\
\text { with a complex matrix (e.g., seawater, tap water) } \\
\text { were tested; On-site electrodeposition was used to } \\
\text { test for compliance with EPA's } \mathrm{Pb}-\mathrm{Cu} \text { rule; Detection } \\
\text { limit for Pb by NTV-ICP-AES was } 25 \mathrm{pg} / \mathrm{mL} \text { after } 3 \\
\text { min electrodeposition. }\end{array}$ & 219 \\
\hline 150 & ETV-AAS & $\begin{array}{l}\text { Solid } \\
\text { envFemental } \\
\text { and } \\
\text { biological } \\
\text { samples }\end{array}$ & Soil sampling & $\mathrm{Hg}$ & $0.12 \mathrm{ng} / \mathrm{g}$ & $\begin{array}{l}\text { Solid } \quad \text { CRMs } \\
\text { calibration } \\
\text { graph; } \\
\text { linear range: } \\
0-50 \quad \text { ng, } \\
\mathrm{R}^{2}=0.9802 ; \\
0-1600 \quad \mathrm{ng}, \\
\mathrm{R}^{2}=0.9992 ;\end{array}$ & $\begin{array}{l}\text { A new, rapid technique for the determination of total } \\
\text { mercury in envFemental and biological samples. } \\
\text { The pyrolysis of the sample in a combustion tube at } \\
750^{\circ} \mathrm{C} \text { under an oxygen atmosphere, collection on a } \\
\text { gold amalgamator and subsequent detection by AAS } \\
\text { using a silicon UV diode detector. }\end{array}$ & 220 \\
\hline 151 & $\begin{array}{l}\text { SS-ETV-ICP- } \\
\text { MS }\end{array}$ & $\begin{array}{l}\text { Geological } \\
\text { Samples } \\
\text { (rock, soil } \\
\text { and } \\
\text { sediment) }\end{array}$ & $\begin{array}{l}\text { Sodium citrate was } \\
\text { used in the pyrolysi } \\
\text { process to improve the } \\
\text { transfer and the } \\
\text { ionization efficieney } \\
\text { of iodine }\end{array}$ & I & $\begin{array}{l}\text { Rock: } 11 \mathrm{ng} / \mathrm{g} \\
\text { Soil: } 9 \mathrm{ng} / \mathrm{g} \\
\text { Sediment: } 8 \mathrm{ng} / \mathrm{g}\end{array}$ & $\begin{array}{l}\text { Matrix-matched } \\
\text { external } \\
\text { calibration } \\
\text { curves }\end{array}$ & $\begin{array}{l}\text { Developing a robust and high-throughput method } \\
\text { based on SS-ETV-ICP-MS for the quantitative } \\
\text { determination of trace iodine in geological materials. } \\
\mathrm{Pd}\left(\mathrm{NO}_{3}\right)_{2} \text { and ascorbic acid were chemical modifier. }\end{array}$ & 221 \\
\hline
\end{tabular}




\begin{tabular}{|c|c|c|c|c|c|c|c|c|}
\hline No. & Instrumental & Matrix & Sample preparation & Element or isotope & LOD or LOQ & Calibration & Application and Technical characteristics & Ref. \\
\hline 152 & $\begin{array}{l}\text { QT } \\
\text {-ETV-QTAT } \\
\text {-AFS }\end{array}$ & $\begin{array}{l}\text { Food } \\
\text { samples }\end{array}$ & Soild sampling & $\mathrm{Pb}$ & $2 \mathrm{pg}$ & $\begin{array}{l}\text { External } \\
\text { standard } \\
\text { method; } \\
\text { linear } \\
\text { range:0.04-4.0 } \\
\text { ng; } \\
\text { correlation } \\
\text { coefficient (R) } \\
\text { was }>0.998\end{array}$ & $\begin{array}{l}\text { A novel QT-ETV-QTAT-AFS } \\
\text { method was developed for the direct determination of } \\
\text { trace } \mathrm{Pb} \\
\text { in food samples. } \\
\text { A quartz tube was first used to trap Pb after SS-ETV } \\
\text { and its relative mechanism was investigated. }\end{array}$ & 222 \\
\hline 153 & ETAAS & Water & Soild sampling & $\begin{array}{l}\mathrm{Cd}, \mathrm{Co}, \mathrm{Cr}, \mathrm{Mn}, \mathrm{Ni}, \\
\mathrm{Pb}\end{array}$ & $0.06-2.3 \mu \mathrm{g} / \mathrm{L}$ & $\begin{array}{l} \\
\text { Cd: } 0-2.0 \mu \mathrm{g} / \mathrm{L} ; \\
\mathrm{Ni} / \mathrm{Pb}: \quad 0-100 \\
\mu \mathrm{g} / \mathrm{L} ; \quad \mathrm{Co}, \quad \mathrm{Cr} \text {, } \\
\mathrm{Mn}: 0-25.0 \mu \mathrm{g} / \mathrm{L}\end{array}$ & $\begin{array}{l}\text { The analytical figures of merit obtaincd with the TCA } \\
\text { using a simple homemade power unit, proved the } \\
\text { potential of this unenclosed TCA as a simple } \\
\text { electrothermal atomization accessory to supplement } \\
\text { AA instruments for trace element analysis of waters. } \\
\text { The analytical performance of an unenclosed tungsten } \\
\text { coil atomizer operating in Ar- } \mathrm{H}_{2} \text { was assessed } \\
\text { byETAAS for the determination of pg to ng levels of } \\
\mathrm{Cd}, \mathrm{Co}, \mathrm{Cr}, \mathrm{Mn}, \mathrm{Ni} \text { and } \mathrm{Pb} \text { in liquid samples. }\end{array}$ & 223 \\
\hline 154 & $\begin{array}{l}\text { d-CPE } \\
\text {-ETAAS }\end{array}$ & $\begin{array}{l}\text { Water and } \\
\text { freshwater } \\
\text { fish samples. }\end{array}$ & d-CPE & $\mathrm{Hg}(\mathrm{II}) \mathrm{CH}_{3} \mathrm{Hg}$ & $0.23 \mu \mathrm{g} / \mathrm{L}$ & $\begin{array}{l}\text { External } \\
\text { standard } \\
\text { method; } \\
\text { linear } \quad \text { range: } \\
0.40-15.0 \quad \mu \mathrm{g} / \mathrm{L} \\
\text { correlation } \\
\text { coefficient } \quad(\mathrm{R}) \\
=0.9997\end{array}$ & $\begin{array}{l}\text { A useful tool for speciation of mercury in water and } \\
\text { freshwater fish samples and an attractive method for } \\
\text { routine quality control laboratories especially for } \\
\text { food applications. } \\
\text { A d-CPE was developed for mercury speciation in } \\
\text { freshwater fish samples by ETAAS. } \\
\text { Method was applied to the speciation of Hg in water } \\
\text { and freshwater fish samples. }\end{array}$ & 224 \\
\hline
\end{tabular}




\begin{tabular}{|c|c|c|c|c|c|c|c|c|}
\hline No. & Instrumental & Matrix & Sample preparation & Element or isotope & LOD or LOQ & Calibration & Application and Technical characteristics & Ref. \\
\hline 155 & $\begin{array}{l}\text { Thermolysis-A } \\
\text { AS }\end{array}$ & $\begin{array}{l}\text { Traditional } \\
\text { Chinese } \\
\text { Medicines }\end{array}$ & Soild sampling & $\mathrm{Hg}$ & $3.9 \mathrm{ng} / \mathrm{g}$ & $\begin{array}{l}\text { External } \\
\text { standard } \\
\text { method; } \\
\text { linear range: } \\
\mathrm{ng} / \mathrm{g} \text { to } \mathrm{mg} / \mathrm{g} ; \\
\text { correlation } \\
\text { coefficient } \\
(\mathrm{R})>0.994\end{array}$ & $\begin{array}{l}\text { Mercury conversion from cinnabar to biological } \\
\text { matrices-bound } \mathrm{Hg} \text { could occur because of the aid of } \\
\text { other ingredients in the formulated drug. } \\
\text { Develop and apply a mercury analyzer system } \\
\text { capable of quantitative analysis of mercury in } \\
\text { Traditional Chinese Medicines (TCM) drugs in the } \\
\text { concentrations range from } \mathrm{ng} / \mathrm{g} \text { to } \mathrm{mg} / \mathrm{g} \text {. }\end{array}$ & 225 \\
\hline 156 & $\begin{array}{l}\text { Electromagneti } \\
\mathrm{c} \text { heating -OES }\end{array}$ & Soil & Soild sampling & $\mathrm{Hg}, \mathrm{Cd}$ and $\mathrm{Pb}$ & $\begin{array}{l}\mathrm{Hg}: 0.008 \mathrm{mg} / \mathrm{kg} ; \\
\mathrm{Cd}: 0.0178 \mathrm{mg} / \mathrm{kg} \\
\mathrm{Pb}: 3.54 \mathrm{mg} / \mathrm{kg}\end{array}$ & $\begin{array}{l}\mathrm{Hg}: 0.015-0.590 \\
\mathrm{mg} / \mathrm{kg}, \\
\mathrm{R}^{2}=0.996 \\
\mathrm{Cd}: 0.060-0.450 \\
\mathrm{mg} / \mathrm{kg}, \\
\mathrm{R}^{2}=0.9917 \\
\mathrm{~Pb}: \quad 14.0-314 \\
\mathrm{mg} / \mathrm{kg}, \\
\mathrm{R}^{2}=0.9918\end{array}$ & | & 226 \\
\hline
\end{tabular}




\begin{tabular}{|c|c|c|c|c|c|c|c|c|}
\hline No. & Instrumental & Matrix & Sample preparation & Element or isotope & LOD or LOQ & Calibration & Application and Technical characteristics & Ref. \\
\hline 157 & $\begin{array}{l}\text { ETV-TC-ICP- } \\
\text { MS }\end{array}$ & Food & Soild sampling & $\mathrm{Cd}$ & LOQ: $0.5 \mathrm{pg}$ & $\begin{array}{l}\text { Matrix-matching } \\
\text { calibration } \\
\text { strategy } \\
0.16 \text { pg-50ng } \\
\mathrm{R}^{2}>0.995\end{array}$ & $\begin{array}{l}\text { The proposed SS-ETV-ICP-MS method is } \\
\text { extremelysuitable for rapid Cd detection for food } \\
\text { sample screening, which maybe a good option for } \\
\text { laboratories that use the ICP-MS. } \\
\text { A tungsten coil trap was firstly employed to ICP-MS } \\
\text { for Cd analysis in food. } \\
\text { The modified gas circuit showed an effective } \\
\text { performance for plasma stability. } \\
\text { The minimum sample mass of fresh food samples } \\
\text { well ground proved }<30 \text { mg. } \\
\text { This SS-ETV-ICP-MS method is fast, accurate, easy, } \\
\text { green and safe. }\end{array}$ & 227 \\
\hline 158 & $\begin{array}{l}\text { SS-ETV-TC-I } \\
\text { CP-MS }\end{array}$ & $\begin{array}{l}\text { Wheat, corn } \\
\text { and rice } \\
\text { samples }\end{array}$ & Soild sampling & $\mathrm{Zn}, \mathrm{Cd}$ & $\begin{array}{l}\mathrm{Zn}: 1 \mathrm{pg} ; \\
\mathrm{Cd}: 0.1 \mathrm{pg}\end{array}$ & $\begin{array}{l}\text { Increasing } \\
\text { masses of } \text { CRM } \\
\text { or } \\
\text { samples; } \\
\mathrm{R}^{2}>0.995\end{array}$ & $\begin{array}{l}\text { ETV-TCT-ICP-MS method is highly suitable for } \\
\text { rapid } \mathrm{Zn} \text { and Cd detection when screening food } \\
\text { samples, which is a good choice for some laboratories } \\
\text { equipped with an ICP-MS. } \\
\text { A method in which a TCT captured } \mathrm{Zn} \text { and Cd atoms } \\
\text { at the same time at room temperature after SS-ETV } \\
\text { was used for the first time. }\end{array}$ & 229 \\
\hline 159 & SS-ETV-AFS & Rice & Soild sampling & $\mathrm{Cd}$ & $40 \mathrm{ng} / \mathrm{L}$ & $\begin{array}{l}\text { Matrix-matching } \\
\text { calibration } \\
\text { strategy } \\
\text { linear range: } 0.3 \\
\mu \mathrm{g} / \mathrm{L}-1.0 \mathrm{mg} / \mathrm{L} \\
\mathrm{R}^{2}>0.995\end{array}$ & $\begin{array}{l}\text { The SS-ETV-AFS method was a good solid } \\
\text { microsample analysis technique to determine trace } \\
\text { Cd in rice and avoided troublesome digestion and } \\
\text { unnecessary dilution procedures. } \\
\text { SS-ETV-AFS was used to detect Cd in rice samples } \\
\text { for the purpose of assessing the homogeneity and } \\
\text { minimum sample mass. }\end{array}$ & 230 \\
\hline
\end{tabular}




\begin{tabular}{|c|c|c|c|c|c|c|c|c|}
\hline No. & Instrumental & Matrix & Sample preparation & Element or isotope & LOD or LOQ & Calibration & Application and Technical characteristics & Ref. \\
\hline 160 & $\begin{array}{l}\text { hydride } \\
\text { generation } \\
\text { (HG)-DBD-A } \\
\text { FS }\end{array}$ & Water & / & As & $1.0 \mathrm{ng} / \mathrm{L}$ & \begin{tabular}{ll|} 
External & \\
standard & \\
method; & \\
linear $\quad$ range: \\
$0.05 \quad \mu \mathrm{g} / \mathrm{L}-5$ \\
$\mu \mathrm{g} / \mathrm{L}$, \\
linear & regression \\
coefficient $\left(\mathrm{R}^{2}\right)>$ \\
0.995
\end{tabular} & $\begin{array}{l}\text { A novel dielectric barrier discharge reactor (DBDR) } \\
\text { was utilized to trap/release arsenic coupled to } \\
\text { HGAFS. } \\
\text { A coaxial DBDR installed between HG and AFS to } \\
\text { enrich arsine under ambient temperature and } \\
\text { atmospheric pressure, novel HG-DBD-AFS system } \\
\text { was applied to measure ultra-trace arsenic in surface } \\
\text { water. }\end{array}$ & 232 \\
\hline 161 & ETV-ICP-OES & $\begin{array}{l}\text { Avian bone } \\
\text { and slag }\end{array}$ & Soild sampling & $\begin{array}{l}\mathrm{Al}, \mathrm{Ca}, \mathrm{Fe}, \mathrm{Mg}, \mathrm{S}, \mathrm{Ag}, \\
\mathrm{As}, \mathrm{Au}, \mathrm{Ba}, \mathrm{Cd}, \mathrm{Ce}, \\
\mathrm{Co}, \mathrm{Cr}, \mathrm{Cs}, \mathrm{Cu}, \mathrm{Dy}, \\
\mathrm{Eu}, \mathrm{Ga}, \mathrm{Hf}, \mathrm{Hg}, \mathrm{Ho}, \\
\mathrm{In}, \mathrm{K}, \mathrm{La}, \mathrm{Mn}, \mathrm{Mo}, \\
\mathrm{Na}, \mathrm{Nd}, \mathrm{Ni}, \mathrm{P}, \mathrm{Pb}, \mathrm{Rb} \\
\mathrm{Sb}, \mathrm{Sc}, \mathrm{Se}, \mathrm{Si}, \mathrm{Sm} \\
\mathrm{Sr}, \mathrm{Ti}, \mathrm{U}, \mathrm{V}, \mathrm{W}, \mathrm{Yb} \\
\mathrm{Zn}, \mathrm{Zr}\end{array}$ & I & $\begin{array}{l}\text { External } \\
\text { calibration } \\
\text { curves, which } \\
\text { were constructed } \\
\text { using DUWF-1, } \\
\text { NIST } 8433, \\
\text { NIST } 2711 \text {, and } \\
\text { SL-1, with a } \\
\text { mass range of } 1- \\
3.5 \text { mg; } \\
\mathrm{R}^{2}=0.97-0.99\end{array}$ & $\begin{array}{l}\text { Use the ETV-ICP-OES method to perform an initial } \\
\text { investigation on the effect of slag ingestion on the } \\
\text { elemental composition of avian bones, elemental } \\
\text { ratios may be used as a fingerprint for slag, allowing } \\
\text { further confirmation of slagingestion. } \\
\text { Developing a method of direct analysis of solid avian } \\
\text { bone and slag samples to determine bulk (Al, Ca, Fe, } \\
\mathrm{Mg}, \mathrm{S} \text { ) and trace (Ag, As, Au, Ba, Cd, Ce, Co, Cr, } \\
\mathrm{Cs}, \mathrm{Cu}, \mathrm{Dy}, \mathrm{Eu}, \mathrm{Ga}, \mathrm{Hf}, \mathrm{Hg}, \mathrm{Ho}, \mathrm{In}, \mathrm{K}, \mathrm{La}, \mathrm{Mn}, \mathrm{Mo} \text {, } \\
\mathrm{Na}, \mathrm{Nd}, \mathrm{Ni}, \mathrm{P}, \mathrm{Pb}, \mathrm{Rb}, \mathrm{Sb}, \mathrm{Sc}, \mathrm{Se}, \mathrm{Si}, \mathrm{Sm}, \mathrm{Sr}, \mathrm{Ti} \text {, U, } \\
\mathrm{V}, \mathrm{W}, \mathrm{Yb}, \mathrm{Zn}, \mathrm{Zr} \text { ) element concentrations, without } \\
\text { the need for sample digestion, using ETV-ICPOES. }\end{array}$ & 233 \\
\hline 162 & $\begin{array}{l}\text { ICP-oa-TOF- } \\
\text { MS }\end{array}$ & $\begin{array}{l}\text { Food and } \\
\text { beverages }\end{array}$ & Microwave digestion & $\begin{array}{l}\text { Multi-element } \\
\text { analysis }\end{array}$ & $0.04-1360 \mathrm{ng} / \mathrm{g}$ & $\begin{array}{l}\text { Internal } \\
\text { standardization } \\
\left({ }^{103} \mathrm{Rh}\right) \\
0-50 \mathrm{mg} / \mathrm{L}\end{array}$ & $\begin{array}{l}\text { The advantages of ICP-TOF-MS for food control } \\
\text { procedures. } \\
\text { Accurated results are obtained for some elements by } \\
\text { ICP-oaTOF-MS which was difficult for Q-ICP-MS. }\end{array}$ & 234 \\
\hline
\end{tabular}




\begin{tabular}{|c|c|c|c|c|c|c|c|c|}
\hline No. & Instrumental & Matrix & Sample preparation & Element or isotope & LOD or LOQ & Calibration & Application and Technical characteristics & Ref. \\
\hline 163 & $\begin{array}{l}\text { ICP-oa-TOF- } \\
\text { MS }\end{array}$ & $\begin{array}{l}\text { Indocalamus } \\
\text { tesselatus } \\
\text { samples }\end{array}$ & Microwave digestion & $\begin{array}{l}\mathrm{Pb}, \mathrm{Cd}, \mathrm{Mn}, \mathrm{Ni}, \mathrm{Cr} \\
\mathrm{As}, \mathrm{Hg}, \mathrm{Cu}, \mathrm{Zn}\end{array}$ & 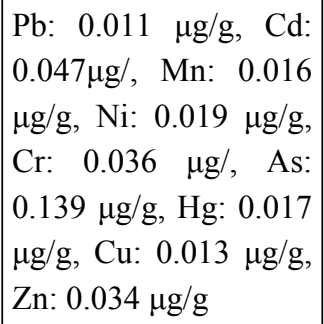 & $\begin{array}{l}\text { Cd, Ni, As, } \mathrm{Hg}: \\
0-20 \mu \mathrm{g} / \mathrm{L} ; \quad \mathrm{Cu}, \\
\mathrm{Zn}, \quad \mathrm{Cr}: \quad 5-200 \\
\mu \mathrm{g} / \mathrm{L} ; \quad \mathrm{Mn}: \\
0-1000 \mu \mathrm{g} / \mathrm{L}, \mathrm{Pb}: \\
0-40 \mu \mathrm{g} / \mathrm{L} ; \\
\mathrm{R}^{2}>0.992\end{array}$ & $\begin{array}{l}\text { Showed I. tesselatus can be unreservedly used as } \\
\text { food packing materials without any health risk. } \\
\text { Proposed a method for the determination of heavy } \\
\text { metals by ICP-oa-TOF-MS. }\end{array}$ & 235 \\
\hline 164 & SF-ICP-MS & $\begin{array}{l}\text { Grape (Vitis } \\
\text { vinifera sp.) } \\
\text { seeds and } \\
\text { skins, green } \\
\text { tea (Camellia } \\
\text { sinensis) } \\
\text { leaves and } \\
\text { Limousin } \\
\text { oak (Quercus } \\
\text { robur) } \\
\text { heartwood }\end{array}$ & Microwave digestion & $\begin{array}{l}\text { Multi-element } \\
\text { analysis }\end{array}$ & 1 & 1 & $\begin{array}{l}\text { The ICP-MTS elemental profile confirmed the levels } \\
\text { of potentially toxic contaminants. } \\
\text { MALDI-TOF-MS and UV-vis informed on } \\
\text { food-grade tannins composition and authenticity. } \\
\text { ICP-MS highlighted the elemental composition of } \\
\text { tannin additives. }\end{array}$ & 236 \\
\hline 165 & SF-ICP-MS & River water & cidifiead & ${ }^{226} \mathrm{Ra}$ & $\begin{array}{l}0.46 \quad \mathrm{fg} / \mathrm{L} \text { or } 0.02 \\
\mathrm{mBq} / \mathrm{L}\end{array}$ & 1 & $\begin{array}{l}\text { The naturally existed } \mathrm{Ba} \text { was used as a yield tracer to } \\
\text { quantify }{ }^{226} \mathrm{Ra} \text { concentration. } \\
\text { A novel and simple method to measure ultra-trace } \\
{ }^{226} \mathrm{Ra} \text { in river water samples at } \mathrm{fg} / \mathrm{L}(\mathrm{mBq} / \mathrm{L}) \text { levels. }\end{array}$ & 237 \\
\hline 166 & SF-ICP-MS & $\begin{array}{l}\text { Japanese } \\
\text { coastal } \\
\text { seawater }\end{array}$ & 100 -fold with $0.5 \%$ & $\mathrm{I}$ & $0.23 \mathrm{ng} / \mathrm{m}$ & $\begin{array}{l}\text { Internal standard } \\
(\mathrm{Te})\end{array}$ & $\begin{array}{l}\text { Applied for the study of total iodine concentrations in } \\
\text { Japanese coastal waters for the estimation of } \\
\text { sediment-seawater distribution coefficient (Kd) and } \\
\text { concentration ratios (CRs). } \\
\text { Reported a sensitive analytical method for direct } \\
\text { analysis of total iodine in seawater using SF-ICP-MS. }\end{array}$ & 238 \\
\hline
\end{tabular}




\begin{tabular}{|c|c|c|c|c|c|c|c|c|}
\hline No. & Instrumental & Matrix & Sample preparation & Element or isotope & LOD or LOQ & Calibration & Application and Technical characteristics & Ref. \\
\hline 167 & SF-ICP-MS & Milk & $\begin{array}{l}\text { Muffle furnace; } \\
\text { high pressure asher; } \\
\text { Microwave digestion }\end{array}$ & $\begin{array}{l}\text { Multi-element } \\
\text { analysis }\end{array}$ & 1 & $\begin{array}{l}\text { External } \\
\text { calibration } \\
\text { method;standard } \\
\text { addition } \\
\text { calibration or } \\
\text { matrix matching } \\
\text { calibration }\end{array}$ & $\begin{array}{l}\text { Developed screening procedure allows the detection } \\
\text { of differences in elemental mass fractions of milk, } \\
\text { feed and water samples from different locations. } \\
\text { Developed an analytical procedure for multi-element } \\
\text { screening of } 40 \text { elements in milk and feed samples. }\end{array}$ & 239 \\
\hline 168 & MC-ICP-MS & Plants & $\begin{array}{l}\text { Dry ashing in } \\
\text { combination with } \\
\text { cation exchange } \\
\text { chromatography and } \\
\text { micro-sublimation }\end{array}$ & $\begin{array}{l}\text { Boron } \\
\text { analysis }\end{array}$ & 1 & / & $\begin{array}{l}\text { The } \delta^{11} \mathrm{~B} \text { variation in different plants, the } \\
\text { fractionation among different parts within plants and } \\
\text { the underlying reasons were explained, will replenish } \\
\text { the fractionation mechanisms of boron isotopes, and } \\
\text { expand the application of } \delta^{11} \mathrm{~B} \text { in biogeochemistry } \\
\text { and atmospheric B cycling. } \\
\text { A valid chemical and mass spectrometric method was } \\
\text { developed to separate and determine } \delta 11 \mathrm{~B} \text { of plant } \\
\text { tissues including dry ashing, cation exchange } \\
\text { chromatography and micro-sublimation. }\end{array}$ & 240 \\
\hline 169 & $\begin{array}{l}\text { LA-MC-ICP- } \\
\text { MS }\end{array}$ & $\begin{array}{l}\text { Individual } \\
\text { planktonic } \\
\text { foraminifera }\end{array}$ & 1 & Boron isotopes & 1 & 1 & $\begin{array}{l}\text { Individual foraminifera (O.universa) boron isotope } \\
\text { analyses by LA-MC-ICP-MS without the need for } \\
\text { matrix matched standards. }\end{array}$ & 241 \\
\hline 170 & LIBS & Soil samples & / & $\begin{array}{l}\mathrm{Ba}, \mathrm{Ca}, \mathrm{Cr}, \mathrm{Cu}, \mathrm{Fe}, \mathrm{Li} \\
\mathrm{Mg}, \mathrm{Mn}, \mathrm{Pb}, \mathrm{Sr}, \mathrm{Ti} \\
\text { and } \mathrm{V}\end{array}$ & $\begin{array}{l}<33 \mathrm{ppm} \text {; } \\
\text { a precision lower than } \\
10 \%\end{array}$ & $\begin{array}{l}\text { Single-point } \\
\text { calibration } \\
\text { Approach, } \\
\mathrm{R}^{2}>0.90\end{array}$ & $\begin{array}{l}\text { Applied to the analysis of bulk soil samples for } \\
\text { discrimination between specimens. } \\
\text { Developed a method for the quantitative elemental } \\
\text { analysis of surface soil samples using LIBS, } \\
\text { employed a LIBS with } 266 \mathrm{~nm} \text { laser to soil analysis } \\
\text { for forensic purposes, and limits of detection that are } \\
\text { sufficiently low to conduct forensic analysis. }\end{array}$ & 244 \\
\hline
\end{tabular}




\begin{tabular}{|c|c|c|c|c|c|c|c|c|}
\hline No. & Instrumental & Matrix & Sample preparation & Element or isotope & LOD or LOQ & Calibration & Application and Technical characteristics & Ref. \\
\hline 171 & LIBS & $\begin{array}{l}\text { Water } \\
\text { (mineral } \\
\text { salts) }\end{array}$ & I & $\mathrm{Cd}, \mathrm{Ni}, \mathrm{Cr}$ & $\begin{array}{l}\mathrm{Cd}, \mathrm{Ni}, \mathrm{Cr}: \\
532 \mathrm{~nm}: 9.61, \quad 8.49, \\
71.6 \mu \mathrm{g} / \mathrm{L} \\
1064 \mathrm{~nm}: 22.5,20.4 \\
83.8 \mu \mathrm{g} / \mathrm{L}\end{array}$ & \begin{tabular}{l|} 
Calibration \\
curves, \\
Ni: $\quad 0.118-2.36$ \\
$\mu \mathrm{g} / \mathrm{g}$, \\
Cr: $\quad 0.0975-1.95$ \\
$\mu \mathrm{g} / \mathrm{g}$, \\
$\mathrm{Cd}: \quad 0.246-4.92$ \\
$\mu \mathrm{g} / \mathrm{g}$
\end{tabular} & $\begin{array}{l}\text { Aluminum oxide nanoparticles to enrich } \mathrm{Cd}, \mathrm{Ni}, \mathrm{Cr} \text { in } \\
\text { water sample to improve LIBS detection limit. } \\
\mathrm{Al}_{2} \mathrm{O}_{3} \text { nanoparticles adsorption enrichment of target } \\
\text { elements was verified, and the detection sensitivity } \\
\text { was improved by increasing the amount of sample } \\
\text { solutions. }\end{array}$ & 245 \\
\hline 172 & LIBS & Red wine & Gel formation & $\mathrm{Mg}, \mathrm{Ca}, \mathrm{K}, \mathrm{Na}$ & I & 1 & $\begin{array}{l}\text { Applied to the identification of geographical origins } \\
\text { of agri-food. } \\
\text { Wine samples belonging to different Spanish } \\
\text { geographical regions have been analyzed by LIBS. } \\
\text { A novel liquid-to-solid matrix conversion by gel } \\
\text { formation have been applied, reported on a simple } \\
\text { and fast classification procedure for the quality } \\
\text { control of red wines withprotected designation of } \\
\text { origin (PDO) by LIBS technique. Neural Networks } \\
\text { were selected as classification methods to } \\
\text { discriminate between wines. }\end{array}$ & 246 \\
\hline 173 & LIBS & $\begin{array}{l}\text { Animal } \\
\text { histological } \\
\text { sections }\end{array}$ & / & Trace elements & I & / & $\begin{array}{l}\text { Distinguished trace elements between normal and } \\
\text { malignant tumor cells from animal histological } \\
\text { sections by LIBS. } \\
\text { The first LIBS application to our knowledge to } \\
\text { explore the possibility of using LIBS for cancer } \\
\text { detection. }\end{array}$ & 247 \\
\hline
\end{tabular}




\begin{tabular}{|c|c|c|c|c|c|c|c|c|}
\hline No. & Instrumental & Matrix & Sample preparation & Element or isotope & LOD or LOQ & Calibration & Application and Technical characteristics & Ref. \\
\hline 174 & LIBS & $\begin{array}{l}\text { Fruit and } \\
\text { Vegetables }\end{array}$ & / & $\mathrm{P}, \mathrm{S}$ & $\begin{array}{l}\text { P: } 0.009-0.029 \mathrm{mg} / \mathrm{kg} \\
\mathrm{Cd}: 1.6 \mathrm{ng} / \mathrm{g}\end{array}$ & $\begin{array}{l}\text { Calibration } \\
\text { curves } \\
\text { P: } 0-0.25 \mathrm{mg} / \mathrm{kg} ; \\
\mathrm{R}^{2}>0.89 \\
\mathrm{Cd}: 3-60 \mathrm{ng} / \mathrm{g} \\
\mathrm{R}^{2}=0.917\end{array}$ & $\begin{array}{l}\text { Used the nanoparticle-enhanced LIBS technique to } \\
\text { study the distributions of harmful chemicals in } \\
\text { vegetable leaves. } \\
\text { Employed nanoparticle-enhanced LIBS technique to } \\
\text { enhance the analytical sensitivity of pesticide residue } \\
\text { and Cd in fruit and vegetables, and achieved Cd } \\
\text { mapping analysis on edible plant leave revealing the } \\
\text { elemental uneven distribution. }\end{array}$ & 248 \\
\hline 175 & LIBS & $\begin{array}{l}\text { Sugar cane } \\
\text { leaves }\end{array}$ & / & $\begin{array}{l}\mathrm{Ca}, \mathrm{Mg}, \mathrm{K}, \mathrm{P}, \mathrm{Cu}, \mathrm{Mn}, \\
\mathrm{Zn}\end{array}$ & $\begin{array}{l}\mathrm{Ca} 0.01 \mathrm{~g} / \mathrm{kg}, \mathrm{Mg} 0.01 \\
\mathrm{~g} / \mathrm{kg}, \\
\mathrm{K} 1.4 \mathrm{~g} / \mathrm{kg}, \mathrm{P} 0.03 \mathrm{~g} / \\
\mathrm{kg}, \mathrm{Mn} 0.8 \mathrm{mg} / \mathrm{kg}, \mathrm{Zn} \\
1.0 \mathrm{mg} / \mathrm{kg} \text { and } \\
\mathrm{Cu} 0.6 \mathrm{mg} / \mathrm{kg}\end{array}$ & $\begin{array}{l}\text { Matrix matching } \\
\text { calibration } \\
\text { standards }\end{array}$ & $\begin{array}{l}\text { Proposed a calibration strategy for LIBS analysis of } \\
\text { pellets of plant materials. } \\
\text { Demonstrated for quantitative determination of } \mathrm{Ca} \text {, } \\
\mathrm{Mg}, \mathrm{K}, \mathrm{P}, \mathrm{Cu}, \mathrm{Mn} \text { and } \mathrm{Zn} \text { in pellets of sugar cane } \\
\text { leaves by LIBS and for estimating the detection limits } \\
\text { based on the analysis of the corresponding blank. } \\
\text { Blanks and/or low concentration standards of plant } \\
\text { materials were produced for LIBS analysis. }\end{array}$ & 249 \\
\hline 176 & ICP-AES & $\begin{array}{l}\text { Individual } \\
\text { Biological } \\
\text { Cells }\end{array}$ & Homogenize & $\mathrm{Ca}$ & $0.01 \mathrm{pg}$ & $\begin{array}{l}\text { Using } \\
\text { monodisperse } \\
\text { aerosols }\end{array}$ & $\begin{array}{l}\text { Measure the distribution of calcium content of a large } \\
\text { number of cells; show distributions of different } \\
\text { groups of cells. } \\
\text { Continuously determining the calcium content in } \\
\text { individual biological cells by inductively coupled } \\
\text { plasma atomic emission spectrometry in real time. }\end{array}$ & 251 \\
\hline 177 & $\begin{array}{l}\text { time-resolved } \\
\text { ICP-MS }\end{array}$ & $\begin{array}{l}\text { Unicellular } \\
\text { microbes }\end{array}$ & Cell homogenize & $\begin{array}{l}\mathrm{C}, \mathrm{Mg}, \mathrm{Al}, \mathrm{P}, \mathrm{S}, \mathrm{K}, \\
\mathrm{Ca}, \mathrm{Cr}, \mathrm{Mn}, \mathrm{Fe}, \mathrm{Zn}\end{array}$ & 1 & $\mathrm{R}^{2}=0.9989$ & $\begin{array}{l}\text { Localization of elements in cells. } \\
\text { Realize highly efficient single-cell analysis of } \\
\text { microbial cells by time-resolved inductively coupled } \\
\text { plasma mass spectrometry (ICP-MS). }\end{array}$ & 252 \\
\hline
\end{tabular}




\begin{tabular}{|c|c|c|c|c|c|c|c|c|}
\hline No. & Instrumental & Matrix & Sample preparation & Element or isotope & LOD or LOQ & Calibration & Application and Technical characteristics & Ref. \\
\hline 178 & $\begin{array}{l}\text { time-resolved } \\
\text { ICP-MS }\end{array}$ & $\begin{array}{l}\text { A unicellular } \\
\text { alga } \\
\text { Chlorella } \\
\text { vulgaris, }\end{array}$ & Acid digestion & $\begin{array}{l}\mathrm{Na}, \mathrm{Mg}, \mathrm{Ca}, \mathrm{K}, \mathrm{Mn}, \\
\mathrm{Fe}, \mathrm{Cu}, \mathrm{Co}, \mathrm{Zn}, \mathrm{Mo}\end{array}$ & $10 \mathrm{ng} / \mathrm{ml}$ & $\begin{array}{l}\text { The filtrate } \\
\text { containing } \mathrm{MgO} \\
\text { particles of } \\
\text { average diameter } \\
\text { of } \\
\text { approximately } \\
100 \mathrm{~nm} \text {; } \\
\mathrm{R}^{2}=0.999\end{array}$ & $\begin{array}{l}\text { Quantitative determination of the metal contents of } \\
\text { the algal cells using metal oxide particles for } \\
\text { calibration is feasible. Semi-quantitative } \\
\text { measurement is also possible using aqueous standards } \\
\text { for calibration. } \\
\text { Simultaneous cell counting and determination of } \\
\text { constituent metals in single cells using time-resolved } \\
\text { ICP-MS. }\end{array}$ & 253 \\
\hline 179 & $\begin{array}{l}\text { IEC-SP-ICPM } \\
\mathrm{S}\end{array}$ & Chemicals & Dilute & Silver nanoparticles & 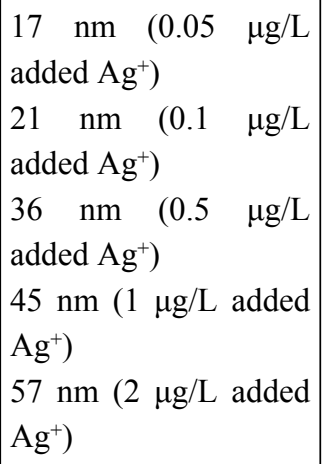 & $\begin{array}{l}\text { Standard } \\
\text { ICP-MS } \\
\text { reference } \\
\text { materials }\end{array}$ & $\begin{array}{l}\text { SP-ICPMS is becoming a very promising technique } \\
\text { for nanoparticle detection and characterization, } \\
\text { especially at very low concentration. } \\
\text { A new approach to attaining lower particle size } \\
\text { detection limits has been developed by the online } \\
\text { coupling of an IEC with SP-ICPMS }\end{array}$ & 254 \\
\hline
\end{tabular}




\begin{tabular}{|c|c|c|c|c|c|c|c|c|}
\hline No. & Instrumental & Matrix & Sample preparation & Element or isotope & LOD or LOQ & Calibration & Application and Technical characteristics & Ref. \\
\hline 180 & SC -ICP-MS & $\begin{array}{l}\text { Single yeast, } \\
\text { green alga, } \\
\text { or red blood } \\
\text { cell }\end{array}$ & Homogenize & $\mathrm{P}, \mathrm{S}, \mathrm{Mg}, \mathrm{Zn}, \mathrm{Fe}$ & $\begin{array}{l}\text { Yeast: } \\
\text { Mg: } 8.79 \mathrm{fg} / \text { cell } \\
\text { Zn: } 1.34 \mathrm{fg} / \text { cell } \\
\text { P: } 115 \mathrm{fg} / \mathrm{cell} \\
\mathrm{S}: 32.6 \mathrm{fg} / \text { cell } \\
\text { Fe: } 0.566 \mathrm{fg} / \text { cell } \\
\text { Green alga: } \\
\text { Mg: } 293 \mathrm{fg} / \text { cell } \\
\mathrm{Zn:} 3.88 \mathrm{fg} / \text { cell } \\
\text { P: } 2044 \mathrm{fg} / \text { cell } \\
\text { S: } 223 \mathrm{fg} / \mathrm{cell} \\
\text { Fe: } 14.5 \mathrm{fg} / \text { cell } \\
\text { RBC: } \\
\text { Mg: } 3.43 \mathrm{fg} / \text { cell } \\
\mathrm{Zn:} 0.497 \mathrm{fg} / \text { cell } \\
\text { P: } 40.1 \mathrm{fg} / \text { cell } \\
\mathrm{S}: 177 \mathrm{fg} / \mathrm{cell} \\
\text { Fe: } 70.2 \mathrm{fg} / \text { cell }\end{array}$ & $\begin{array}{l}\text { Comparing the } \\
\text { integrated } \\
\text { intensity of the } \\
\text { transient signals } \\
\text { from a cell (IC) } \\
\text { with the signal } \\
\text { intensity of an } \\
\text { ionic standard of } \\
\text { known } \\
\text { concentration }\end{array}$ & $\begin{array}{l}\text { Study both the physiological and nutritional } \\
\text { importance and toxicological effects of elements } \\
\text { within a nano-sized sample. } \\
\text { The elemental composition of a single yeast, green } \\
\text { alga, or red blood cell was precisely determined by } \\
\text { using ICP-MS operating in fast time-resolved } \\
\text { analysis (TRA) mode. }\end{array}$ & 257 \\
\hline 181 & GC-MS & Essential oils & Dry & $\begin{array}{l}\text { The aromatic } \\
\text { Monoterpenes; the } \\
\text { thujanes }\end{array}$ & / & $\begin{array}{l}\text { The evaluation } \\
\text { of the biological } \\
\text { activity of the } \\
\text { essential oil }\end{array}$ & $\begin{array}{l}\text { GC-MS Analysis of Essential Oils from Some Greek } \\
\text { Aromatic Plants } \\
\text { and Their Fungitoxicity on Penicillium digitatum. } \\
\text { The isolated essential oils from seven air-dried plant } \\
\text { species were analyzed by GC-MS. }\end{array}$ & 259 \\
\hline
\end{tabular}




\begin{tabular}{|c|c|c|c|c|c|c|c|c|}
\hline No. & Instrumental & Matrix & Sample preparation & Element or isotope & LOD or LOQ & Calibration & Application and Technical characteristics & Ref. \\
\hline 182 & $\begin{array}{l}\text { LC/LC-MS/M } \\
\mathrm{S}\end{array}$ & Proteins & Digestion & Peptides & $10 \mathrm{fmol}$ & $\begin{array}{l}\text { Known yeast } \\
\text { ORFs } \quad(6139 \\
\text { proteins) and a } \\
\text { second database } \\
\text { containing } 6139 \\
\text { bogus proteins }\end{array}$ & $\begin{array}{l}\text { Highly complex protein mixtures can be directly } \\
\text { analyzed. } \\
\text { We have utilized the combination of strong cation } \\
\text { exchange (SCX) and reversed-phase (RP) } \\
\text { chromatography to achieve two-dimensional } \\
\text { separation prior to MS/MS. One milligram of whole } \\
\text { yeast protein was proteolyzed and separated by SCX } \\
\text { chromatography ( } 2.1 \mathrm{~mm} \text { i.d.). }\end{array}$ & 260 \\
\hline 183 & SC-ICP-MS & $\begin{array}{l}\text { Fetal bovine } \\
\text { serum; } \\
\text { plasmocin }\end{array}$ & Homogenize & Cisplatin & $10 \mu \mathrm{mol} / \mathrm{L}$ & $\begin{array}{l}\text { External } \\
\text { standard method }\end{array}$ & $\begin{array}{l}\text { Total Pt analysis in single cells has been implemented } \\
\text { using a total consumption nebulizer coupled to } \\
\text { ICP-MS. } \\
\text { Address the number of cells in the suspension and the } \\
\text { efficiency of the sample introduction system; } \\
\text { Quantitative uptake studies of a nontoxic Tb } \\
\text { containing compound by individual cells were } \\
\text { conducted. }\end{array}$ & 261 \\
\hline 184 & SC-ICP-MS & Cells & Homogenize & $\begin{array}{l}\mathrm{Cu}, \mathrm{Fe}, \mathrm{Zn} \mathrm{Mn}, \mathrm{Co}, \mathrm{P}, \\
\mathrm{S}\end{array}$ & $\begin{array}{l}{ }^{55} \mathrm{Mn}: 0.1 \mathrm{fg}, \\
{ }^{56} \mathrm{Fe}: 1.9 \mathrm{fg}, \\
{ }^{59} \mathrm{Co}: 0.1 \mathrm{fg}, \\
{ }^{65} \mathrm{Cu}: 0.5 \mathrm{fg} \\
{ }^{66} \mathrm{Zn}: 6.6 \mathrm{fg} \\
{ }^{31} \mathrm{P}^{16} \mathrm{O}^{+}: 0.6 \mathrm{pg} \\
{ }^{32} \mathrm{~S}^{16} \mathrm{O}^{+}: 0.4 \mathrm{pg}\end{array}$ & / & $\begin{array}{l}\text { The single-cell analysis of } \mathrm{Mn}, \mathrm{Fe}, \mathrm{Co}, \mathrm{Cu}, \mathrm{Zn}, \mathrm{P} \text {, and } \\
\mathrm{S} \text { in human cancer cell lines and normal human } \\
\text { bronchial epithelial cell line. } \\
\text { ICP-MS equipped with a high efficiency cell } \\
\text { introduction system (HECIS) was developed as a } \\
\text { method of single-cell ICP-MS (SC-ICP-MS). The } \\
\text { method was applied to the single-cell analysis of Mn, } \\
\mathrm{Fe}, \mathrm{Co}, \mathrm{Cu}, \mathrm{Zn}, \mathrm{P} \text {, and } \mathrm{S} \text { in human cancer cell lines } \\
\text { (HeLa and A549) and normal human bronchial } \\
\text { epithelial cell line (16HBE). }\end{array}$ & 262 \\
\hline
\end{tabular}




\begin{tabular}{|c|c|c|c|c|c|c|c|c|}
\hline No. & Instrumental & Matrix & Sample preparation & Element or isotope & LOD or LOQ & Calibration & Application and Technical characteristics & Ref. \\
\hline 185 & ICP-SF-MS & Yeast; Cells & Homogenize, dilute & $\begin{array}{l}\mathrm{Na}, \mathrm{Mg}, \mathrm{Fe}, \mathrm{Cu}, \mathrm{Zn}, \\
\mathrm{Se}\end{array}$ & $\begin{array}{l}\text { Na: } 0.91 \text { fg, } \mathrm{Mg}: 9.4 \\
\text { fg, Fe: } 5.9 \text { fg, } \\
0.54 \text { fg, } \\
72 \text { : } 1.2 \text { fg, }\end{array}$ & $\begin{array}{l}\text { Internal } \\
\text { standard: Indium }\end{array}$ & $\begin{array}{l}\text { Investigate the uptake of essential elements in } \\
\text { selenized yeast cells; develop quantification } \\
\text { procedures for single cell analysis. } \\
\text { Has the detection power to measure elements, in } \\
\text { particular metals, in time resolved single cells. }\end{array}$ & 263 \\
\hline 186 & SC-ICP-MS & $\begin{array}{l}\text { Human } \\
\text { epithelial } \\
\text { lung } \\
\text { adenocarcino } \\
\text { ma cells }\end{array}$ & Homogenize & As & $0.35 \mathrm{fg}$ per cell & \begin{tabular}{ll|} 
External & \\
calibration, & liner \\
range: & $0-75$ \\
$\mathrm{mg} / \mathrm{L}$ & \\
$\left.\mathrm{R}^{2}=0.9998\right)$ &
\end{tabular} & $\begin{array}{l}\text { Evaluate the elemental composition at a single-cell } \\
\text { level; determine minerals such as calcium and } \\
\text { magnesium; assess the cellular uptake of } \mathrm{TiO}_{2} \text { and } \\
\text { Ag. } \\
\text { the cellular bioavailability of arsenite (incubation of } \\
25 \text { and } 50 \mu \mathrm{m} \text { for } 0-48 \mathrm{~h} \text { ) has been successfully } \\
\text { assessed by SC-ICP-MS/MS for the first time directly } \\
\text { after re-suspending the cells in water. }\end{array}$ & 264 \\
\hline 187 & SC-ICP-MS & $\begin{array}{l}\text { Freshwater } \\
\text { algae: } \\
\text { Cyptomonas } \\
\text { ovate }\end{array}$ & Homogenize & Au Nanoparticle & $3 \mathrm{ppb}$ & $\begin{array}{l}\text { Internal } \\
\text { standard: } \\
\mathrm{Cu}^{151}, \\
\mathrm{Co}^{165}, \\
\mathrm{NIST}, \\
\text { Nund } \\
\text { Standards }\end{array}$ & $\begin{array}{l}\text { Quantify the mass of Au metal strongly associated } \\
\text { with fresh water algae (Cyptomonas ovate) for both } \\
\text { nanoparticle and dissolved metal exposures; human } \\
\text { toxicology and nanomedicine. } \\
\text { Quantification of metal concentrations on an } \\
\text { individual cell basis down to the attogram (ag) per } \\
\text { cell level; capable of delivering intact individual cells } \\
\text { into the ICP-MS plasma and quantifying the metal } \\
\text { content associated with each cell down to a few } \\
\text { attograms (ag; } 10-18 \mathrm{~g} \text { ) per cell. }\end{array}$ & 265 \\
\hline 188 & ICP-TQ -MS & Yeast cells & Homogenize & $\mathrm{Se}, \mathrm{P}$ & Se:0.16 fg per cell & $\begin{array}{l}\text { Citrate-stabilize } \\
\text { d gold } \\
\text { nanoparticles }\end{array}$ & $\begin{array}{l}\text { Distinguish between nanoparticle-bound elements } \\
\text { and their corresponding low-molecular species. } \\
\text { The use of complementary analytical strategies that } \\
\text { enabled the detection and characterization of } \\
\text { selenium-containing nanoparticles in selenized yeast. }\end{array}$ & 266 \\
\hline
\end{tabular}




\begin{tabular}{|c|c|c|c|c|c|c|c|c|}
\hline No. & Instrumental & Matrix & Sample preparation & Element or isotope & LOD or LOQ & Calibration & Application and Technical characteristics & Ref. \\
\hline 189 & $\begin{array}{l}\text { SC/SP } \\
\text {-ICP-TQ-MS }\end{array}$ & $\begin{array}{l}\text { Organisms, } \\
\text { S. aureus and } \\
\text { E. coli }\end{array}$ & Homogenize & $\begin{array}{l}\text { Tellurium } \\
\text { nanoparticles } \\
\text { NPs) }\end{array}$ & $\begin{array}{l}\text { Aureus: } 0.5-1.9 \mathrm{fg} \\
\text { Te/cell; } \\
\text { E. coli: } 0.08 \text { to } 0.88 \mathrm{fg} \\
\text { Te/cell }\end{array}$ & $\begin{array}{l}\text { A concentration } \\
\text { range from } 0 \text { to } \\
50 \mathrm{mg} \mathrm{L1} \text { with a } \\
\text { tellurium } \\
\text { standard for ICP } \\
\text { obtained from } \\
\text { Sigma Aldrich }\end{array}$ & $\begin{array}{l}\text { Quantify the uptake of Te NPs in single bacterial; } \\
\text { cells; investigate, quantitatively, nanoparticle uptake } \\
\text { in bacterial cells and to estimate the dimensions of } \\
\text { biogenic Te nanorods. } \\
\text { SC-ICP-MS was used to quantify the uptake of Te } \\
\text { NPs in single bacterial cells. }\end{array}$ & 267 \\
\hline 190 & $\begin{array}{l}\text { time-resolved } \\
\text { ICP-MS }\end{array}$ & $\begin{array}{l}\text { Yeast } \\
\text { suspension }\end{array}$ & Homogenize, dilute & $\begin{array}{l}\mathrm{Mg}, \mathrm{P}, \mathrm{Ca}, \mathrm{Mn}, \mathrm{Fe} \\
\mathrm{Cu}, \mathrm{Zn}\end{array}$ & 1 & 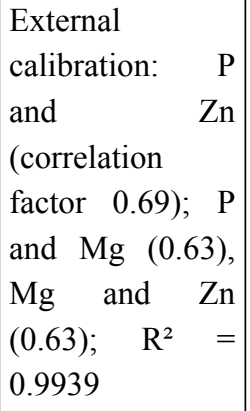 & $\begin{array}{l}\text { Using the HECIS and described method of } \\
\text { multielement analysis with algae and bacteria cells, } \\
\text { along with extracted organelles, is underway in our } \\
\text { laboratory. } \\
\text { Qua-simultaneous multi-element detection for } \\
\text { multielement correlation analysis within cells. }\end{array}$ & 268 \\
\hline 191 & $\begin{array}{l}\text { time-resolved } \\
\text { ICP-MS }\end{array}$ & $\begin{array}{l}\text { Unicellular } \\
\text { alga, } \\
\text { Chlorella } \\
\text { vulgaris }\end{array}$ & Filtration, homogenize & $\mathrm{Mg}$ & $10 \mathrm{ng} / \mathrm{ml}$ & $\begin{array}{l}\text { Aqueous } \\
\text { standards } \quad(10 \\
\mathrm{mg} / \mathrm{L} \text { each of } \mathrm{Li}, \\
\mathrm{Y}, \mathrm{Co}, \mathrm{Ce} \text { and } \\
\mathrm{Tl}) \text { For } \\
\text { calibration; } \\
\text { calibration with } \\
\mathrm{MgO} \text { particles } \\
\left(\mathrm{R}^{2}=0.999\right)\end{array}$ & $\begin{array}{l}\text { A method of simultaneous cell counting and } \\
\text { determination of constituent metals in single cells } \\
\text { using time-resolved ICP-MS. } \\
\text { Quantitative determination of the metal contents of } \\
\text { the algal cells using metal oxide particles for } \\
\text { calibration. Semi-quantitative measurement is also } \\
\text { possible using aqueous standards for calibration. }\end{array}$ & 269 \\
\hline
\end{tabular}




\begin{tabular}{|c|c|c|c|c|c|c|c|c|}
\hline No. & Instrumental & Matrix & Sample preparation & Element or isotope & LOD or LOQ & Calibration & Application and Technical characteristics & Ref. \\
\hline 192 & LA-ICP-MS & $\begin{array}{l}\text { marine } \\
\text { microalgae } \\
\text { Scrippsiella, } \\
\text { trochoidea } \\
\text { (Von Stein) } \\
\text { Loeblich III }\end{array}$ & Degradation & $\mathrm{Cu}$ & 0.5 to $100 \mu \mathrm{g} / \mathrm{L}$ & 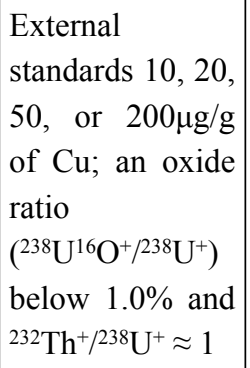 & $\begin{array}{l}\text { Detailed analysis of (sub) cellular } \\
\text { microenvironments. } \\
\text { The accumulation of } \mathrm{Cu} \text { in the model organism } \\
\text { Scrippsiella trochoidea resulting from transition metal } \\
\text { exposure } \\
\text { (ranging from } 0.5 \text { to } 100 \mu \mathrm{g} / \mathrm{L} \text { ) was evaluated. }\end{array}$ & 274 \\
\hline 193 & SP-ICP-MS & $\begin{array}{l}\text { Plastic } \\
\text { particles }\end{array}$ & Filter, dilute. cut, & Carbon-13 isotope & $\begin{array}{l}1.2 \mu \mathrm{m} \text { for } \mathrm{PS} \\
\text { microparticles }\end{array}$ & $\begin{array}{l}\text { Aqueous } \\
\text { dissolved carbon } \\
\text { standards }\end{array}$ & $\begin{array}{l}\text { The analysis of a microplastic suspensions by } \\
\text { ICP-MS operated in single particle mode using } \\
\text { microsecond dwell time. } \\
\text { The analysis of a microplastic suspensions by } \\
\text { ICP-MS operated in single particle mode using } \\
\text { microsecond dwell times. Enables the detection of } \\
\text { metallic nanoparticles below } 10 \mathrm{~nm} \text {. }\end{array}$ & 275 \\
\hline 194 & SP-ICP-MS & $\begin{array}{l}\text { Cat; Spleen } \\
\text { samples }\end{array}$ & $\begin{array}{l}\text { Sonication-homogeniz } \\
\text { e }\end{array}$ & $\mathrm{Au}$ NPs & $100 \mathrm{ng} / \mathrm{L}$ & $\begin{array}{l}\text { An external } \\
\text { calibration curve } \\
\text { using } \mathrm{Rh} \text { as } \\
\text { internal standard }\end{array}$ & $\begin{array}{l}\text { SP-ICPMS is a promising method for the detection of } \\
\text { metal-containing nanoparticles (NPs) and the } \\
\text { quantification of their size and number concentration. } \\
\text { Use of alkaline or enzymatic sample pretreatment } \\
\text { prior to characterization of gold nanoparticles in } \\
\text { animal tissue by single-particle ICPMS. }\end{array}$ & 276 \\
\hline
\end{tabular}




\begin{tabular}{|c|c|c|c|c|c|c|c|c|}
\hline No. & Instrumental & Matrix & Sample preparation & Element or isotope & LOD or LOQ & Calibration & Application and Technical characteristics & Ref. \\
\hline 195 & $\mathrm{SP}-\mathrm{ICP}-\mathrm{MS}$ & Plant tissues & Homogenize, digest & $\mathrm{Au}$ NPs & $1000 \mathrm{NPs} / \mathrm{mL}$ & $\begin{array}{l}\text { AuNP standards } \\
\text { with sizes of } 30, \\
50,80 \text {, and } 100 \\
\mathrm{~nm} \text { served as } \\
\text { particle } \\
\text { calibration } \\
\text { standards }\end{array}$ & $\begin{array}{l}\text { Develop for simultaneous determination of gold NP } \\
\text { (AuNP) size, size distribution, particle concentration, } \\
\text { and dissolved } \mathrm{Au} \text { concentration in tomato plant } \\
\text { tissues. } \\
\text { Simultaneously detect both the particle analyte and } \\
\text { the dissolved analyte. }\end{array}$ & 277 \\
\hline 196 & SP-ICP-MS & $\begin{array}{l}\text { Environment } \\
\text { al samples }\end{array}$ & Homogenize & Nanoparticles & 1 & $\begin{array}{l}\text { Environmental } \\
\text { samples, } \\
\text { detection and } \\
\text { determination of } \\
\text { native particles } \\
\text { in waters }\end{array}$ & $\begin{array}{l}\text { Cope and solve the challenges and problems related } \\
\text { to the analysis of ENMs in environmental samples. } \\
\text { Qualitative information about the presence of } \\
\text { particulate and/or dissolved forms; quantitative } \\
\text { information as particle number as well as mass } \\
\text { Concentrations; characterization information about } \\
\text { the mass of elements per particle and particle size.. }\end{array}$ & 278 \\
\hline 197 & SP-ICP-MS & $\begin{array}{l}\text { Drinking } \\
\text { water }\end{array}$ & Disinfection. & $\begin{array}{l}\text { Titanium dioxide, } \\
\text { silver, and gold } \\
\text { nanoparticles }\end{array}$ & $\begin{array}{l}\text { Ti: } 0.75 \mu \mathrm{g} / \mathrm{L} \\
\text { Ag: } 0.10 \mu \mathrm{g} / \mathrm{L} \\
\text { Au: } 0.10 \mu \mathrm{g} / \mathrm{L}\end{array}$ & $\begin{array}{l}\text { Citrate-capped } \\
\text { Au NPs and Ag } \\
\text { NPs were used } \\
\text { as particle } \\
\text { calibration } \\
\text { standards }\end{array}$ & $\begin{array}{l}\text { Rapid tracking of nanoparticles during simulated } \\
\text { drinking water treatment; investigate the fate and } \\
\text { transportation of NPs during drinking water } \\
\text { treatments. } \\
\text { Single particle-ICP-MS methods for analysis for } \\
\text { TiO2, Ag, and Au nanoparticles. } \\
\text { Rapid tracking of nanoparticles during simulated } \\
\text { drinking water treatment. } \\
\text { Nanoparticles are removed during lime softening and } \\
\text { alum coagulation. } \\
\text { Ti-containing particles present in source water were } \\
\text { removed by water treatment. }\end{array}$ & 279 \\
\hline
\end{tabular}




\begin{tabular}{|c|c|c|c|c|c|c|c|c|}
\hline No. & Instrumental & Matrix & Sample preparation & Element or isotope & LOD or LOQ & Calibration & Application and Technical characteristics & Ref. \\
\hline 198 & $\mathrm{SP}-\mathrm{ICP}-\mathrm{MS}$ & Radish & Lyophilization, grind & $\begin{array}{l}\text { Cerium oxide and } \\
\text { copper } \\
\text { nanoparticles }\end{array}$ & $\begin{array}{l}0.39 \text { and } 4.3 \mu \mathrm{g} / \mathrm{L} \text { for } \\
\mathrm{Ce} \text { and } \mathrm{Cu}\end{array}$ & $\begin{array}{l}\text { External } \\
\text { calibration, liner } \\
\text { ranges: } 0.0-20 \\
\mu \mathrm{g} / \mathrm{L}\end{array}$ & $\begin{array}{l}\text { A powerful tool for the analysis of } \mathrm{NPs} \text { in } \\
\text { environmental samples. } \\
\text { The presented methodology was developed to study } \\
\text { the bio-accessibility of cerium oxide }\left(\mathrm{CeO}_{2}\right) \text { and } \\
\text { copper oxide }(\mathrm{CuO}) \mathrm{NPs} \text { from radish after the in vitro } \\
\text { simulation of gastro intestinal digestion using } \\
\text { single-particle inductively coupled plasma mass } \\
\text { spectrometry (SP-ICP-MS). }\end{array}$ & 280 \\
\hline 199 & SP-ICP-MS & Plant tissues & Homogenize, digest & $\mathrm{Au}$ NPs & $1000 \mathrm{NPs} / \mathrm{mL}$ & $\begin{array}{l}\text { AuNP standards } \\
\text { with sizes of } 30, \\
50,80 \text {, and } 100 \\
\text { nm served as } \\
\text { particle } \\
\text { calibration } \\
\text { standards }\end{array}$ & $\begin{array}{l}\text { Develop for simultaneous determination of gold NP } \\
\text { (AuNP) size, size distribution, particle concentration, } \\
\text { and dissolved } \mathrm{Au} \text { concentration in tomato plant } \\
\text { tissues. } \\
\text { Simultaneously detect both the particle analyte and } \\
\text { the dissolved analyte. }\end{array}$ & 281 \\
\hline 200 & SP-ICP-MS & $\begin{array}{l}\text { Arabidopsis } \\
\text { Plants }\end{array}$ & Homogenize & $\begin{array}{l}\text { Silver nanoparticles } \\
\text { (Ag NPs) }\end{array}$ & $0.02 \mathrm{mg} / \mathrm{L}$ & $\begin{array}{l}\text { The } 30 \mathrm{~nm} \mathrm{Au} \\
\text { NP standard was } \\
\text { used for particle } \\
\text { calibration }\end{array}$ & $\begin{array}{l}\text { The measurement of the size distribution of gold } \\
\text { nanoparticles (Au NPs) in NP-exposed tomato plants; } \\
\text { the analysis of water, food matrices, materials, } \\
\text { biological tissues, body fluids for trace metals, and } \\
\text { toxic elements. } \\
\text { A powerful tool to directly quantify single particle } \\
\text { size, concentration, and size distribution. }\end{array}$ & 282 \\
\hline
\end{tabular}




\begin{tabular}{|c|c|c|c|c|c|c|c|c|}
\hline No. & Instrumental & Matrix & Sample preparation & Element or isotope & LOD or LOQ & Calibration & Application and Technical characteristics & Ref. \\
\hline 201 & SP-ICP-MS & $\begin{array}{l}\text { Chicken } \\
\text { meat }\end{array}$ & $\begin{array}{l}\text { Sonication-homogeniz } \\
\text { e, enzymatic digestion }\end{array}$ & $\begin{array}{l}\text { Silver nanoparticles } \\
\text { (Ag NPs) }\end{array}$ & $0.05 \mathrm{mg} / \mathrm{kg}$ & $\begin{array}{l}\text { Standard of the } \\
60 \text {-nm gold NPs; } \\
\text { ionic silver } \\
\text { standards in the } \\
\text { con } \\
\text { centration range } \\
\text { of } 0.2-5 \mu \mathrm{g} / \mathrm{L} \text { for } \\
\text { calibration }\end{array}$ & $\begin{array}{l}\text { Using SP-ICP-MS for the sizing and quantification of } \\
\text { silver NPs in a food matrix. } \\
\text { Sizing and quantifying nano-silver in chicken meat } \\
\text { using single particle ICP-MS. }\end{array}$ & 283 \\
\hline
\end{tabular}

